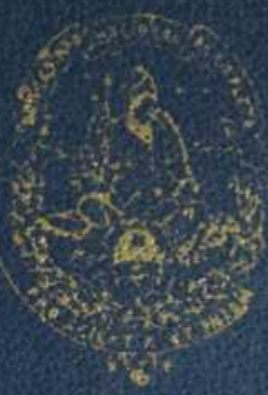

UNIVERSIDAD NACIONAL DE LA PLATA FACULTAD DE INEDRMATICA

Tesis de Macister en

iecnclogia lnformatica Aplicada en Educacion

Gamidules Virtuales de Aorandizaje Colaboracion - Goperación en remas Nucleares

Univerelded Necional de La Plat FACULTAD DE INFORMATICA

Blblloteca

50 y 120 La Plata,

biblioteca@info.unip.edu.ar

Tol (54-221) 423-0124 - int.: 59

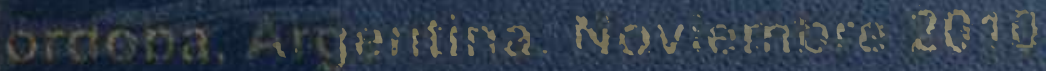




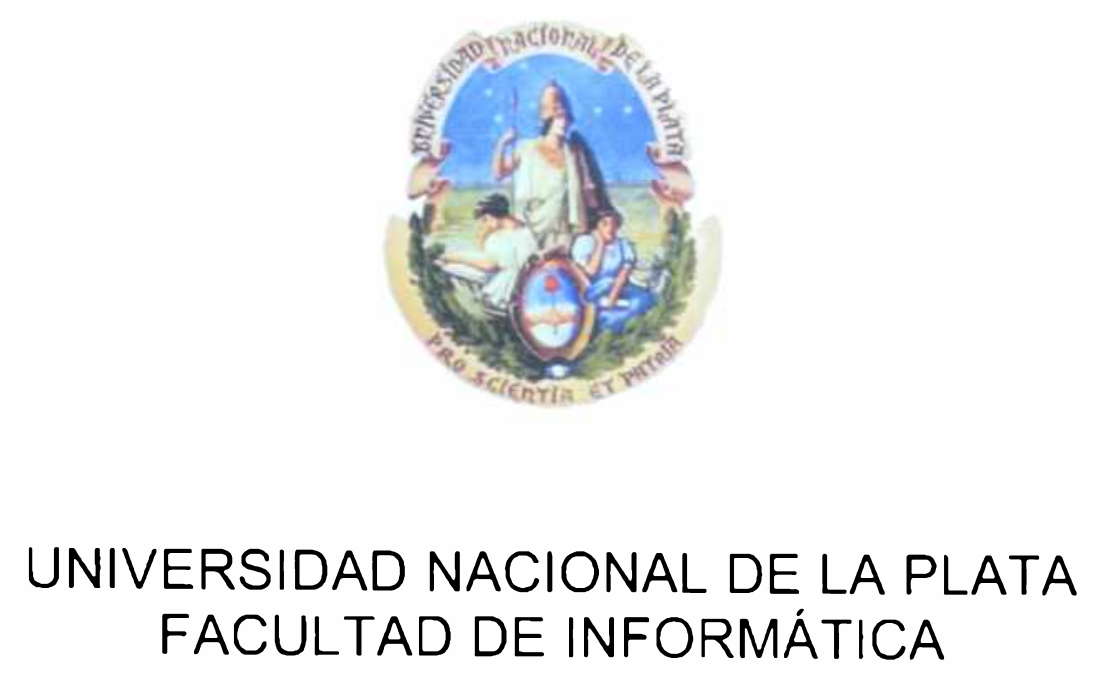

Tesis de Magister en Tecnología Informática Aplicada en Educación

\title{
Comunidades Virtuales de Aprendizaje Colaboración y Cooperación en Temas Nucleares
}

\author{
Norma Adriana Chautemps \\ Directora: Dra. Mónica Gallino \\ Co-Directora: Dra. Cecilia Sanz
}

Córdoba, Argentina. Noviembre 2010 


\section{Agradecimiento}

Agradezco a mi familia por su infinita paciencia y comprensión.

A mi amiga Alejandra por impulsarme a realizar la maestria y acompañarme en el andar.

Al grupo del trabajo del Reactor Nuclear RA-0, por su apoyo incondicional. Muy especialmente a Carlos y Eduardo por ayudarme con la tecnologia.

A Mónica Gallino por confiar en mi, alentarme, facilitarme material de estudio y fundamentalmente guiarme en los primeros pasos de la tesis.

A Cecilia Sanz, toda mi admiración y profundo agradecimiento por su completa dedicación y esmero. Momentos muy importantes en su vida ocurrieron mientras dirigía mi tesis, sin embargo no claudicó y alli estuvo presente, con palabras de aliento y perseverancia.

¡Gracias! 


\section{Índice}

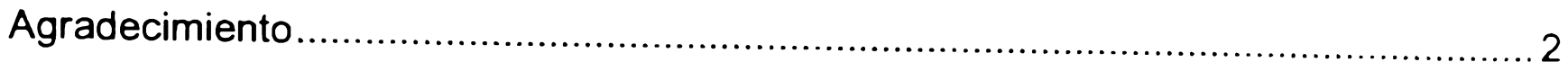

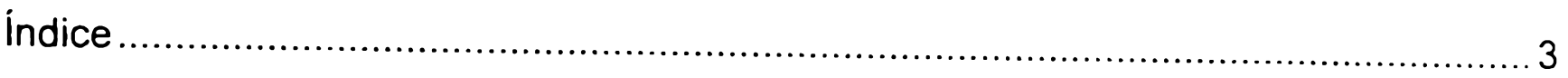

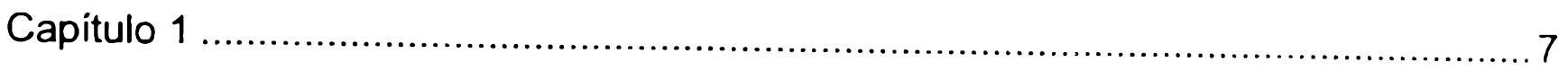

Introducción ................................................................................................. 7

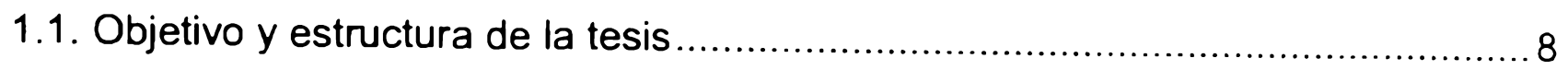

1.2. Marco Teórico: Introducción ................................................................ 9

1.3. Comunidad de Aprendizaje............................................................... 12

1.4. Revisión de algunos conceptos claves en vinculación con el aprendizaje ....... 13

1.4.1 Aprendizaje Cooperativo ........................................................... 16

1.4.2 Aprendizaje Colaborativo............................................................ 17

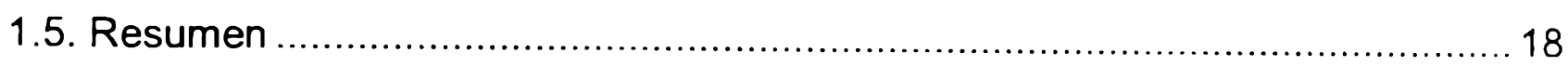

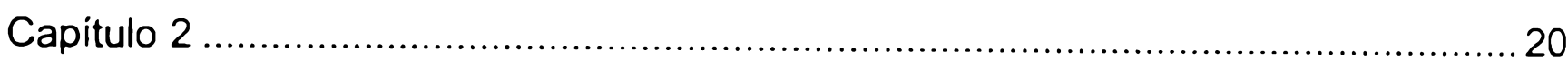

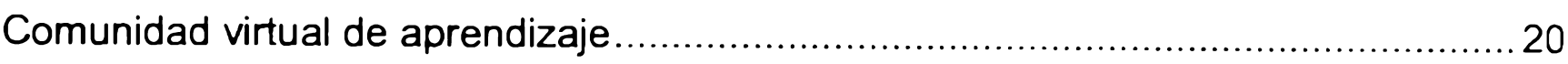

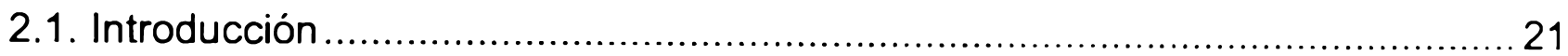

2.2. Diferencias entre Entorno Virtual de Enseñanza y Aprendizaje y Comunidad

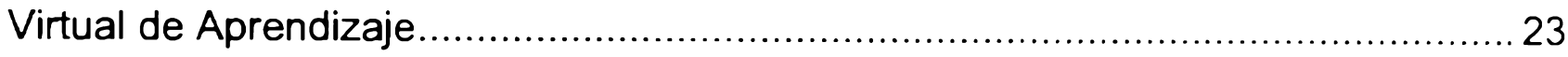

2.3. Tipos de comunidades..................................................................... 24

2.4. Ejemplos de comunidades virtuales ...................................................... 28

2.5. Requerimientos para generar una comunidad virtual de aprendizaje ............... 34

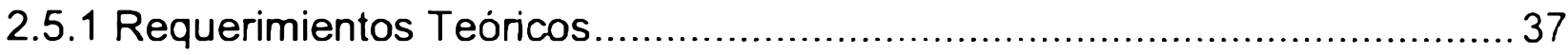

2.5.2 Requerimientos Arquitectónicos y Tecnológicos .................................. 38

2.6. Monitoreo y Evaluación de una Comunidad Virtual de Aprendizaje ................. 40

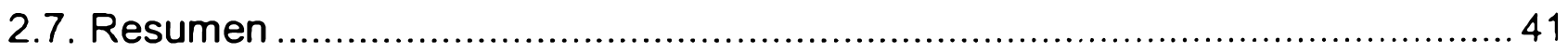

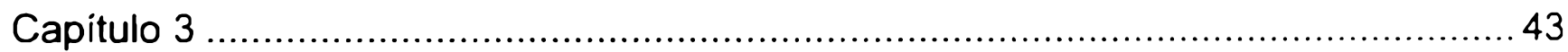

Propuesta metodológica para el diseño de una comunidad virtual de aprendizaje referida a temas nucleares ................................................................... 43

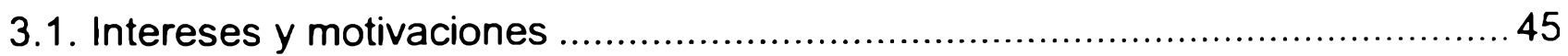

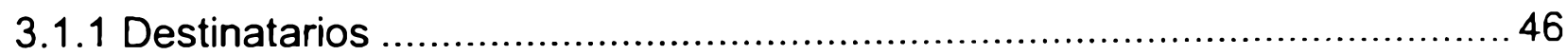

3.1.2 Indagación al grupo de trabajo que conformará la comunidad virtual de

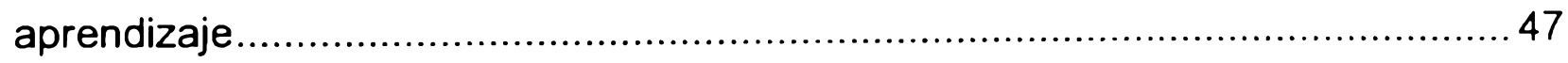

3.2. Vinculación y comunicación entre miembros ........................................ 58

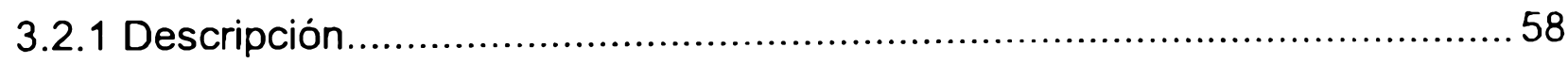


3.2.2. Nuestra experiencia.

3.2.3. Propuesta para generar la vinculación y comunicación entre los miembros de la CVA.

3.3. Liderazgo y coordinación

3.3.1. Experiencia adquirida a través del dictado de cursos con modalidad semipresencial. 66

3.3.2. Asignación de roles para la CVA propuesta 67

3.4. Estimulación de procesos de aprendizaje 69

3.5. Incentivo a la cultura de participación 70

3.5.1. Nuestra experiencia. 71

3.6. Resumen 75

Capitulo 4 .77

Diseño y desarrollo de una comunidad virtual de aprendizaje referida a temas nucleares 77

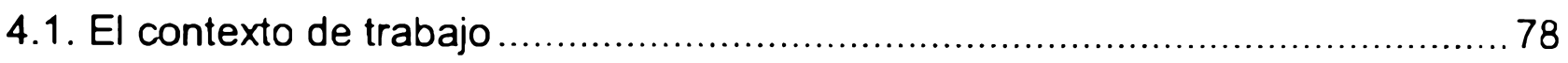

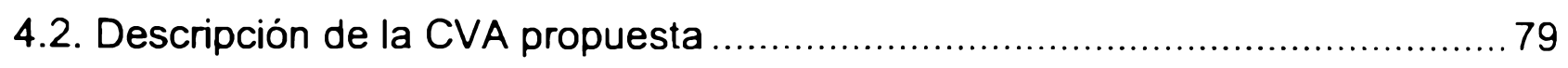

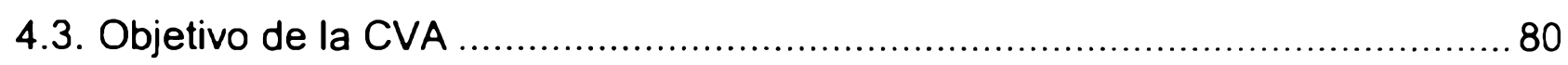

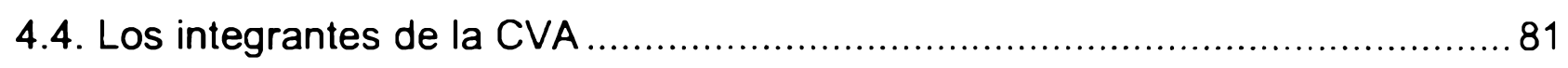

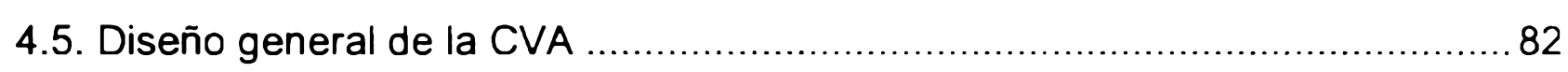

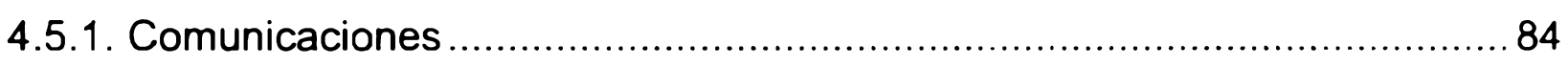

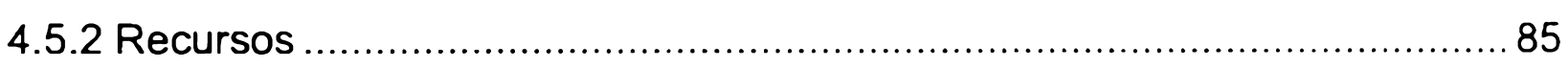

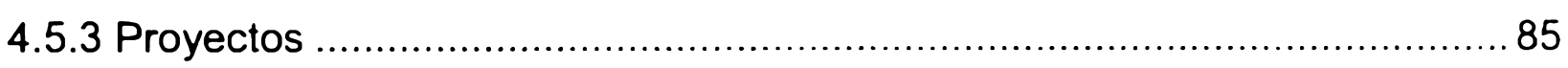

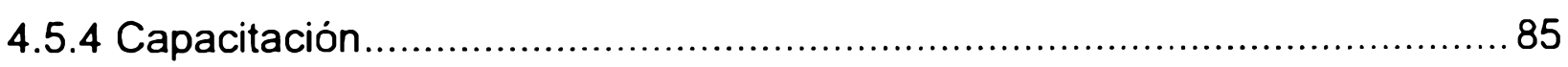

4.6. Descripción de las vinculaciones ubicadas dentro de cada sección principal de

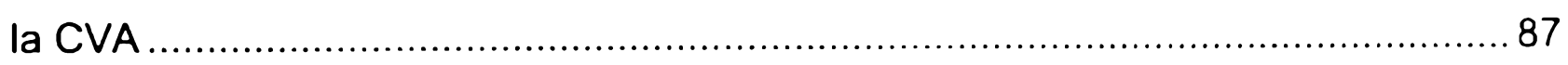

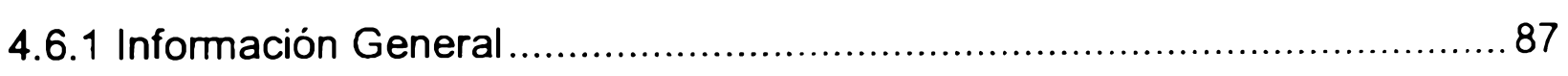

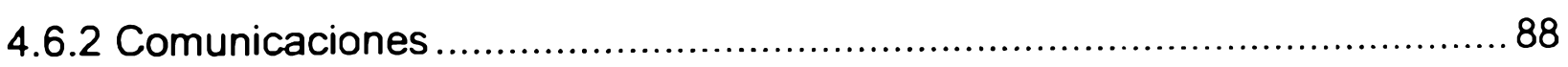

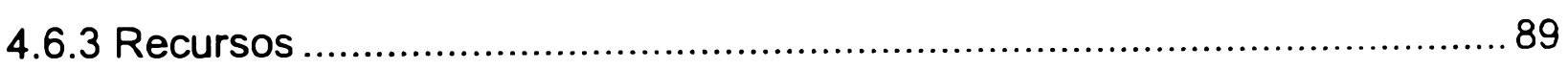

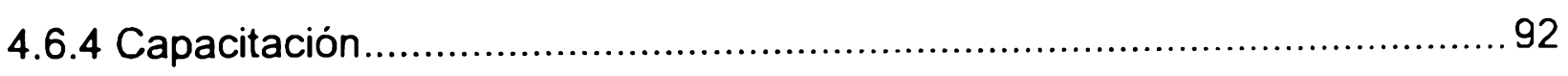

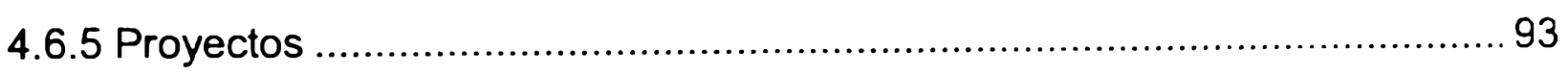

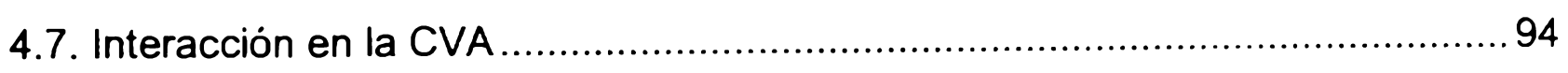

4.8. Implementación de un primer prototipo de CVA .......................................... 95

4.8.1 Espacio de información general ......................................................... 96

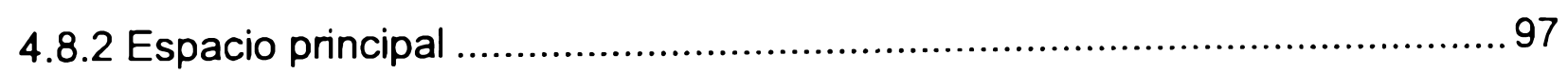

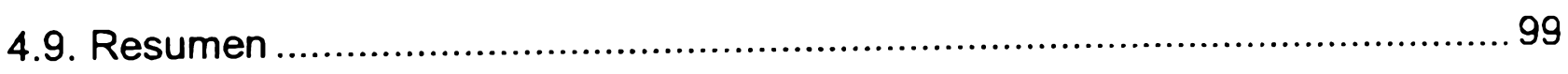


Capitulo 5 100

Evaluación de la comunidad virtual de aprendizaje. 100

5.1. Objetivo 101

5.2. Metodologia 102

5.3. Destinatarios. 107

5.4. Instrumentos de Evaluación. 107

5.5. Resumen 108

Capitulo 6 109

Conclusiones 109

6.1. Conclusiones generales 110

6.2. Trabajo a futuro 111

6.3. Palabras finales 112

Bibliografía 114

Otras fuentes documentales: 121

Anexos 123

Anexo A: Cuestionario para los gestores de la CVA 124

Concepto de Comunidad Virtual de Aprendizaje 124

Anexo B: Encuesta del curso “Energia y Medio Ambiente" .................................. 125

Anexo C: Encuesta inicial de evaluación de la CVA .......................................... 128

Anexo D: Encuesta de evaluación de la CVA ............................................. 130

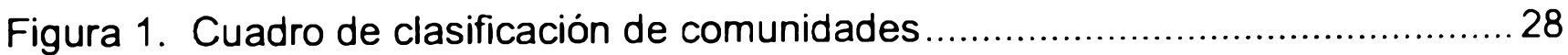

Figura 2. Esquema sobre la metodologia de la consulta ..................................49

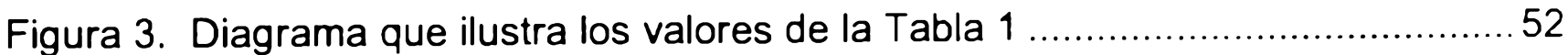

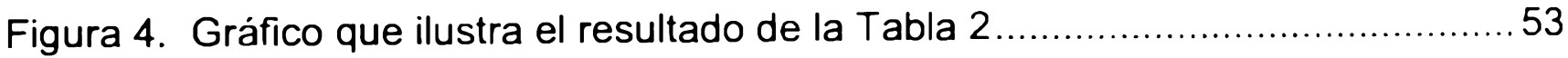

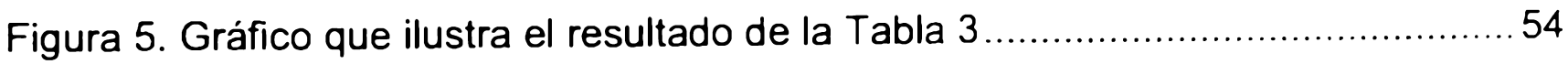

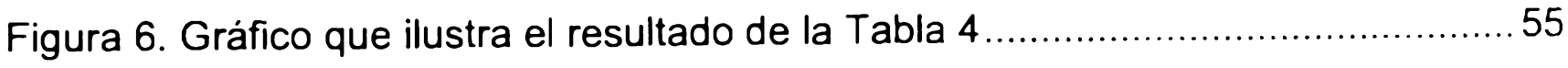

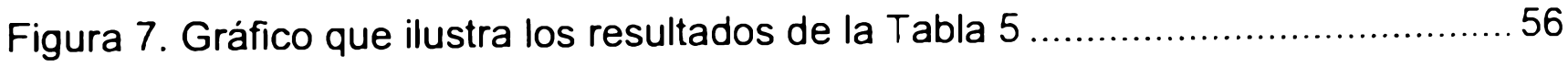

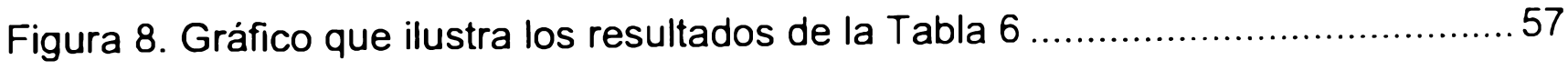

Figura 9. Presentación del grupo Cedsan_ar en Google .....................................6 60

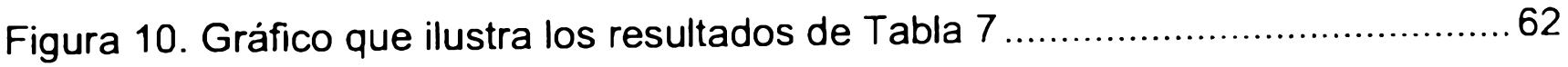

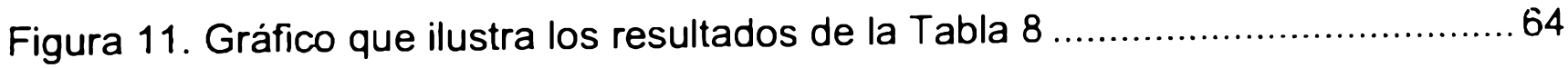

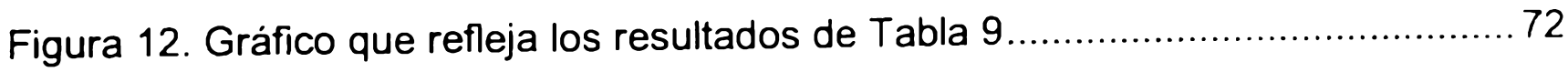

Figura 13. Imagen del video explicativo de Moodle: presentación ............................ 73

Figura 14. Imagen del video explicativo de Moodle: avances ................................73 
Figura 15. Imagen del Power Point explicativo de Moodle .74

Figura 16. Imagen del manual explicativo de Moodle ............................................. 74

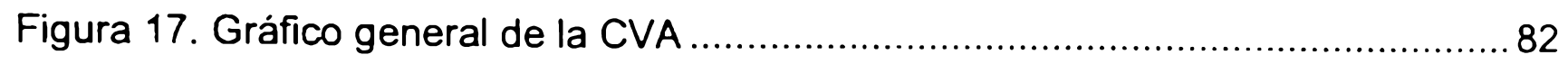

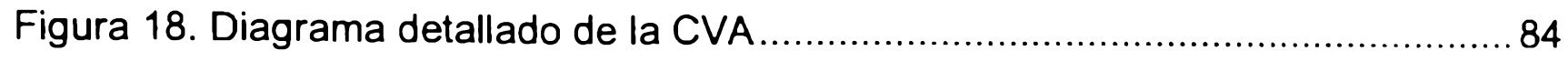

Figura 19. Imagen del material de aprendizaje diseñado para conceptos generales de Fisica Nuclear. 90

Figura 20. Imagen de material de aprendizaje que presenta un video explicativo ......90

Figura 21. Imagen de un material de aprendizaje que presenta un proyecto de simulación.

Figura 22. Imagen de un material de aprendizaje que muestra la simulación de una planta nuclear. 91

Figura 23. Imagen de la página del Reactor Nuclear donde se encuentra la CVA......95

Figura 24. Imagen de la CVA. .96

Figura 25. Categorias e indicadores para evaluar el impacto de la CVA 102

Figura 26. Categorias e indicadores para evaluar el diseño de la CVA 103

Tabla 1. Número de encuestados que sabe lo que es una CVA 51

Tabla 2. Número referido a la necesidad de contar con una CVA 52

Tabla 3. Número de encuestados que estima que mejorará su trabajo con una CVA 54

Tabla 4. Número de preferencias para trabajar dentro de la CVA 55

Tabla 5. Número que considera se dispone de tecnologia para generar una CVA .... 56

Tabla 6. Número de sugerencias aportadas para generar una CVA ........................57

Tabla 7. Resultados indicativos de los posibles usos de foros..............................62

Tabla 8. Resultados de las comunicaciones con los tutores ................................63

Tabla 9. Resultados sobre la facilidad de manejo del aula virtual .........................72 
Capítulo 1

Introducción 
Las tecnologias de la información y la comunicación facilitan la interacción social y la agrupación de personas con objetivos y necesidades comunes, en un espacio y tiempo determinados. Cuando a eso se le suma la gestión del conocimiento, estamos hablando de comunidades virtuales de aprendizaje (CVA) como espacios que propician el conocimiento a través de lazos comunicacionales y afectivos.

\subsection{Objetivo y estructura de la tesis}

El objetivo del presente trabajo es estudiar el concepto de comunidad virtual, en particular, comunidad virtual de aprendizaje. Analizar las posibilidades que ésta ofrece, en ambientes y actividades de colaboración y cooperación, en procesos educativos y/o de formación y enriquecimiento de las personas. Abordar una metodología de diseño de Comunidad Virtual de Aprendizaje, y finalmente, establecer las bases para el desarrollo de una comunidad concreta, donde se fomente el aprendizaje y el desarrollo profesional, aprovechando sus potencialidades para la comunicación y el intercambio de conocimientos y experiencias.

En particular, se diseñará una comunidad virtual de aprendizaje vinculada al tema de reactores nucleares para usos pacíficos. El desarrollo estará relacionado con sectores de la Comisión Nacional de Energía Atómica, la Autoridad Regulatoria Nuclear y con el Organismo Internacional de Energía Atómica, dado que en estas instituciones se realizan actividades profesionales en área nuclear, tanto en aspectos tecnológicos como en capacitación e investigación, interaccionando entre sí. Además habrá vinculación con áreas de la Universidad Nacional de Córdoba. Se propone que a través de la comunidad virtual planteada en esta tesis, se potencien las interacciones entre los miembros participantes a través del intercambio de experiencias y conocimiento, y se fortalezcan los vínculos sociales en pos de un objetivo común.

A continuación se detallará como se organizará el presente trabajo en capitulos y qué temas se abordarán respectivamente en cada uno.

En una primera etapa (capitulos 1 y 2) se analizan aspectos teóricos referidos a una comunidad de aprendizaje. Se aborda el concepto de comunidad, diferentes tipos de comunidades virtuales, sus diferencias con otros tipos de espacios virtuales, las teorias subyacentes sobre el aprendizaje en estos entornos, requerimientos y metodologia para generar una comunidad virtual de aprendizaje, análisis y comparaciones de las mismas.

En una segunda parte (capitulo 3), se plantea un marco metodológico donde se presenta una metodologia de diseño para generar una comunidad virtual de 
aprendizaje centrada en la Web, que cumpla con los conceptos e ideas consideradas. En particular, se muestra un proceso metodológico realizado en función de un caso concreto que es una comunidad virtual de aprendizaje referida a temas nucleares. En este sentido, la propuesta surge a partir del Reactor Nuclear RA-0 de la Facultad de Ciencias Exactas, Fisicas y Naturales de la Universidad Nacional de Córdoba. Alli desempeñan sus actividades un grupo integrado por profesionales de distintas disciplina, técnicos y estudiantes universitarios. Los profesionales tienen a su cargo tareas de operación del reactor, investigación y docencia (de grado y postgrado) en aspectos que tienen que ver con la energia nuclear, sus usos pacíficos y la aplicación de radioisótopos y radiaciones en distintas áreas de biomedicina.

En tercer lugar, se presenta un primer prototipo de comunidad virtual de aprendizaje (capitulo 4), desarrollado en el marco de esta tesis, y se explica el contexto donde se enmarca, los antecedentes en trabajos dentro de otros espacios virtuales, y la propuesta para esa comunidad referida a temas nucleares. Seguidamente, (capitulo 5) se plantea una estrategia inicial de evaluación de la comunidad virtual de aprendizaje con la finalidad de recoger información necesaria para reorientar los procesos de funcionamiento que garanticen el cumplimiento de los objetivos propuestos.

Finalmente, (capitulo 6) se extraen las conclusiones generales, el trabajo a futuro tendiente a introducir mejoras en la CVA, y algunas posibles lineas de investigación vinculadas.

\subsection{Marco Teórico: Introducción}

Esta primera parte de la tesis aborda el marco teórico que permite dar fundamento a los temas que se tratan en los capitulos que presentan el aporte fundamental de este trabajo.

A continuación se define comunidad de aprendizaje, para lo cual se analiza el concepto de comunidad, y luego se revisan diferentes concepciones acerca del aprendizaje. Seguidamente se establecen diferencias entre entornos virtuales de enseñanza y aprendizaje (EVEA) y comunidades virtuales de aprendizaje, para luego abordar este último concepto que es el principal tema de interés de esta tesis.

Los términos comunidad y comunicar provienen de las mismas raices, comunis (común) y communicare (establecer una comunidad). Palloff y Pratt (1999), señalan que gravitamos hacia un medio que nos posibilite comunicarnos y formar comunidades porque es ello, lo que de hecho nos torna más humanos. Definen comunidad como un todo dinámico que emerge cuando un grupo de gente comparte 
prácticas comunes, son independientes, toman decisiones compartidas, se identifican con algo mayor que la suma de sus relaciones individuales, y realizan compromisos a largo plazo sobre el bien común del grupo.

Comunidad es un grupo en constante transformación y evolución, que en su interrelación genera un sentido de pertenencia e identidad social, tomando sus integrantes conciencia de si como grupo, y fortaleciéndose como unidad y potencialidad social. Sus miembros comparten intereses, objetivos, necesidades y problemas en un espacio y tiempo determinado, desarrollando y empleando recursos para lograr sus fines (Montero, 1998).

La gente se agrupa en una comunidad porque desea adquirir e intercambiar conocimientos en un tema de su interés, tiene necesidad de autorrealización, pero al mismo tiempo, desea relacionarse y establecer amistad con otras personas con sus mismos intereses. Además, existe una necesidad de pertenencia, estima y reconocimiento. El reconocimiento del trabajo del otro consiste en la valoración que realizan los pares mediante el cual cada uno de los participantes consolida su identidad.

La comunidad tiende a dar seguridad al individuo manteniendo la cohesión del grupo por la presencia de sus miembros y la necesidad de sentirse vinculados. La socialización es el vínculo que los une y forma parte de una estructura que se mantiene en la medida que la misma se haga más fuerte. A su vez si mayor es la participación habrá más posibilidad de entablar relaciones sociales, que marcan el sentido de pertenencia a la comunidad. (Merton, 1964).

Ahora bien, la sociedad se explica tanto por sus fuerzas que tienden a la integración como por sus conflictos. Entonces en las comunidades también hay dificultades, luchas, colaboraciones, alianzas (Kreimer, 2009).

En cuanto a la comunidad virtual, el concepto fue acuñado por Rheingold (1996), quien las define como agregaciones sociales que emergen de la red, cuando un número suficiente de personas entablan discusiones públicas durante un tiempo lo suficientemente largo, para formar redes de relaciones personales en el ciberespacio'. Las primeras comunidades virtuales aparecieron en el ámbito académico entre activistas sociales de defensa de causas comunes y entre personas que buscaban compartir sus intereses, creencias y valores con otras. La diferencia entre comunidad y comunidad virtual, es la base territorial que en este último caso es el ciberespacio, lo

\footnotetext{
1 Ciberespacio: del término en inglés cyberspace, originado por el escritor William Gibson en su novela "Neuromanecer the Word cyberspace" y que se usa para describir la totalidad de los recursos informáticos disponibles a través de las redes de cómputo. Royo (2004).
} 
cual permite realizar actividades que no se ven limitadas por el territorio. En ellas es esencial el sentimiento de comunidad, ya que las mismas requieren algo más que el mero acto de conexión; la clave está en la interacción humana utilizando la red (Cherny, 1999).

La conformación de la comunidad virtual de aprendizaje, implica que el grupo de participantes experimente procesos de comunicación que den cuenta de sus mismos intereses temáticos, y cuyo objetivo radica en la profundización de dicho tópico mediante la comunicación entre pares (que pueden ser académicos), para lo cual utilizan el mismo lenguaje y el mismo lugar de encuentro en la red.

Estas comunidades se utilizan como una manera de construcción compartida del conocimiento, disponiendo de un contexto académico, un espacio para la experiencia social, y una infraestruciura de participación que facilite el aprendizaje y la comunicación.

En esta tesis se aborda el concepto de comunidad virtual descrito. Se diseña una CVA sobre la base de un conjunto de personas vinculadas entre si por motivos laborales, pero que verán ampliadas sus potencialidades a través de la red y que tendrán como uno de sus objetivos principales el aprendizaje.

Es por ello, que a continuación se rescatan algunos conceptos vinculados al aprendizaje, y al conocimiento, que marcan una postura frente a estos temas necesaria para abordar la tesis.

El concepto de aprendizaje es uno de los mecanismos fundamentales del desarrollo, en el que el contexto social ocupa un lugar central (Vigotsky, 1979).

El medio social es crucial para el aprendizaje e influye en la cognición por medio de sus objetos culturales, su lenguaje e instituciones sociales. Puede considerarse al aprendizaje como el proceso de adquirir conocimientos, habilidades, actitudes 0 valores, a través del estudio y la experiencia. Por otra parte, el conocimiento es parte del capital de una organización, el cual puede ser motivado y administrado, y contribuye a la competitividad y competencia entre las organizaciones, pudiendo ser extraido de la práctica propia y de otros grupos e individuos.

Es en el medio social donde se desarrolla y transmite el conocimiento, y la ciencia como tal depende de la estructura social existente, por lo que, para que cumpla con su finalidad de entregar conocimiento es necesario que no entre en competencia con la estructura social (Merton, 1964).

Asi también lo expresa Kreimer (2009): “...el conocimiento es producto de una actividad social y no la inspiración de alguien que puede revelar leyes ocultas...". 
Los integrantes de la comunidad pueden compartir experiencia, acceder, cogenerar y construir conocimientos a partir de las relaciones que alli se establecen.

En ese sentido, el conocimiento es una suma de experiencias, valores, información adquirida en un entorno social, que sirve para generar nuevas experiencias e información, y que se trasmite a través de estructuras sociales.

En resumen, se quiere rescatar de estos párrafos la importancia del medio en los procesos de aprendizaje, y el concepto de conocimiento. Estos aspectos serán de importancia en el marco de esta tesis.

En la siguiente sección se tratará la definición de comunidad de aprendizaje y se presentará una breve revisión de algunas teorias sobre el aprendizaje que sirven de marco para el trabajo.

\subsection{Comunidad de Aprendizaje}

Por comunidad de aprendizaje se entiende al grupo de participantes activos dentro de un contexto social, que asumen la responsabilidad de su propio aprendizaje. Aparecen como opciones para fomentar el intercambio y aprendizaje entre individuos y grupos de trabajo. También, permiten hacer frente a desafios como son: evitar cometer los mismos errores, fortalecerse como individuos y/u organizaciones.

Las comunidades de aprendizaje son grupos de personas que se encuentran en un mismo entorno, ya sea virtual o presencial, y que tienen un interés común de aprendizaje. Ese entorno formativo implica que es necesario un lenguaje, códigos de funcionamiento y acción comunes. Se basan en la confianza y el reconocimiento de la diversidad y la disposición para compartir experiencias y conocimientos. A través de este tipo de comunidades se busca establecer procesos de aprendizaje a largo plazo que apunten a la innovación, el desarrollo de capacidades, el mejoramiento de la práctica de aprendizaje y el fortalecimiento de los vínculos entre miembros.

En las comunidades de aprendizaje existe un proceso interactivo de comunicación. Tradicionalmente el ser humano ha generado comunidades que acumulan $y$ comparten su aprendizaje colectivo en prácticas comunitarias, donde el conocimiento no solamente es entendido como una construcción social e histórica, sino comunicativa e interactiva (Sarramona, 2000).

En la comunidad de aprendizaje se da una reciprocidad entre un conjunto de individuos que saben diferenciar y contrastar sus puntos de vista, de tal manera, que llegan a generar formas de construcción de conocimiento. Puede ser considerada 
como un proceso en el que cada individuo aprende más de lo que aprenderia por si solo, fruto de la interacción de los integrantes del equipo a través de la comunicación. Las comunidades de aprendizaje pueden encontrarse en ámbitos escolares, geográficos, instituciones educativas, profesionales, etc. En todos los casos, se las vincula a desarrollos económicos, de capital social o humano.

En los últimos tiempos, ha habido una expansión de las mismas debido a la globalización, la necesidad de interacción entre distintas sociedades, regiones, paises, la participación de la sociedad en los distintos ámbitos, el uso y avance de las nuevas tecnologias, la investigación y los cambios en áreas como la educación, la necesidad de innovar, la búsqueda de nuevos paradigmas educativos.

La comunidad de aprendizaje es una propuesta solidaria que se concreta en la sociedad, aprovechando sus recursos, sus instituciones, necesidades, posibilidades, con el fin de lograr un objetivo de aprendizaje.

Lo que se pretende es satisfacer necesidades de aprendizaje entre diferentes generaciones, entre pares, a través de un esfuerzo conjunto valiéndose de las potencialidades de la comunidad, el material disponible, los proyectos regionales y la sinergia de esfuerzos compartidos.

Las comunidades en general, tienen sus propias redes de enseñanza y aprendizaje, y cada miembro tiene capacidad para enseñar y aprender. La responsabilidad es colectiva y de cada persona individualmente. El aprendizaje es significativo para quien aprende, es decir se conecta con sus intereses, necesidades, conocimientos y experiencias previas, y motiva a continuar aprendiendo. La cooperación y la solidaridad tienen que ser vistas como norma y como recurso para asegurar los conocimientos, habilidades, valores $y$ actitudes que forman parte del fondo cultural $y$ educativo de una comunidad.

\subsection{Revisión de algunos conceptos claves en vinculación con el aprendizaje}

En esta tesis se abordará el concepto de aprendizaje vinculado a los principios constructivistas y cognitivistas de Piaget, defensor de la construcción activa del conocimiento por parte del individuo, a partir de su propia experiencia, y de los principios de la producción social del mismo, defendido por el construccionismo, que tiene sus antecesores como Dewey (1929) o Vigostsky (1978). Según esta perspectiva, el conocimiento se genera a partir del desarrollo de actividades que están basadas en el diseño y producción de un aprendizaje compartido. 
Para Duffy y Cunningham (1996) el aprendizaje es un proceso activo de construcción de significados más que un proceso de adquisición de información, y la instrucción un proceso de soporte o mediación de dicha construcción que va más allá de la comunicación o transmisión de información acabada. También hay coincidencia, tal como planteara Bruner (1990), en que el conocimiento no está en el contenido disciplinar, sino en la actividad constructivista de la persona sobre el dominio de contenido, tal como ocurre en un contexto socioeducativo determinado.

Diaz Barriga y Hernández (1998), establecen diferentes enfoques y situaciones referidas a aprendizaje, por ejemplo:

- El modelo expertos-novatos

El experto (profesor) modela y promueve los saberes del novato (alumno). El profesor asume el rol de entrenador del alumno. Los diseños instruccionales basados en el aprendizaje artesanal son una muestra de esta estrategia.

- El descubrimiento individual y colaborativo

Los alumnos, individualmente o en grupo, llevan a cabo tareas que implican descubrimiento y solución de problemas. El foco de la enseñanza se centra en que los alumnos desarrollen las habilidades de cuestionamiento y prueba de conjeturas. El aprendizaje basado en problemas es un claro ejemplo de esta estrategia de instrucción.

- Las comunidades de aprendizaje

El conocimiento se produce con la participación conjunta en experiencias socioculturales y colectivas relevantes y auténticas. Por lo que se enfatiza el trabajo colaborativo y la co-construcción del conocimiento.

- Las comunidades de prácticas

El conocimiento reside en las personas. Sin embargo los actos sociales, constructivos, tienen sentido dentro de contextos de aplicación y uso determinados.

Por ejemplo, las comunidades que comparten conocimientos, lenguajes, simbolos, signos y herramientas que les son propios.

En todos estos enfoques y situaciones se ve claramente la importancia que tiene la acción social y el contexto, en el aprendizaje. En los párrafos posteriores se busca enfatizar la relación entre el saber y el hacer de manera de justificar la concepción que se toma en esta tesis sobre el aprendizaje. 
En la enseñanza reciproca (Brown y Palincsar, 1989), el profesor asume el rol de entrenador, mientras que en la instrucción fundada en el aprendizaje basado en problemas y en los diseños basados en la experiencia, que toman al educando como cientifico, la enseñanza se desplaza a las habilidades de cuestionamiento y prueba sistemática de conjeturas.

La brecha entre aprendizaje y aplicación es denominada "folklóricamente" por la diferencia entre el "saber qué" y "saber cómo", que puede ser producto de las prácticas pedagógicas llevadas a cabo en los sistemas educativos (Brown, Collins y Duguid, 1989).

Varios métodos didácticos asumen que el conocimiento es una única entidad y que el "saber" y el "hacer", deben ponerse en práctica.

Sin embargo, recientes investigaciones han cambiado esta separación entre lo que se aprende y la forma en la que el saber es aprendido y usado. La actividad en la que el conocimiento es desarrollado no está separada del propio aprendizaje y de la cognición, no es neutral. Es parte integral de lo que es aprendido. Las situaciones de aprendizaje son "co-productoras" del conocimiento y éste, se adquiere mediante aquellas. Aprendizaje y cognición son interdependientes y desde este punto de vista, fundamentalmente situados (Salomon, 1993).

El aprendizaje se refuerza cuando las personas le dan su impronta a los conceptos a partir de su visión del mundo en el que actúan y del uso académico y escolar. Es un proceso continuo que se desarrolla a lo largo de la vida, resultando de acciones en diferentes situaciones. Se relaciona con la socialización dado que la gente adopta modelos culturales de los diferentes grupos sociales a los que pertenece, tanto académicos como en la cultura cotidiana.

Hay muchos lugares de aprendizaje como el hogar, escuela, naturaleza, calle, comunidad, trabajo, iglesia, grupo de amigos, medios de comunicación, biblioteca, Internet, etc. También varias fuentes de aprendizaje como el juego, la lectura, la observación, reflexión, conversación, la práctica, el ensayo y el error y el autoestudio. Todos ellos son relevantes y complementarios para asegurar aprendizajes significativos en el contexto del aprendizaje permanente.

Aprender no es asimilar contenidos, sino realizar actividades que generen un conocimiento integrado y significativo como búsqueda de información, análisis crítico, sintesis, construcción de contenidos, desartollo de competencias relacionadas con lo aprendido. Retenemos el $10 \%$ de lo que leemos, el $20 \%$ de lo que escuchamos, el 
$30 \%$ de lo que vemos, el $50 \%$ de lo que vemos y escuchamos, el $70 \%$ de lo que decimos y discutimos, el $90 \%$ de lo que hacemos y decimos (Santamaria, 1995).

A continuación se presentan algunos conceptos claves en vinculación con el aprendizaje cooperativo y colaborativo. Esto resulta de interés en el marco de esta tesis que aborda el tema de comunidades de aprendizaje donde intervienen procesos de colaboración y cooperación.

\subsubsection{Aprendizaje Cooperativo}

El aprendizaje cooperativo requiere una división de tareas entre los integrantes del grupo (Dillenbourg, 1999).

Las personas necesitan aprender profundamente y aprender cómo aprender, cómo formular preguntas y seguir lineas de investigación, de tal forma que puedan construir un nuevo conocimiento.

Las ideas son más concretas y precisas cuando se necesita expresarlas en un grupo. En el aprendizaje cooperativo cada persona depende de los demás para alcanzar sus objetivos, de tal manera que un individuo alcanza su objetivo si los otros participantes alcanzan el suyo.

Éste tipo de participación mejora la comunicación entre los miembros, la preocupación por los demás, y la confianza en sí mismo y en el grupo. Por lo expuesto, para tener éxito en el aprendizaje cooperativo, es importante la conformación de los grupos de trabajo. Estos pueden ser heterogéneos en sexo, raza, estatus económico, habilidad y aprenden a resolver los problemas que surjan, en colaboración mutua (Johnson y Johnson, 1999).

Es importante que exista un grado de simetria en los roles que desempeñan los participantes en una actividad grupal, planificación y discusión en conjunto, y división del trabajo entre los miembros. También se requiere de una evaluación del avance personal y grupal para conocer quién necesita más ayuda, y evitar que unos descansen en el trabajo de los demás. (Santamaria, 1995). En cuanto a los roles, el compendiador resume las conclusiones, el inspector asegura que todos expresen como llegaron a las respuestas, el entrenador corrige los errores, el narrador se encarga de solicitar que se relacionen los nuevos conceptos y estrategias con lo aprendido, el investigador consigue los materiales que el grupo necesita, el registrador escribe las decisiones del grupo y edita el reporte del trabajo, el animador refuerza las contribuciones de los miembros, y el observador cuida que el grupo trabaje de manera adecuada (Johnson, Johnson y Holubec, 1999). 


\subsubsection{Aprendizaje Colaborativo}

El aprendizaje colaborativo responde a una manera de aprender socialmente en función de un objetivo común, interaccionando y construyendo el conocimiento. Driscoll y Vergara (1997) expresan: "para que exista un verdadero aprendizaje colaborativo, no sólo se requiere trabajar juntos, sino también cooperar en el logro de una meta que no se puede lograr individualmente. Para ello, cada miembro asumirá su responsabilidad bajo una meta común desarrollando un trabajo en equipo, solucionando inconvenientes, estableciendo estrategias de aprendizaje, evaluando el avance y efectuando los cambios necesarios".

El aprendizaje colaborativo requiere una estrategia pedagógica que favorezca la interdependencia cognitiva y social entre los estudiantes, tomando en consideración las diferencias interindividuales.

En este proceso de aprendizaje los estudiantes colaboran con el grupo y éste con el aprendizaje individual. El estudiante comparte los recursos con el grupo y utiliza el trabajo realizado en éste para aprender. La exploración y experimentación se realizan libremente.

En el aprendizaje colaborativo se adquieren destrezas y actitudes como resultado de la actividad en grupo.

La premisa básica del mismo es la construcción del consenso, a través del aporte de los miembros del grupo. Se comparte la autoridad, y entre todos se acepta la responsabilidad de las acciones del grupo, mientras que en la cooperación la interacción está diseñada para facilitar el logro de una meta o producto final específico por un grupo de personas que trabajan juntas (Panitz, 1998).

Los foros de discusión son potenciales espacios para el aprendizaje colaborativo. Alli se evidencia la riqueza de los intercambios frente a los modelos expositivos de información. Esos intercambios se producen desde un miembro al grupo, ya sea solicitando o aportando información, estableciendo relaciones de debate y confrontación de ideas, o a través de la argumentación y co-construcción de significados, propios de modelos comunicativos centrados en la colaboración.

Aprender colaborativamente implica intercambio entre pares, interacción entre iguales, capacidad de intercambio de roles en diferentes momentos. La colaboración lleva a la sinergia, y asume que el todo es más que la suma de las partes, de tal forma que aprender colaborativamente tiene el potencial de producir ganancias de aprendizaje superiores al aprendizaje aislado (Zañartu, 2003). 
En conclusión, el aprendizaje colaborativo es un proceso de socioconstrucción en el cual se promueve el diálogo y trabajo en grupo, lo que potencia las habilidades y la adquisición de destrezas. La interacción colaborativa enriquece los resultados y promueve la creatividad. Aumenta la motivación al generar en los individuos sentimientos de pertenencia, lo que estimula productividad y responsabilidad en el grupo.

Todo este proceso dependerá de los integrantes del grupo, la propuesta de trabajo, el contexto, las herramientas y medios elegidos para la interacción.

Para complementar ambas formas de enseñanza, cooperativa y colaborativa, resulta interesante comenzar por propiciar en el alumno el desarrollo de habilidades que le permitan fortalecer su responsabilidad y toma de decisiones, o sea de tipo cooperativo donde el profesor controlará su avance, para luego facilitarle el trabajo en grupo donde podrá realizar un aprendizaje autónomo.

Hay autores que hablan de modelos de interacción cooperativo-colaborativo como es el caso de Lage y Cataldi (2000).

Estos autores plantean un ejemplo, donde se presenta una serie de problemas a resolver a partir de objetivos dados, donde la resolución de los mismos implica comprenderlos, subdividirlos y establecer una organización jerárquica y relacional entre ellos para luego abordarlos. Utilizan el modelo llamado 4C (cascada para capacitación cooperativa-colaborativa) con el cual se demuestra la complementariedad de ambas formas de aprendizaje. De esta manera, el trabajo cooperativo se basa en dividir las tareas entre los participantes, responsabilizando a cada uno de una parte para lograr la resolución total. En tanto, el colaborativo incluye el compromiso mutuo en un esfuerzo coordinado para resolver problemas juntos.

Este modelo 4C integra todas las fases de trabajo, y cada una soporta diferentes tipos de interacción y roles, que evolucionan desde un trabajo guiado por el coordinador en una primer etapa, hasta un trabajo conducido por el grupo en una etapa posterior, pasando por etapas cooperativas, cooperativas-colaborativas y colaborativa pura.

\subsection{Resumen}

El capitulo comienza esbozando los objetivos de la tesis y la estructura dispuesta para alcanzarlos. A continuación se transita el camino hacia la definición de comunidad virtual de aprendizaje, comenzando por comunidad (tomando autores como Merton y Kreimer) y comunidad virtual, y estableciendo las diferencias entre ambas. El concepto de aprendizaje se presenta a través de la visión de Vigotsky, 
teniendo en cuenta la influencia del medio social en que se desarrolla. Este enfoque sobre el aprendizaje es importante para el marco de esta tesis, ya que se hablará de comunidades virtuales de aprendizaje, y el contexto y grupo social jugarán un rol esencial.

Luego se analiza lo que se entiende como comunidad de aprendizaje y su influencia en la construcción de conocimientos.

Finalmente, se presentan algunos conceptos en vinculación con la concepción del aprendizaje que resultan relevantes y son los pilares que nos permiten fundamentar la visión de comunidad de aprendizaje. Se resalta la importancia de las actividades compartidas en la construcción de conocimiento. También se introducen las diferencias entre aprendizaje cooperativo y colaborativo, procesos que pueden darse en las comunidades. 
Capítulo 2

Comunidad virtual de aprendizaje 
Existen diferentes maneras y objetivos para agruparse en torno a un espacio virtual, lo que genera distintas formas de trabajo, de organización y roles. De alli la importancia de indicar esas diferencias entre conceptos que pueden tomarse como similares. Tal es el caso del entorno virtual de enseñanza y aprendizaje respecto a comunidad virtual de aprendizaje.

Navegar por comunidades virtuales de aprendizaje existentes permite indagar sobre sus organizaciones, recursos, gestión del conocimiento, intereses y objetivos; lo cual aporta información relevante para el objetivo de esta tesis. Es por ello que en este capitulo se hace una revisión de algunas comunidades virtuales que permiten ejemplificar el marco teórico.

Finalmente se analizan los requerimientos teóricos, tecnológicos y arquitectónicos necesarios para crear una comunidad virtual de aprendizaje, los que luego son tenidos en cuenta en el diseño de la comunidad propuesta en esta tesis.

\subsection{Introducción}

Las comunidades virtuales de aprendizaje difieren de la interpretación común de comunidades porque no están limitadas por la geografia, la industria, la profesión, el sexo, la raza, religión o edad. Tienen el poder de trascender esas fronteras.

Las CVA podrian ser comunidades de investigadores e indagadores donde se valora el proceso colectivo de descubrimiento.

En una comunidad de aprendizaje, es necesario contar con algunos factores que permitan sostenerla y hacerla perdurable. Para ello es de destacar el trabajo realizado por Garcia Fernández (2002), que hace referencia a los siguientes items como condiciones minimas para llegar a la gestación de una comunidad y su funcionamiento en el tiempo:

- Cambios institucionales que faciliten el desarrollo de las comunidades de aprendizaje.

- Modelos efectivos para el funcionamiento.

- Innovaciones técnicas y herramientas de trabajo que propicien entomos modernos y flexibles.

- Participación abierta y horizontal de todos los miembros de la comunidad.

- Acceso de todos, sin tener en cuenta su condición o lugar que habiten. 
A los cuales, se les pueden agregar los siguientes:

- Recursos tecnológicos y financieros.

- Grupo humano con formación adecuada.

- Material bibliográfico.

- Organización acorde a las necesidades de la comunidad.

- Temas propios de la comunidad.

- Un objetivo en común de los participantes.

- Interés de las personas en establecer relaciones sociales.

- Deseo de disfrutar de experiencias gratificantes.

- Necesidad de realizar intercambio de datos, conocimientos, informes. recursos.

Por ejemplo, en los procesos de educación a distancia mediados por TICs suelen generarse comunidades de aprendizaje entre los alumnos y los docentes involucrados, respetándose varios de los puntos mencionados anteriormente (necesidad de realizar intercambios, puesta en común de material bibliográfico, recursos tecnológicos y financieros que sostienen el proceso, etc.). La interacción entre estudiantes en el contexto de una comunidad de aprendizaje puede constituir un potente recurso de apoyo, esencial para el desarrollo de experiencias de aprendizaje basadas en la reflexión y colaboración (Garrison, 2000 y 2001); facilitando asi el logro de dos de las metas tradicionales de la educación a distancia, el aprendizaje y la socialización (Mugridge y Kaufman, 1986).

Al respecto, Morueta, Carreño y Guzmán (2008) encuentran en su análisis que las participaciones socio-emotivas facilitan un sentimiento de comodidad e identificación con el grupo, que son condiciones indispensables para la generación de comunidades de aprendizaje. La mayor frecuencia de participación, por ejemplo en los foros, condiciona positivamente la creación de comunidades de aprendizaje.

Una comunidad virtual se caracteriza porque sus miembros se sienten parte de un grupo social, existe una red de relaciones, una corriente de intercambio de contenidos que tiene valor para sus integrantes y se mantiene en el tiempo, creando un conjunto de historias compartidas (Figallo, 1998). Los integrantes de una comunidad virtual mantienen un conjunto de motivaciones para formarla y alimentarla, como son sus intereses y objetivos comunes, el deseo de compartir una experiencia o establecer relaciones sociales, disfrutar de experiencias gratificantes y realizar transacciones de diversa indole (Hagel y Armstrong, 1997). 


\subsection{Diferencias entre Entorno Virtual de Enseñanza y Aprendizaje y Comunidad Virtual de Aprendizaje}

Es necesario diferenciar entre "Entorno Virtual de Enseñanza y Aprendizaje" y "Comunidad Virtual de Aprendizaje" dado que, suelen encontrarse en la bibliografia con diferentes acepciones, y pueden generar confusiones.

En los entornos virtuales de enseñanza y aprendizaje (EVEA) existen roles bien definidos, se trabaja a nivel de cursos 0 aulas que permiten describir y presentar la propuesta docente. Existe el rol docente, alumno, administrador y hay asimetria entre lo que pueden hacer los diferentes miembros. Estos entornos proveen funcionalidades diferentes para cada uno de esos roles. Asi por ejemplo, el docente organiza la agenda de trabajo, hace el seguimiento de los alumnos, coordina y modera las comunicaciones y evalúa el progreso en el aprendizaje. El alumno accede a la propuesta planificada por el docente, a través de la estructura del EVEA y sus diferentes herramientas. En tanto el administrador, realiza el diseño macro del entorno, instalación y actualización de programas, gestión de usuarios y soluciona problemas referidos al manejo del sistema.

A su vez, podria darse que en un EVEA se conforme una comunidad virtual de aprendizaje, desde el punto de vista que se comparten intereses temáticos con el objetivo de profundizarlos y realizar una construcción compartida del conocimiento dentro de un contexto académico común.

En esta tesis hablamos de comunidades virtuales de aprendizaje en un sentido más amplio, haciendo referencia a aquellos espacios en la Web donde no existen necesariamente los roles mencionados, y suele haber mayor horizontalidad.

Una comunidad virtual de aprendizaje se desarrolla en torno a temas centrales, la responsabilidad es compartida, la participación es abierta sin obligatoriedad de esquemas jerárquicos, con espacios de comunicación y vinculación con el exterior. Los roles que suelen identificarse son los de facilitador o coordinador, y participantes, y éstos últimos varian en cuanto a su constancia y forma de participar. Las comunidades virtuales de aprendizaje agrupan personas relacionadas con una temática especifica, que además de las listas de distribución, comparten documentos y recursos a través de un entorno de participación y realización de actividades.

Pueden estar orientadas hacia el usuario, y ellos definen el tema de la comunidad. $O$ bien ser temáticas, donde se discuten temas de interés, ya sea cientifico, cultural, político, comercial, recreativo, económico o social. Orientadas hacia la organización, 
en las cuales el tema se define según el objetivo y área de trabajo de la CVA. A su vez, se pueden subdividir en:

- Verticales: agrupan usuarios de diferentes ámbitos y actividades.

- Funcionales: se refieren a un área especifica del funcionamiento de una institución, por ejemplo desarrollos tecnológicos, capacitación, investigación.

- Geográficas: concentradas en una zona geográfica cubierta por la comunidad, por ejemplo instituciones de Latinoamérica.

La dinámica de una CVA está orientada de acuerdo al principio del beneficio creciente, tanto para la organización que administra la comunidad como para sus miembros o usuarios, y éste se produce en la forma de un espiral acumulativo creciente. Como punto de partida, un contenido interesante atrae miembros a la comunidad, lo cual genera a su vez más contenidos producidos por los interesados, que a su vez hace más atractivo el contenido. Se completa asi el primer ciclo acumulativo. De esta manera los usuarios perciben un mayor valor en la comunidad lo cual promueve mayor y mejor interacción entre ellos, creando lealtad hacia la misma y mayor permanencia.

\subsection{Tipos de comunidades}

En general las comunidades se pueden clasificar en tres grandes categorias: de ocio, profesionales y de aprendizaje y pueden estar

- Centradas en las personas.

- Centradas en el tema.

- Centradas en un acontecimiento.

Según Coll (2001) hay cuatro categorias:

- Referidas al aula.

- Referidas al centro educativo.

- Referidas a una ciudad, región o zona territorial.

- Las que operan en un entorno virtual. 
Según la clasificación de Hagel y Armstrong (1997), las comunidades virtuales de aprendizaje pueden estar orientadas a:

- Usuario

- Organización

En las orientadas a los usuarios, son ellos los que definen el tema de la comunidad y se pueden dividir en:

- Geográficas: agrupan personas que viven o están interesadas en intercambiar información sobre una misma área geográfica.

- Temáticas: orientadas a la discusión de un tema de interés para los usuarios.

- Demográficas: reúnen usuarios de características demográficas similares.

- De ocio y entretenimiento: dirigidas a aquellos cibernautas que ocupan su tiempo libre en juegos de red. Se crean por tipos de juegos como estratégicos, de simulación.

- Profesionales: para aquellos expertos en una materia que desarrollan su actividad concreta en un área profesional definida, generalmente asociada a una formación superior.

- Gubernamentales: los organismos gubernamentales crean comunidades a las que puede acudir el ciudadano para informarse y/o discutir.

- Eclécticas: son aquellas comunidades virtuales mixtas, que se involucran con varios aspectos: ocio, via de transmisión y comportamiento cultural.

En las orientadas hacia la organización el tema es definido según los objetivos y áreas de trabajo donde reside la comunidad, como se mencionó en 2.2.

También se puede establecer una división de acuerdo a las normas de funcionamiento, en comunidades virtuales abiertas o restringidas, según se pueda suscribir o dar de baja a propia voluntad, y libres o moderadas, si existe o no control sobre las intervenciones de los participantes.

Para Salinas (2003), hay grupos de comunidades virtuales en función de

a) El modo de asignación de los miembros:

- De asignación libre. 
- De asignación voluntaria.

- De asignación obligatoria.

b) La función primaria que se adjudica a la comunidad virtual:

- Distribuir: cuando la principal función de la comunidad radica en la distribución de información, mensajes, entre los miembros.

- Compartir: se trata de comunidades donde prima el intercambio de experiencias y recursos.

- Crear: cuando se generan procesos de trabajo colaborativo con el objeto de lograr materiales, documentos, proyectos compartidos.

c) La gestión de la comunidad virtual:

- Abiertas: cuando el acceso y los recursos de la comunidad virtual están a disposición tanto de los miembros como de personas que no pertenecen a la comunidad.

- Cerradas: cuando existe algún procedimiento que impide a las personas ajenas a la comunidad el acceso, de tal forma que los recursos, materiales, producciones, histórico, etc. son sólo accesibles para los miembros.

En la linea de la clasificación descrita anteriormente, las comunidades se pueden clasificar en función del objeto que persiguen (Salinas, 2003):

- Comunidades de aprendizaje propiamente dichas cuando han sido creadas para que el grupo humano que se incorpora desarrolle procesos de aprendizaje, en programas diseñados al efecto.

- Comunidades de práctica, constituidas con el fin de desarrollar un conocimiento especializado, compartiendo aprendizajes basados en la reflexión conjunta sobre experiencias prácticas.

- Comunidades de investigación que desarrollando actividades de aprendizaje, tienen como objeto principal poner en marcha proyectos de investigación conjunta, de acuerdo con la filosofía del trabajo cooperativo a través de redes. 
- Comunidades de innovación buscan compartir, intercambiar y generar procesos de innovación en distintos campos.

Jonassen, Pech, y Wilson (1998) proponen cuatro tipos de comunidades virtuales:

- De discurso, para compartir intereses con otras personas mediante los medios de comunicación.

- De práctica, donde se forman grupos de trabajo, asignan roles, se enseña y apoya a otros. Se desarrollan identidades que son definidas por las funciones que desempeña cada uno en beneficio del grupo.

- De construcción de conocimiento, cuyo objetivo es apoyar a los estudiantes a perseguir estratégica y activamente el aprendizaje como una meta.

- De aprendizaje, una organización social de personas que comparten conocimiento, valores y metas.

En esta última clasificación parecieran tener en común aquellas que son de construcción de conocimiento y de aprendizaje por lo que las consideraremos conjuntamente.

Las comunidades que interesan en éste trabajo son las virtuales centradas sobre dimensiones formativas, ya sea de tipo abierto como restringido, moderadas, con diferentes roles entre los participantes, de práctica, de construcción del conocimiento, pero sobre todo cercanas a las denominadas comunidades de aprendizaje.

En el siguiente cuadro, elaborado en el marco de esta tesis, se presentan diferentes categorias de clasificación de comunidades que retoman algunas de las ideas presentadas por los autores revisados. En algunos casos se puede dar una combinación de estas clasificaciones. Se indica en amarillo la clasificación, en base a caracteristicas generales, entorno, organización, orientación, asignación de miembros y objeto de la CVA y se ha marcado el fondo de las que resultan en particular de interés para esta tesis. 


\begin{tabular}{|l|l|l|l|l|l|}
\hline $\begin{array}{l}\text { CENTRADAS } \\
\text { EN }\end{array}$ & ENTORNO & ORIENTACIÓN & $\begin{array}{l}\text { ORGANIZACIÓN } \\
\text { (Gestión) }\end{array}$ & $\begin{array}{l}\text { ASIGNACIÓN } \\
\text { MIEMBROS }\end{array}$ & OBJETO \\
\hline Personas & Aula & Geográficas & Abiertas & Libre & Aprendizaje \\
\hline Temas & $\begin{array}{l}\text { Centro } \\
\text { Educativo }\end{array}$ & Temáticas & Cerradas & Voluntario & Práctica \\
\hline Acontecimiento & Regional & Demográficas & Libres & Obligatorio & Investigación \\
\hline & Virtual & Ocio & Moderadas & & Innovación \\
\hline & $\begin{array}{l}\text { Empresa } \\
\text { Organización }\end{array}$ & Profesionales & & & Discurso \\
\hline & & $\begin{array}{l}\text { Gubernamenta- } \\
\text { les }\end{array}$ & & & $\begin{array}{l}\text { Construcción } \\
\text { de } \\
\text { conocimiento }\end{array}$ \\
\hline & & Eclécticas & & & \\
\hline
\end{tabular}

Figura 1. Cuadro de clasificación de comunidades

\subsection{Ejemplos de comunidades virtuales}

De acuerdo a la clasificación realizada en el punto anterior, se buscaron algunos ejemplos de comunidades virtuales de aprendizaje, tales como Comunidad Educa Red, Comunidad de Aprendizaje Permanente, Red TELAR, Red VIT@LIS y IEARN, que pueden encuadrarse como comunidades virtuales de aprendizaje propiamente dichas, donde se trabaja colaborativamente en la construcción del conocimiento; Red TELAR orientada al ámbito educativo formal (escuelas), en tanto La Red VIT@LIS promueve la colaboración entre proyectos regionales. Dentro de esa misma clasificación se encuentran las comunidades virtuales de aprendizaje Proyecto Mentor (CNICE-MECD) y comunidades autónomas de España, pero orientadas a una formación para adultos dentro de la educación no formal.

La comunidad MIPE-DIPE es una comunidad de aprendizaje e investigación destinada a promover los proyectos de investigación y generar espacios de comunicación en el ámbito de la psicología de la educación.

El Centro Comunitario de Aprendizaje es un ejemplo de comunidad de práctica dado que permite desarrollar habilidades en los usuarios.

Respecto a las comunidades de discurso donde el foco es la comunicación entre los miembros, se encuentran Eduso y Mundo Latino. Como ejemplo de comunidad basada en temas se pueden mencionar EcoPorta.net dedicado al medio ambiente y e-Learning América Latina, dedicada especificamente a temas referidos a educación a distancia. Los ejemplos aqui expuestos no son excluyentes y en general fueron buscados pensando en la tesis, que se vincula con la creación de una comunidad virtual de aprendizaje, donde las personas interesadas comparten un espacio de colaboración para el aprendizaje, la participación para trabajar en conjunto en temas 
afines, la discusión en temas de interés y el intercambio de experiencia y conocimiento.

Es importante que el diseño de la CVA incluya en alguna de sus etapas instrumentos psicopedagógicos para analizar y comprender la evolución respecto a sus prácticas y el uso de los recursos que hacen los usuarios. La finalidad de este punto es diversificar los recursos o eliminar aquellos que no ayuden a un proceso formativo (Coll, Sánchez y Rocamora, 2007).

De cada una de las comunidades virtuales de aprendizaje analizadas se presenta: Nombre, tipo de comunidad, objetivo, integrantes, sistema de admisión, generalidades y dirección en la Web.

- Nombre: Comunidad EducaRed (España, Brasil, Chile, Perú, Colombia).

Tipo de comunidad: de construcción de conocimiento y aprendizaje, virtual, abierta y de innovación.

Objetivo: favorecer la inclusión de las nuevas tecnologias de la información y la comunicación en las escuelas con el objeto de enriquecer las prácticas de la enseñanza, promover aprendizajes genuinos y construir conocimiento socialmente relevante.

Integrantes: el programa promueve el desarrollo de proyectos de interés educativo y cultural en los que Internet es usada para facilitar la colaboración entre alumnos, docentes y de éstos con la comunidad en general.

Sistema de admisión: gratuito para toda la comunidad educativa con especial énfasis en los educadores y alumnos de la Educación General Básica, la Educación Secundaria Básica y el nivel Secundario Polimodal.

Generalidades: constituye un referente en el que los docentes pueden encontrar información, herramientas, propuestas de actualización y espacios para el intercambio y la difusión de aquellas experiencias educativas que se ven potenciadas por el uso de las nuevas tecnologías.

Dirección: muw.educared.org.ar

- Nombre: Comunidad de Aprendizaje Permanente.

Tipo de comunidad: centrada en temas de aprendizaje y construcción de conocimiento y abierta. 
Objetivo: compartir intereses en Relaciones Humanas, Efectividad y Desarrollo Personal, Profesional y Organizacional.

Integrantes: comunidad internacional de habla hispana.

Sistema de admisión: por inscripción y pago de cuota.

Generalidades: se ofrecen cursos, acceso a una revista bimestral, a los archivos de ser humano y trabajo, módulo de aprendizaje personal, participación de foros.

Dirección: $\underline{m w}$.sht.com.ar

- Nombre: Red TELAR (Todos En LA Red)

Tipo de comunidad: centrada en temas educativos, abierta, para compartir conocimientos.

Objetivo: promover la utilización pedagógica de las nuevas tecnologías de la información y la comunicación mediante el trabajo en proyectos colaborativos nacionales e internacionales

Integrantes: todas las escuelas interesadas, docentes y alumnos.

Sistema de admisión: por registro libre y gratuito

Generalidades: los temas están relacionados con la realidad social de nuestra época dentro de los estándares curriculares nacionales y regionales. TELAR forma parte de la Red Global iEARN (Red Internacional de Educación y Recursos), de modo que las escuelas que participan tienen posibilidad de relacionarse con establecimientos educativos en 110 paises. Esta red es administrada y auspiciada por Fundación Evolución, y cuenta con facilitadores en la mayoria de las provincias que llevan adelante el acompañamiento y seguimiento de docentes, además de otras tareas.

Dirección: www.telar.org

\section{- Nombre: La Red VIT@LIS}

Tipo de comunidad: de innovación, de práctica. Es abierta

Objetivo: fortalecer la colaboración entre regiones y capitalizar los proyectos existentes, facilitando la adopción y transferencia de prácticas exitosas y al mismo tiempo la creación de nuevos proyectos. Los principales inspiradores son reciprocidad en la colaboración, inclusión social y digital para todos, promoción del diálogo "multistakeholder" (gestión del dialogo entre actores implicados de distintos sectores), valorización de los resultados y de las mejores prácticas existentes, orientación a la innovación en todas sus dimensiones: tecnológica, 
social, económica y institucional y en todo su ciclo de vida, desde la investigación hasta la aplicación en las comunidades locales.

Integrantes: universidades, gobiernos, agencias públicas, redes internacionales, empresas y autoridades locales de Europa, América Latina y Caribe.

Sistema de admisión: abierto y gratuito, pero se debe estar participando en alguna actividad de la Red y estar dispuesto a compartir resultados e ideas.

Generalidades: cuenta con más de 200 socios, entre los cuales se encuentra la Oficina Nacional de Tecnologias de Información (ONTI) de Argentina, que es la principal agencia gubernamental en el uso de las tecnologías de información de la Administración Pública. Funciona como dependiente de la Subsecretaria de Gestión Pública y está conformada por un grupo multidisciplinario de profesionales y de especialistas. Su función principal es asistir a la Subsecretaria de Gestión Pública en la formulación de politicas y la puesta en práctica de procesos de desarrollo y de innovación de tecnologia para la reingenieria y la modernización del Estado Argentino.

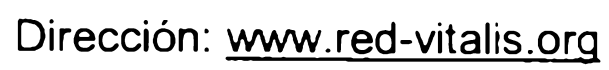

- Nombre: Proyecto Mentor (CNICE-MECD) y comunidades autónomas de España

Tipo de comunidad: de aprendizaje, gubernamental, virtual, moderada y restringida.

Objetivo: formación de adultos y profesionales

Integrantes: toda la población española sin límite de edad que esté interesada en realizar cursos de formación dentro de enseñanzas no regladas.

Sistema de admisión: por matriculación y pago por curso a tomar.

Generalidades: promovido por el Centro Nacional de Información y Comunicación Educativa del Ministerio de Educación, Cultura y Deporte en colaboración con un amplio número de instituciones, ministerios, comunidades autónomas, centros educativos, ayuntamientos, que garantizan flexibilidad en el aprendizaje y atención directa y cercana al estudiante.

Dirección: wuw.mentor.mecd.es

- Nombre: MIPE-DIPE

Tipo de comunidad: de aprendizaje e investigación. 
Objetivo: potenciar el desarrollo y difusión de las líneas de investigación, posibilitar el acceso a docentes y estudiantes a información de calidad promoviendo el intercambio cientifico, el debate y la discusión. Brindar espacios de comunicación para compartir información y preocupaciones, relacionadas al trabajo de investigación, conducente a la realización de tesis doctoral.

Integrantes: alumnos y docentes del programa interuniversitario en Psicologia de la Educación.

Sistema de admisión: tiene dos niveles de privacidad, uno centrado en recursos generales (biblioteca, enlaces, foro, noticias) para todos los miembros de la comunidad; el segundo para uso exclusivo de los grupos naturales de la comunidad (coordinadores, profesores y estudiantes), asi como para aquellos que se pudieran formar en furıción de intereses comunes.

Generalidades: se ha generado la comunidad de postgrado que se utiliza como fuente de información actualizada sobre los ejes temáticos de postgrado, y la comunidad estudiantil para realizar consultas o establecer comunicación con otras universidades.

Dirección: wnw.psyed.edu.es

- Nombre: Centro Comunitario de Aprendizaje en México.

Tipo de comunidad: de práctica y aprendizaje, demográfica, restringido.

Objetivo: posibilitar el acceso a material educativo mediante computadoras conectadas a Internet, desarrollar las habilidades para el trabajo $y$, en general, para mejorar la calidad de vida de los mexicanos.

Integrantes: participantes de zonas rurales, semi-rurales y urbanas que interactuan con alumnos del Tecnológico de Monterrey quienes actúan como tutores en linea y asesoran en los cursos.

Sistema de admisión: gratuito por matriculación.

Generalidades: esta comunidad cuenta con tutores, grupos de discusión con los alumnos, actividades prácticas con la finalidad de relacionar a los alumnos con la comunidad. También, dispone de una red para donar contenidos educativos teniendo en cuenta que dentro de la comunidad pueden surgir nuevas necesidades, y otras pueden modificarse o evolucionar.

Se dictan cursos a través de la plataforma Web Tec.

Dirección: $\underline{m w w . c c a . o r g . m x}$ 
- Nombre: Eduso:

Tipo de comunidad: virtual, temática, de discurso y abierta.

Objetivo: proporcionar información pertinente sobre la educación social, y ofrecer espacios de conversación sincrónica, foros de discusión, tablones de anuncios, correo personal.

Integrantes: personas y entidades vinculadas a la educación social.

Sistema de admisión: libre, abierto y gratuito.

Generalidades: Se puede acceder a todos los servicios, clasificados en los niveles "Internacional", "Estatal" y "por Comunidades autónomas".

Dirección: wuw.eduso.net

- Mundo Latino:

Tipo de comunidad: virtual, de discurso, ocio y abierta.

Objetivo: brindar servicios de comunicación con diferentes miembros del mundo hispano.

Integrantes: interesados de habla hispana.

Sistema de admisión: por registro gratuito.

Generalidades: ofrece actividades de recreación, información sobre arte, cultura, educación, salud, espiritualidad, etc. También brinda cursos a distancia y la posibilidad de participar escribiendo artículos $u$ opiniones a través de un sistema de mensajeria.

Dirección: http://mww.mundolatino.org

\section{- Nombre: EcoPorta.net/ campus virtual}

Tipo de comunidad: virtual, temática, moderada, de discurso y restringida.

Objetivo: herramienta de consulta y espacio informativo y educativo sobre el Medio Ambiente, la Naturaleza, los Derechos Humanos y la Calidad de Vida. Integrantes: interesados de habla hispana.

Sistema de admisión: por registro con costo de inscripción.

Generalidades: ofrece un espacio de convergencia para organizaciones y personas interesadas o vinculadas a la temática. Es proveedor de contenidos de importantes medios de Comunicación, y publica semanalmente la Revista Electrónica "Ambiente y Sociedad" (http:/lays.ecoportal.net) que ha superado los 92.000 suscriptores, entre los que se encuentran más de 15.000 organizaciones no gubernamentales y muchos organismos públicos como legislaturas 
municipales y provinciales. Brinda asesorias, cursos, difusión de campañas de bien público, enlaces a sitios relacionados, etc.

Dirección: wmw.ecoportal.net

http://campus.ecoportal.net

En resumen, se han revisado algunos ejemplos de comunidades virtuales, con diferentes organizaciones y objetivos. La finalidad de esta acción ha sido analizar los tipos de comunidades y presentaciones de sus espacios en la Web, de manera tal que sirva de base para el propósito de esta tesis.

\subsection{Requerimientos para generar una comunidad virtual de aprendizaje}

Dado que a través de las comunidades virtuales de aprendizaje interaccionan varios grupos de trabajo, es pertinente considerar aquellos elementos tendientes a garantizar el buen funcionamiento.

El éxito de la comunidad virtual de aprendizaje está en afianzar los vinculos y alcanzar los objetivos propuestos, de alli la importancia de analizar los indicadores de los procesos involucrados.

Organizar una comunidad virtual de aprendizaje implica tener en cuenta todos los factores relacionados con la sociabilización en el ambiente de aprendizaje y con la construcción conjunta del conocimiento (Sánchez y Saorin, 2001), los cuales se resumen en los siguientes items:

- Construir sobre procesos en marcha.

- Definir beneficiarios y participantes.

- Participar en el diseño, ejecución y evaluación de la comunidad.

- Generar asociaciones y construir alianzas.

- Formar recursos humanos.

- Intervenir sistemáticamente como coordinadores o tutores.

- Sistematizar, evaluar y difundir la experiencia.

- Continuar y sustentar los esfuerzos.

- Establecer procesos y resultados de calidad con uso eficiente de los recursos. 
La comunidad virtual de aprendizaje no se constituye como modelo cerrado, limitado al ámbito local, sino centrada alrededor de un plan de desarrollo e interacción con otros grupos de trabajo.

Bucheli y Romo (2005) plantean como elementos y estrategias para el éxito de una comunidad de aprendizaje los siguientes puntos que se vinculan con su diseño y funcionamiento:

1. Planificación y punto de partida.

2. Vinculación y comunicación entre miembros.

3. Liderazgo y coordinación.

4. Estimulación de procesos de aprendizaje.

5. Incentivo de cultura de participación.

Que se analizan a renglón seguido:

\section{Planificación y punto de partida}

Las comunidades virtuales de aprendizaje pueden surgir por diferentes motivos e intereses, algunas a partir de una oferta de financiamiento, y otras por la demanda de las instituciones o de grupos que necesitan realizar intercambio de conocimientos, enseñanza y aprendizaje. Como primera etapa, para generar una comunidad virtual de aprendizaje, es importante analizar esos intereses tanto organizacionales como personales a fin de lograr una sintonia que facilite la disposición de tiempo y recursos, y las motivaciones necesarias para participar en el proyecto.

2. Vinculación y comunicación entre miembros:

Definidos los intereses que la motivaron, se comienza a trabajar a partir de vinculos preestablecidos conformando grupos de trabajo o reforzando los existentes, en un marco que asegure sustentabilidad a la comunidad virtual de aprendizaje.

Es importante la participación de profesionales con amplia trayectoria que puedan enriquecer el intercambio con aportes de calidad, a partir de su experticia.

Para generar sentido de pertenencia con la comunidad y motivación, se pueden personalizar las relaciones a través de actividades que las promuevan, como reuniones periódicas (que pueden ser virtuales). Este aspecto es cuidadosamente establecido cuando se diseña la CVA, y luego cuando ya está en funcionamiento. 
3. Liderazgo y coordinación

La vida de la comunidad depende de los contactos e interrelaciones entre los miembros, por ello, es crucial garantizar una interacción minima y fluida.

Es recomendable que existan facilitadores o coordinadores de las diferentes acciones que tengan a su cargo la conducción general de la comunidad, y fomenten esa interacción necesaria entre los miembros.

Pueden disponer de lideres temáticos que se destaquen por su conocimiento especializado en algún tema relevante, para apoyar al facilitador en la profundización del intercambio y/o reflexión sobre el tema en que es experto.

En algunas ocasiones, se puede contar además con un apoyo técnico que da soporte a las aplicaciones tecnológicas, producción de boletines informativos o sitios Web.

4. Estimulación de procesos de aprendizaje

Una manera de lograr la estimulación de los procesos de aprendizaje es identificando y agrupando temas o proyectos de trabajo, de manera que los grupos se conformen en base a esas propuestas. El estado de avance podria ser comunicado al resto de la comunidad para recibir aportes y retroalimentar al resto de los participantes. De alli la importancia de la documentación que se produce y distribuye para generar conocimiento y debate. La difusión de los aprendizajes influye positivamente sobre otras personas $u$ organizaciones y desarrolla capital intelectual.

5. Incentivo de cultura de participación

Promover la identidad de la comunidad virtual de aprendizaje es básico para generar a su vez apropiación de sus miembros, ya sea a través de un simbolo o un nombre. A continuación buscar mecanismos de comunicación que sean interactivos, para lograr la participación de todos y hacer respetar las diferencias y divergencias. Además, se debe tomar conciencia que las actividades que se planteen incentivarán a la cultura de la participación.

Estos cinco puntos conformarán la base metodológica para el diseño de la comunidad virtual de aprendizaje propuesta.

También se van a considerar requerimientos teóricos, tecnológicos y arquitectónicos, los que se describen en la siguiente sección. 


\subsubsection{Requerimientos Teóricos}

Llamaremos requerimientos teóricos a una serie de aspectos a tener en cuenta en forma previa a la creación de la comunidad virtual. Entre ellos, mencionamos aquellos vinculados con la Identidad de la comunidad:

- ¿Cuáles son los beneficios que recibirán los interesados/beneficiarios de la comunidad?

- ¿Cuáles son las necesidades especificas que la comunidad atenderá?

- ¿Cómo se definirá la comunidad virtual?

- ¿Cuáles son los temas principales a tratar en la comunidad?

- ¿Quiénes serán los usuarios de la CV?

- ¿Qué tipo de conocimiento será compartido en la comunidad?

- ¿Qué tareas administrarán a través de la comunidad?

Es necesario preguntarse: ¿Quiénes participarán en el diseño de la comunidad? ¿Qué capacitación previa requieren? Para aquellos vinculados con el grupo gestor de la comunidad, será fundamental el conocimiento que tengan en cuanto a recursos tecnológicos que se van a utilizar, modos de operar en la comunidad, necesidades. Por ello es importante que ese grupo sea interdisciplinario, con profesionales especializados en tecnologia informática, recursos humanos, diseño gráfico, sumados a los especialistas en los temas propios de la comunidad. En cuanto a los integrantes, que posean destrezas comunicativas, conocimientos sobre la gestión de la información que se maneja dentro de la comunidad, disponibilidad y acceso a la misma, capacidad para analizarla y procesarla.

Es substancial que aquellos que cumplan con roles de coordinación tengan capacitación y experiencia en manejo de grupos, pues de sus acciones dependerá en gran medida el éxito en el funcionamiento, y el logro de objetivos propuestos por la comunidad virtual de aprendizaje; capacidad para estimular procesos de reflexión e investigación entre los participantes, como asi también para actuar como moderador cuando haya divergencias.

Antes de convocar y organizar una comunidad, es importante participar en otras ya establecidas, a fin de adquirir experiencia y entablar relaciones con grupos y personas que puedan colaborar en el proyecto. 
También es necesario preguntarse en cuanto a sus políticas:

- ¿Cuáles son las politicas y lineamientos que regirán la operación de la comunidad virtual?

- ¿Cuáles son los roles que serán asignados a los miembros de la comunidad virtual?

- ¿Cuáles son las funciones que tendrán asignadas cada rol?

- ¿Cuáles son los procesos básicos propuestos para la comunidad virtual: actividades, servicios, experiencia, memoria?

\subsubsection{Requerimientos Arquitectónicos y Tecnológicos}

Los requerimientos arquitectónicos de las comunidades virtuales de aprendizaje tienen en cuenta la categorización y organización de la información disponible. Proporcionan el lugar donde se desarrollan las interacciones entre las personas y los materiales dentro del proceso de aprendizaje. Establecen el espacio básico del entorno y organizan el acceso a los espacios externos y a los recursos (Loughlin y Suina, 1995). Constituyen la taxonomia base que tendrá la comunidad. En este sentido, es importante lograr un ambiente propicio para que las personas puedan gestar procesos de formación disponiendo de todo el material y herramientas necesarios para lograrlo. Se debe considerar también alli aspectos de diseño como la sencillez, atractivo y facilidad de navegación. Las páginas bien estructuradas para la rápida localización del servicio deseado y los recursos abiertos, es decir que se pueda acceder desde cualquier lugar sin dificultad.

Los requerimientos tecnológicos se definen en función de los procesos establecidos, son los necesarios para soportar dichos procesos. Una opción recomendada es realizar una matriz de los mismos donde se vinculen procesos y herramientas tecnológicas

Resulta fundamental que el usuario pueda interactuar con otros de manera asincrónica y/o sincrónica, realizar trabajos en equipo, configurar su ambiente de aprendizaje, contar con mecanismos para la producción de cursos, y para la generación de modelos de cursos genéricos. Que disponga de herramientas existentes para la preparación de hipertextos, multimedia, y que le permita analizar la información que genera la interacción de los participantes contando con recursos para administrar el material, tipos de usuarios y privilegios. También es importante que 
existan mecanismos de retroalimentación, para comentar sobre el material mismo y calificarlo. Ese material estará disponible en cualquier momento y será independiente de la plataforma utilizada.

Con el fin de seleccionar los recursos tecnológicos que mejor se adecuen a la comunidad, es necesario conocer el público en cuanto a edades, idiomas, paises, asi como tener en cuenta los objetivos y temas a abordar.

Un equipo técnico interdisciplinario puede ayudar en el diseño y creación del ambiente virtual, y servir como soporte para realizar modificaciones, o capacitar a los usuarios en el uso de las herramientas virtuales. Dar apoyo a cursos de distintas áreas, los cuales requieran diferentes metodologías de trabajo.

A continuación se mencionan algunos recursos que pueden estar disponibles para ser utilizados en una comunidad virtual de aprendizaje:

- Servicio de documentación: enlaces a Web relacionadas con el tema, a documentos electrónicos internos y externos, acceso a los mensajes de la lista archivados, revista o publicación electrónica, búsqueda avanzada para artículos dentro de la comunidad o en Internet, directorio de todos los miembros de la comunidad y enlaces a páginas personales.

- Servicio de comunicación e intercambio: chat que permite realizar reuniones en tiempo real, correo electrónico, foro de discusión, lista de distribución a través de la cual los miembros se comunican e intercambian información, y tablón de anuncios. Videoconferencia que se utiliza como herramienta de comunicación sincrónica permitiendo utilizar técnicas interactivas para debate con imágenes y sonido, haciendo posible el proceso de comunicación sin necesidad de desplazamiento. Se pueden intercambiar datos, documentos, información gráfica, videos o diapositivas, entre otros.

- Zona de trabajo colaborativo que no requiere la instalación de ningún software ni herramienta adicional, admite intercambiar documentos de cualquier tipo, y los usuarios pueden hacer revisiones y trabajar sobre ellos en forma conjunta.

- Multimedia para diseño asistido, simulación de experimentos científicos, y grandes bases de datos de investigación que contienen recursos multimedia como gráficos, video y audio comprimidos. Existen software como sistemas de información geográfica, paquetes de matemática y estadística, idiomas. También se puede utilizar la multimedia para desarrollar herramientas de resolución de problemas y toma de decisiones, basadas en la propia experiencia. 
Estos elementos se tendrán en cuenta en el capitulo referido al diseño de la comunidad virtual de aprendizaje.

\subsection{Monitoreo y Evaluación de una Comunidad Virtual de Aprendizaje}

En esta sección se hará una revisión sobre posibles formas de realizar el seguimiento y la evaluación de una CVA, de manera tal de tener este marco teórico a la hora de realizar la propuesta de trabajo.

La evaluación es concebida como una comprobación de los objetivos de la comunidad, donde la principal exigencia es instrumentar la comparación de los resultados del aprendizaje con objetivos planificados (Tyler, 1973).

El objetivo fundamental de la evaluación es el perfeccionamiento del proceso (Stufflebeam y Shinkfield, 1987).

Teniendo en cuenta la perspectiva de la construcción del conocimiento como parte de las comunidades virtuales, la evaluación es inherente a un proceso generador de cambio que puede ser utilizado y dirigido a promover el aprendizaje, tendiente a la formación profesional (Quaas, 2000).

Se puede monitorear y evaluar una comunidad virtual de aprendizaje, viendo el progreso de la misma a través de tres niveles (Bucheli y Romo, 2005) que son:

- Esfuerzo e implementación de actividades.

- Evaluación.

- Medición del impacto.

El primero, relacionado con el esfuerzo y la implementación de las actividades, posee los siguientes indicadores:

- Número de participantes.

- Variación de niveles de participación.

- Flujo de intercambio de información entre participantes.

- Número de documentos generados con nuevos conocimientos.

- Nivel de cumplimiento de las responsabilidades asumidas. 
El segundo nivel se enfoca en los resultados obtenidos a partir de las actividades realizadas, los efectos en los miembros del uso de los productos derivados de la acción de la comunidad, y qué beneficios les trae. Este nivel corresponde a la evaluación y algunos indicadores son:

- Satisfacción y apropiación de los integrantes de la comunidad.

- Desarrollo de capacidades y mejora en la práctica.

- Generación de conocimientos lograda.

En el tercer nivel se identifica el cambio en la situación original sobre la cual se queria influenciar, se refiere a la medición del impacto. Los indicadores son:

- Cumplimiento de los objetivos institucionales/comunitarios.

- Institucionalización de mejores prácticas.

- Fortalecimiento institucional/comunitario.

- Profesionalización de los recursos humanos.

Esos indicadores se pueden evaluar a través de instrumentos tales como consultas a los integrantes, encuestas al finalizar alguna de las actividades como cursos de capacitación, desarrollos tecnológicos, producción de documentos, informes técnicos, prestación de servicios; asignando espacios para comentarios y sugerencias, entre otros.

Obtenidos los resultados se analizan con el objetivo de establecer mejoras. Se sugiere consultar con especialistas, realizar modificaciones en la organización, fortalecer sectores de la comunidad, atender a las sugerencias. En definitiva, apuntar a la mejora continua de la comunidad virtual de aprendizaje, a la calidad de los resultados obtenidos, excelencia en los trabajos, ajuste de objetivos, satisfacción de miembros o participantes, y transparencia en los procesos.

\subsection{Resumen}

En el presente capitulo se analizan las condiciones minimas necesarias para que una comunidad virtual de aprendizaje sea sostenible y perdurable. Seguidamente se realiza una diferenciación entre entorno virtual de enseñanza y aprendizaje, respecto a 
comunidad, poniendo especial énfasis en los roles de cada una de ellas, las responsabilidades, el tipo de participación, la orientación y los esquemas jerárquicos. Finalmente y siguiendo varios autores, se hace una clasificación de las comunidades y se señala dentro de ellas, el tipo de comunidad objeto de esta tesis. En base a esa clasificación se presentan ejemplos según el tipo de comunidad, objetivos, integrantes, y sistema de admisión. Se describen además algunos aspectos generales de cada caso analizado. La finalidad es disponer de una base de conocimiento sobre comunidades virtuales de aprendizaje que estén funcionando, y puedan servir como ejemplo y fuente de información, necesaria para la realización de la comunidad que se propone.

Luego, se plantean los puntos metodológicos básicos de diseño y funcionamiento que aseguren la continuidad en el tiempo, tales como planificación, vincuiación entre miembros, coordinación, estimulación del aprendizaje e incentivo en la participación.

Seguidamente, se analizan los requerimientos teóricos para conformar una comunidad virtual de aprendizaje. Otros de los requerimientos que se consideran son los tecnológicos y arquitectónicos en cuanto al diseño y uso de plataformas, a fin de dar soporte a los procesos y servicios planificados.

Un aspecto a tener en cuenta a la hora de conformar una comunidad virtual de aprendizaje es el monitoreo y la evaluación que indican el progreso. En ese sentido se presentan algunos indicadores a considerar en la realización de la evaluación.

En conclusión se dispone de herramientas necesarias para trabajar en el diseño y configuración de la comunidad virtual de aprendizaje que se propone en el marco de esta tesis. 
Capítulo 3

Propuesta metodológica para el diseño de una comunidad virtual de aprendizaje referida a temas nucleares 
De lo analizado hasta aqui, se desprende la importancia de generar espacios para compartir experiencias y conocimiento sobre todo en ámbitos educativos, como modo de mejorar los procesos de aprendizaje y el desarrollo de capacidades. Según se ha investigado en párrafos anteriores, la globalización ha contribuido a la expansión del uso de tecnologias de la información y la comunicación en áreas de educación, lo que facilita la construcción de espacios que utilicen esas tecnologias, como son las comunidades virtuales de aprendizaje, acompañadas de procesos de cooperación y colaboración para la construcción del conocimiento. Se trata de proponer nuevas formas de trabajo, que no se reduzcan a una búsqueda de información, sino a una gestión del conocimiento. En ese sentido, se plantea el desarrollo de una CVA que funcione en un ámbito académico, universitario, donde ya se cuenta con recursos tecnológicos para afrontar el desafio, se tiene experiencia de trabajo dentro de comunidades virtuales de enseñanza y aprendizaje, y se dispone de grupos de profesionales interesados en interactuar a través de dicho espacio.

En este capitulo se presentan las decisiones para delinear una comunidad virtual de aprendizaje, en base a lo desarrollado en el capitulo 2 de esta tesis, que da marco a una propuesta metodológica de diseño. Se consideran los siguientes puntos para diseñar la CVA:

1. Planificación y punto de partida

2. Vinculación y comunicación entre miembros

3. Liderazgo y coordinación

4. Estimulación de procesos de aprendizaje

5. Incentivo de cultura de participación

En el marco de cada uno de estos apartados, se abordarán algunos de los requerimientos teóricos, tecnológicos y arquitectónicos que se han detectado como punto de partida para el diseño de la comunidad. Estos aspectos se completarán en el siguiente capitulo.

Primeramente, como parte de la planificación se analiza al grupo gestor en cuanto a intereses y motivaciones. Luego se presenta una propuesta para conformar los grupos de trabajo o reforzar los existentes a través de las vinculaciones y comunicaciones entre los miembros. Seguidamente se hace un planteo referido a la coordinación de la CVA, en base a la experiencia adquirida y a los recursos tecnológicos disponibles. Como otra de las etapas de diseño, se tiene en cuenta la forma de estimular los 
procesos de aprendizaje. Finalmente, se analiza la importancia de contar con un sitio que le dé identidad a la CVA, y que disponga de los medios necesarios para aprender a utilizar las herramientas informáticas facilitando asi la participación del grupo de trabajo.

En las siguientes secciones se responderán algunas de las preguntas planteadas en la sección de requerimientos teóricos, abordada en el capitulo anterior.

\subsection{Intereses y motivaciones}

La idea de generar una comunidad virtual de aprendizaje referida a temas nucleares surge a partir de la experiencia de algunos años de trabajo en la organización y dictado de cursos, desde el ámbito del Reactor Nuclear RA-0 (RA-0) de la Facultad de Ciencias Exactas, Fisicas y Naturales (FCEF y $N$ ) de la Universidad Nacional de Córdoba (UNC), observando las potencialidades de los espacios virtuales, y la conveniencia de contar con uno propio para temas especificos de nuestra área de incumbencia.

El Reactor Nuclear RA-O es una instalación donde se realiza una reacción nuclear controlada, dentro de un dispositivo adecuado. A su vez se denomina con ese nombre al grupo de trabajo responsable de la operación del reactor. Ese plantel de operación pertenece al departamento Reactor Nuclear RA-0 de la FCEF y N, y lleva adelante actividades de capacitación, desarrollos tecnológicos, investigación y entrenamiento en reactores nucleares. Un gran número de profesionales interactúan en el grupo de trabajo, participando en los distintos sectores, ya sea personalmente o a través de herramientas virtuales de comunicación y trabajo como son el chat, mail y plataforma educativa moodle, para el desarrollo de acciones de capacitación. Organizar a esos grupos dentro de una comunidad virtual de aprendizaje. facilitaria los procesos de comunicación y aprendizaje en temas comunes, y potenciaría los resultados alcanzados en desarrollo e investigación.

El grupo del Reactor Nuclear RA-0 está conformado por seis integrantes de diferentes profesiones (Ingenierias y Química), a los que se le suman algunos invitados externos (de las áreas de Física y Biologia) que trabajan habitualmente con la FCEF y N. Estas personas están interesadas en participar conjuntamente en la generación de actividades que promuevan el aprendizaje.

Entre las actividades que se realizan desde el Reactor Nuclear RA-0, está el dictado de cursos, seminarios y ciclos de conferencias, destinados a profesionales del área de la salud, ciencias exactas, biología, quimica, investigación, centrales nucleares, 
instalaciones nucleares y servicios de medicina nuclear. También los dirigidos a docentes de nivel medio y superior; alumnos universitarios y de nivel intermedio; fuerza de intervención y seguridad, como para público en general.

Uno de los objetivos del Reactor Nuclear RA-0 es capacitar, entrenar y difundir los usos pacificos de la energia nuclear a través de la realización de prácticas de laboratorio, simulacros, mesas redondas, talleres.

Actualmente, se realiza capacitación en distintas modalidades, presenciales en las que los alumnos se dirigen a las aulas de la UNC para recibir clases teóricas, prácticas y de laboratorio y modalidad a distancia a través del espacio virtual de enseñanza y aprendizaje Moodle. Esta última forma de trabajo permite llegar a grupos con dificultades para asistir a clases presenciales, ya sea por la distancia o por la falta de disponibilidad de horarios, como así también innovar en recursos tecnológicos y educativos que contribuyen a mejorar el proceso de aprendizaje a través de imágenes, videos, y otros recursos posibles debido a las TICs.

Conformar, la comunidad virtual de aprendizaje referida a temas nucleares, implica generar un espacio para facilitar la interacción entre pares académicos, utilizando el mismo lenguaje y lugar de encuentro, y teniendo un punto de referencia para acceder a materiales de estudio, recursos educativos o a proyectos en marcha a los que puedan sumarse, para realizar sus aportes en pos de la construcción compartida del conocimiento. Ofrecer una identidad, un espacio compartido, un lugar de retroalimentación, es parte del objetivo.

\subsubsection{Destinatarios}

Como parte del diseño que se propone aquí, se detallan los destinatarios de la CVA que actualmente pertenecen a los grupos de capacitación descriptos, y a los que se le suman los de investigación y desarrollo tecnológico, algunos de los cuales se vinculan actualmente sólo en la presencialidad, perdiendo por lo tanto posibilidades de interacción con grupos distantes.

La finalidad de reunir a esos profesionales en torno a una comunidad virtual de aprendizaje, es disponer de un adecuado flujo de información, y una red de intercambio de experiencias y conocimientos, de manera de lograr aprendizajes entre los distintos miembros. Alcanzar ese objetivo depende de la accesibilidad, cultura de participación, colaboración, diversidad y disponibilidad a compartir, que condicionan la calidad de vida de la comunidad, las destrezas comunicativas entre los miembros, y 
del contenido relevante (Pazos, Pérez Garcia y Salinas, 2001); lo que representa un desafio.

\subsubsection{Indagación al grupo de trabajo que conformará la comunidad virtual de aprendizaje}

Como se menciona en el marco teórico, capitulo 2.1, los integrantes de una CVA mantienen motivaciones para formarla y alimentarla, como son intereses y objetivos comunes, el deseo de compartir una experiencia o establecer relaciones sociales.

En ese sentido, para conformar una comunidad virtual de aprendizaje es necesario indagar la motivación de los integrantes, los conocimientos que poseen sobre el significado de comunidad virtual de aprendizaje, la necesidad de disponer de ese espacio, sus expectativas, beneficios potenciales que perciben, como asi también las actividades que consideran prioritarias para desarrollar alli. Esa fuente de información aporta indicadores sobre la motivación y el interés para generar la comunidad virtual de aprendizaje. Dado que una CVA gira en torno a los trabajos colaborativos y al intercambio de experiencias y conocimientos, es importante conocer al grupo encargado de plasmar esos objetivos.

Por ello la importancia de saber si se cuenta con personas interesadas en realizar esas interacciones cooperativa y colaborativamente como parte de una comunidad virtual de aprendizaje, o analizar la manera de despertar ese interés.

Actualmente los grupos que trabajan en torno a temas nucleares vinculados con el Reactor Nuclear RA-0 a nivel nacional son los siguientes:

- Facultad de Ciencias Médicas: aplicaciones en medicina nuclear.

- Facultad de Ciencias Químicas: investigación y aplicaciones bioquímicas.

- Facultad de Matemática, Astronomía y Física: investigación y desarrollos.

- Comisión Nacional de Energía Atómica (CNEA): investigación, aplicaciones y desarrollos.

- Autoridad Regulatoria Nuclear: control y gestión.

- Organismo Internacional de Energía Atómica: capacitación, convenios regionales.

- Ministerio de Ciencia y Tecnologia: divulgación y desarrollos.

- Rectorado de la UNC: seguridad radiológica y nuclear.

- Ministerio de Educación de la Provincia de Córdoba: capacitación y difusión.

- Nucleoeléctrica Argentina S.A., Central Nuclear Embalse: servicios y capacitación. 
- Dioxitek S.A. (Empresa Argentina para la Producción de Dióxido de Uranio y Fuentes Selladas de Co-60) capacitación.

- Fuesmen (Fundación Escuela de Medicina Nuclear, Mendoza): capacitación y entrenamiento.

Son pocas las actividades que se desarrollan desde comunidades virtuales de aprendizaje con los grupos mencionados, y están en su mayoria orientadas a la capacitación. Hay varios proyectos de trabajo y desarrollo tecnológico cuyos resultados se verian potenciados trabajando a través de una comunidad virtual de aprendizaje en temas nucleares. Como ejemplo se mencionan los siguientes:

- Análisis e implementación de nueva instrumentación para reactores nucleares de investigación.

- Diseño de monitores de área en trabajo conjunto con profesionales de otras instalaciones.

- Irradiación de muestras para proyectos de investigación desarrollados en otros sectores de la CNEA (Bariloche, Buenos Aires).

- Evaluación del impacto ambiental de la generación de energía, desde diversos sectores (energias alternativas, energia hidroeléctrica, energia nuclear)

- Diseño y construcción de un módulo sobre energia, para un museo interactivo en conjunto con la Facultad de Matemática, Astronomia y Fisica.

Para evaluar la motivación e intereses del grupo destinatario se realiza un trabajo de análisis con algunos de los involucrados. A continuación se detalla la metodologia e instrumentos utilizados, y los resultados obtenidos. 


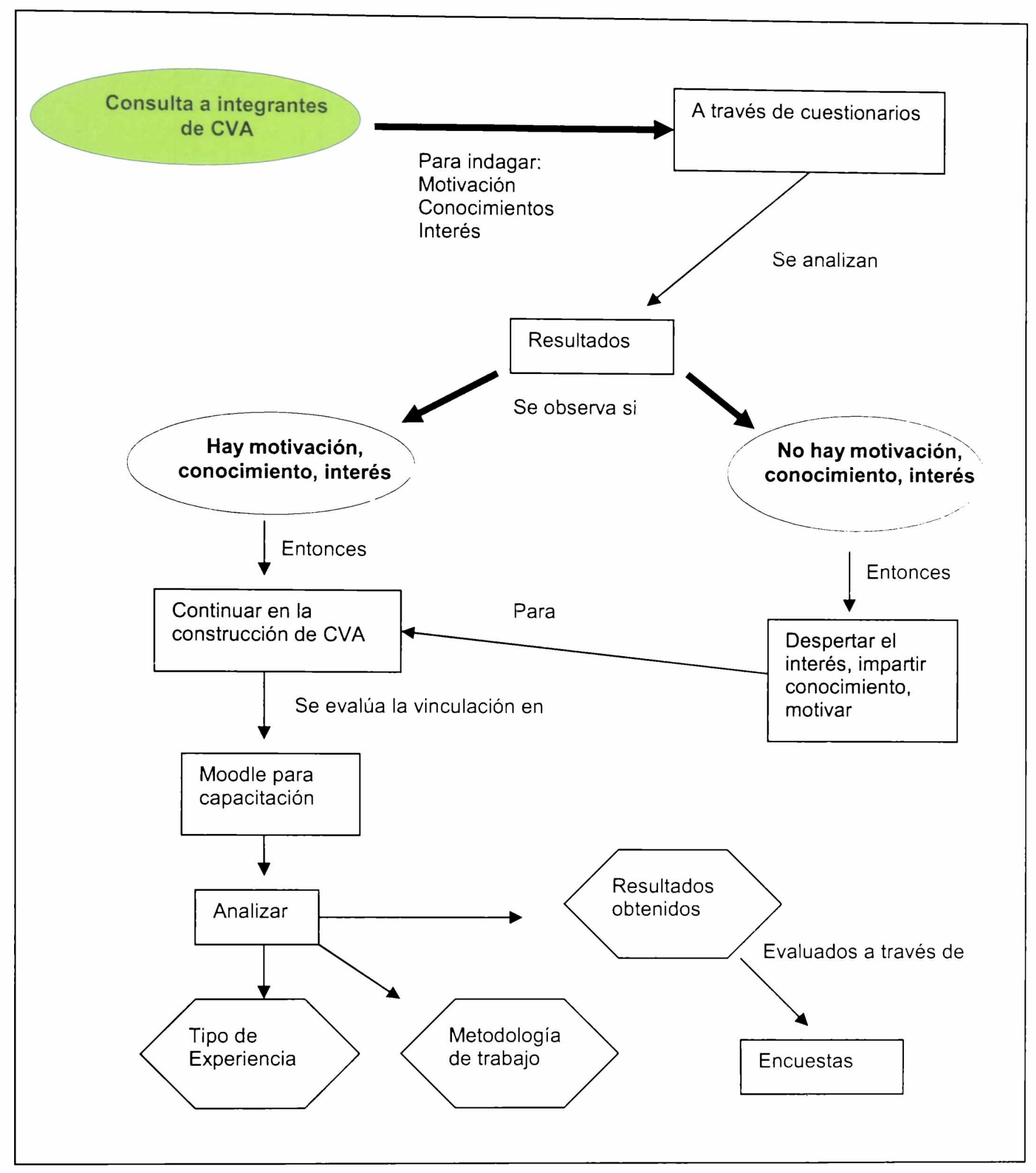

Figura 2. Esquema sobre la metodología de la consulta

- Primeramente se realiza una consulta a quienes serán inicialmente integrantes de la CVA, a fin de indagar sobre las motivaciones, intereses y conocimientos respecto a una CVA, tal como se menciona en párrafos anteriores. La consulta consiste en un cuestionario con seis preguntas generales.

- Seguidamente se evalúan los resultados recogidos de cada pregunta y se vuelcan en un diagrama donde se aprecia el porcentaje de cada respuesta. 
- Con lo analizado se extraen las conclusiones enfocadas a percibir la disponibilidad de un grupo con motivaciones e intereses para comenzar a trabajar en la CVA.

\subsubsection{Destinatarios de la encuesta}

De todos los grupos que desarrollan actividades con el Reactor Nuclear RA-0, se seleccionan algunas personas, con las que se estuvo trabajando en el último año en el dictado de cursos, y en trabajos de investigación a través de entornos virtuales de enseñanza y aprendizaje, o de grupos Google. También se incluyen integrantes del grupo del Reactor Nuclear RA-0, desde donde surge la propuesta de generar la comunidad virtual de aprendizaje.

\subsubsection{Metodologia}

Se entrega un cuestionario con preguntas abiertas para indagar sobre los siguientes puntos:

- Conocimiento sobre CVA.

- Necesidad de disponer de ese espacio.

- Beneficios.

- Posibles participantes.

- Sectores involucrados.

- Recursos tecnológicos.

En la pregunta dos del cuestionario hay un hipervínculo donde se desarrolla el concepto de CVA para avanzar con el cuestionario. La defirición se encuentra a continuación de las preguntas.

Las respuestas se reciben por mail, entregadas personalmente, y en algunos casos, se realizan mesas de debate sobre CVA, a través de la metodología "Focus Group". Esta última, es una de las formas de estudio cualitativo en el que se reúne a un grupo de personas, para indagar acerca de actitudes y reacciones frente a un producto, servicio, concepto, etc. Son mini sesiones, conformadas con un máximo de cinco miembros, y se hacen preguntas con opciones múltiples y algunas abiertas.

\footnotetext{
${ }^{2}$ Focus Group: témmino en inglés que significa sesiones de grupo. Método de exploración que permite a los participantes expresar sus opiniones. (Zeller y Carmines, 1980).
} 


\subsubsection{Cuestionario}

Las preguntas que se formulan son las siguientes (Ver Anexo A):

1. ¿Qué es una Comunidad Virtual de Aprendizaje?

2. A partir del concepto de CVA que encuentra al hacer clic AQUI (Ver Anexo A) ¿Considera necesario disponer de una CVA en temas nucleares? ¿Por qué?

3. ¿Piensa que podrá mejorar su trabajo disponiendo de esa CVA?

4. ¿Con quién le gustaría interactuar a través de la CVA?

5. ¿Disponemos de la tecnologia necesaria para conformar la CVA?

6. ¿Tiene alguna sugerencia para conformar la CVA?

\subsubsection{Resultados de la consulta}

De un total de 11 consultados, que son los profesionales que integran el grupo Reactor Nuclear, y algunos colaboradores, (ver punto 3.1.2) las respuestas presentadas son las siguientes:

\section{Pregunta 1:}

¿Qué es una Comunidad Virtual de Aprendizaje?

Seis de los consultados arriesga una respuesta intuitiva y algunos afirman tener un conocimiento aproximado, esto es, que mencionan algunos elementos propios de una CVA tales como colaboración, interés común, tema especifico, vinculación, entomo educativo, sitio para compartir experiencias. Se tiende a desglosar el término y dar significados por separado.

\begin{tabular}{|l|c|}
\hline Respuestas & Resultados \\
\hline No sabe & 3 \\
\hline Arriesga una respuesta & 6 \\
\hline Conoce & 2 \\
\hline
\end{tabular}

Tabla 1. Número de encuestados que sabe lo que es una CVA 


\section{¿Qué es una CVA?}

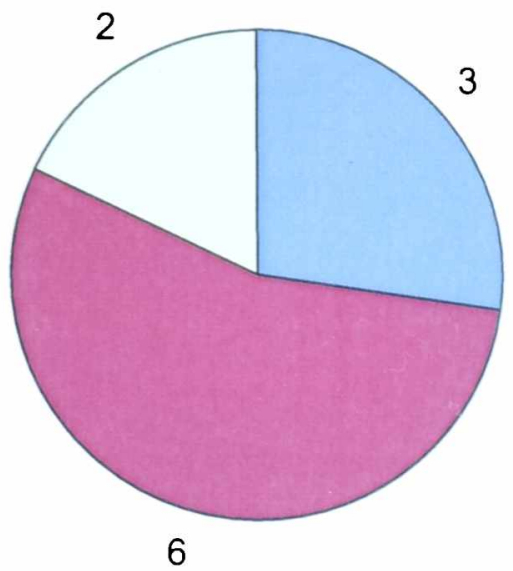

Figura 3. Diagrama que ilustra los valores de la Tabla 1

\section{Pregunta 2:}

A partir del concepto de CVA que encuentra al hacer clic AQUI, ¿Considera necesario disponer de una CVA en temas Nucleares? ¿Por qué?

Respecto a la necesidad de disponer de una CVA las respuestas se vinculan a la primera, es decir, los que tienen una idea aproximada muestran mayor interés en disponer de este espacio. En otros casos, luego de leer el concepto en el anexo, comienzan a interiorizarse y hacer sugerencias para conformar una CVA.

\begin{tabular}{|l|c|}
\hline Respuestas & Resultados \\
\hline $\mathrm{Si}$ & 11 \\
\hline No & 0 \\
\hline Otra & 0 \\
\hline
\end{tabular}

Tabla 2. Número referido a la necesidad de contar con una CVA 


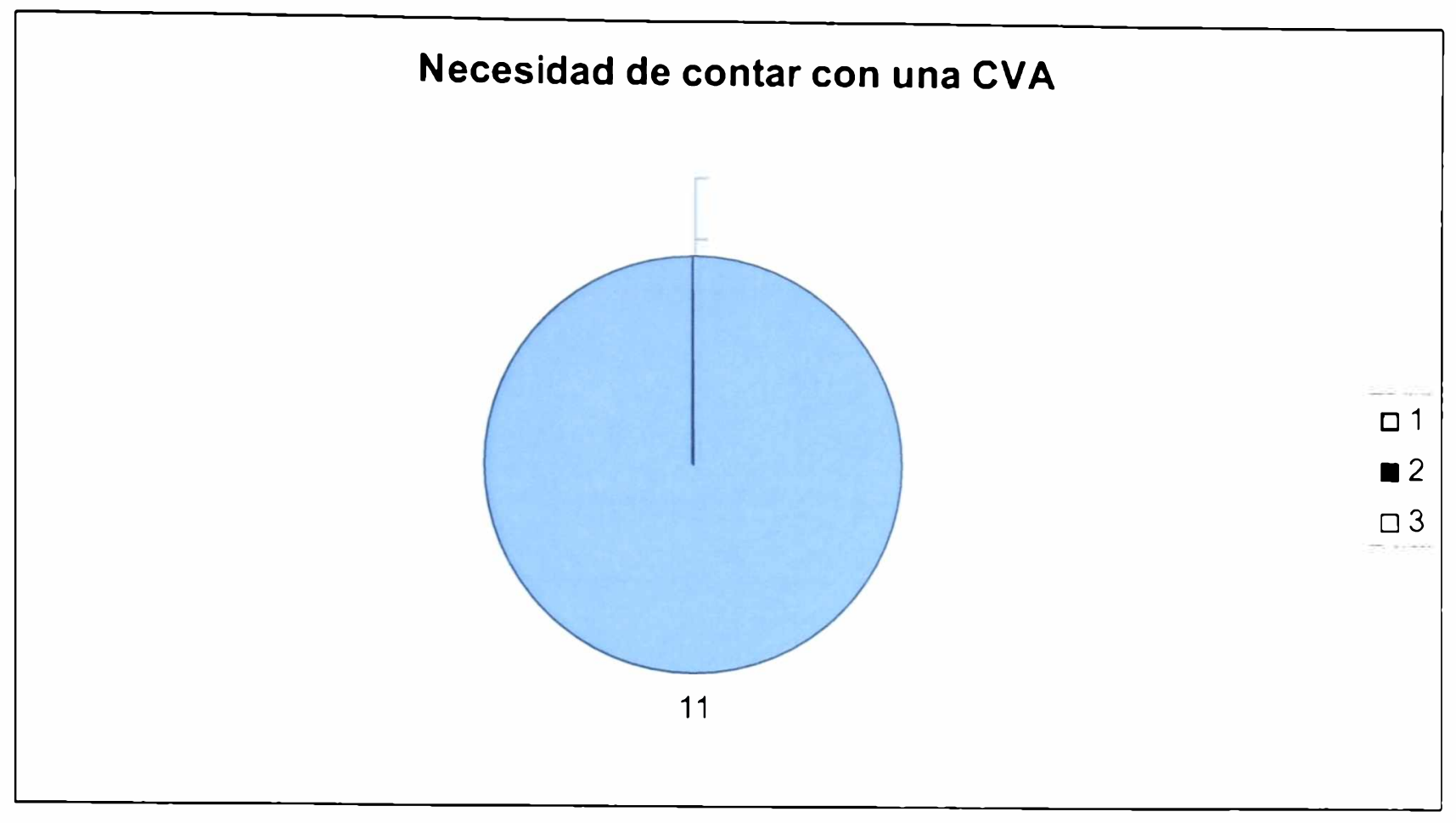

Figura 4. Gráfico que ilustra el resultado de la Tabla 2

En cuanto al "¿Por qué?" de la pregunta, las respuestas dadas se presentan a continuación:

Se puede colaborar a través de ese espacio.

Permite profundizar temas y compartir conocimientos y experiencias.

Facilita flexibilidad de horarios para trabajar con los integrantes.

Promueve adquirir conocimientos y divulgar temas vinculados.

Se obtiene rápida información, a costos bajos, con llegada a todos los sectores sociales.

Propicia y promueve el aprendizaje y facilita la comunicación.

Esto refleja la presencia de algunos elementos correspondientes a las CVA, en quienes consideran conveniente disponer de la misma.

\section{Pregunta 3:}

¿Piensa que podrá mejorar su trabajo disponiendo de esa CVA?

Del total de encuestados, ocho consideran que si puede mejorar su trabajo disponiendo de la CVA. Otros tres vinculan el mejoramiento a determinadas circunstancias referidas a los participantes y a las prioridades de la CVA. Es decir, asocian las ventajas a la posibilidad de establecer contactos con profesionales de destacada trayectoria académico-científica, y a las actividades que se organicen 
desde la comunidad, como congresos, grupos de trabajo, cursos. Las respuestas se clasifican en "Si", "No" y "Otra". En esta última opción, algunos encuestados, responden en función de su trabajo actual y no sobre los posibles proyectos a desarrollar a través de la CVA. En otros casos expresan: Mi trabajo no seria afectado por esos temas, suponiendo que trabajará con algún tema especifico que no lo involucrará.

\begin{tabular}{|l|c|}
\hline Respuestas & Resultados \\
\hline $\mathrm{Si}$ & 8 \\
\hline No & 0 \\
\hline Otra & 3 \\
\hline
\end{tabular}

Tabla 3. Número de encuestados que estima que mejorará su trabajo con una CVA

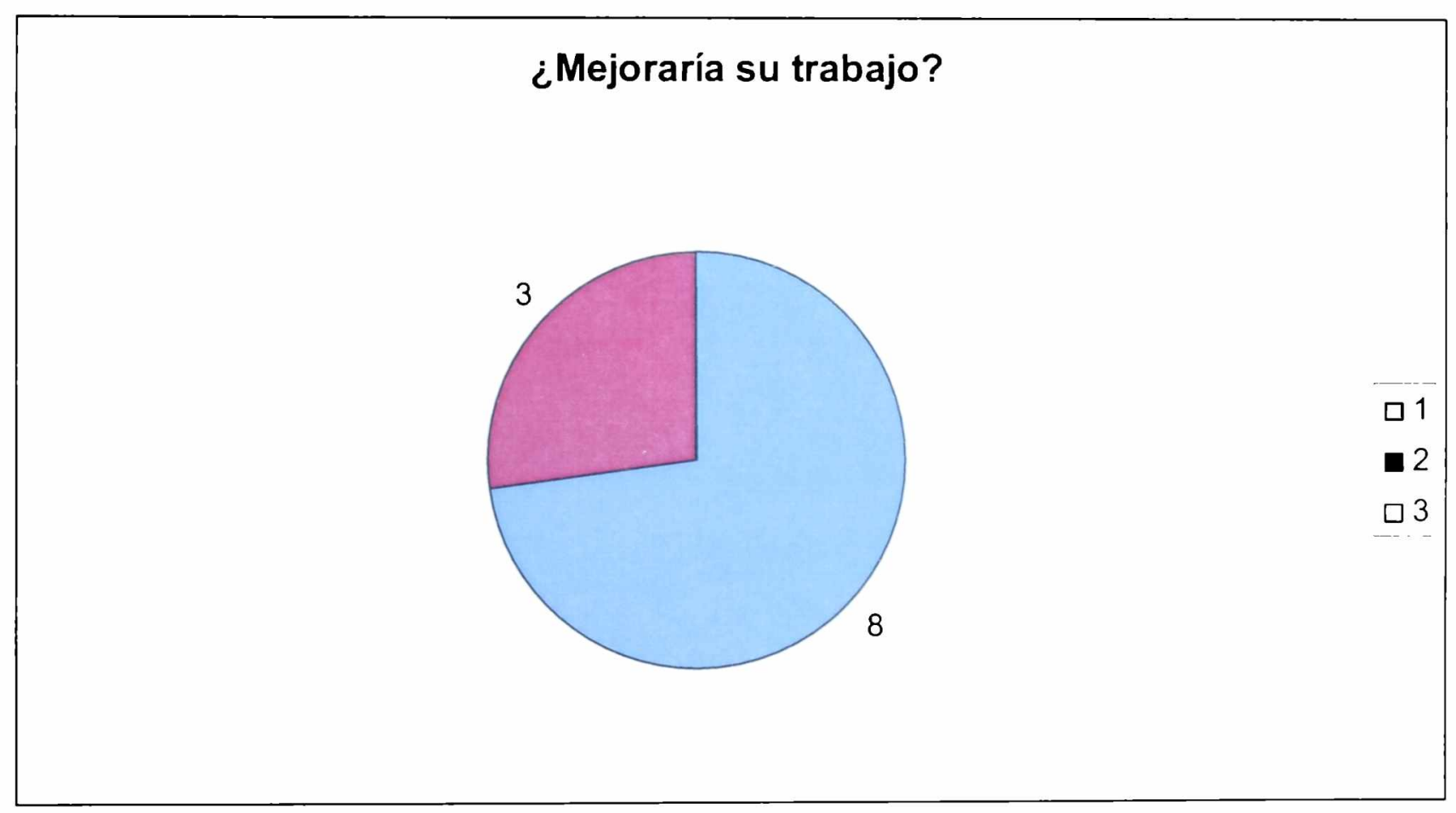

Figura 5. Gráfico que ilustra el resultado de la Tabla 3

\section{Pregunta 4:}

¿Con quién le gustaria interactuar a través de la CVA? 
Cinco de los consultados coinciden en la necesidad de contar con especialistas y expertos. Otros cinco buscan afinidad en los temas o en las tareas que desarrollan. Hay quienes mencionan como conveniente iniciar grupos de trabajo con profesionales de otras latitudes que se desempeñen en tareas similares, están los que consideran fundamental invitar a profesionales con títulos de postgrado a fin de elevar el nivel académico de los participantes de la CVA. En "otra" se incluyen respuestas tales como: no responde, gente que no sepa nada y quiera aprender.

\begin{tabular}{|l|c|}
\hline Respuestas & Resultados \\
\hline $\begin{array}{l}\text { Temas afines a los } \\
\text { propios }\end{array}$ & 5 \\
\hline Especialistas & 5 \\
\hline Otra & 1 \\
\hline
\end{tabular}

Tabla 4. Número de preferencias para trabajar dentro de la CVA

\section{Personas con quienes quisiera interactuar}

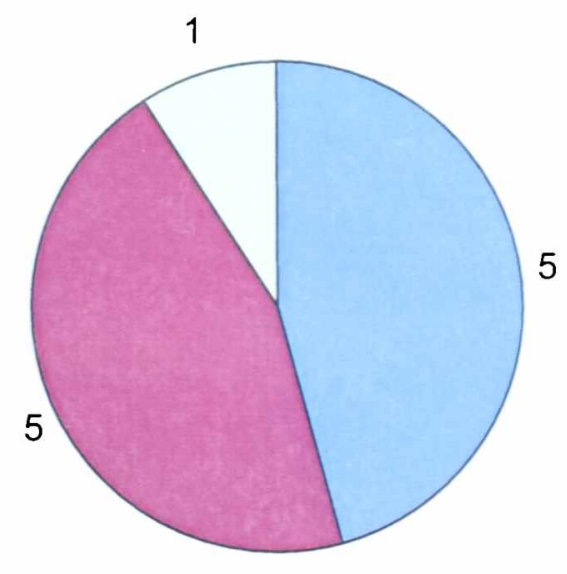

Figura 6. Gráfico que ilustra el resultado de la Tabla 4

\section{Pregunta 5:}

¿Disponemos de la tecnologia necesaria para conformar la CVA? 
En este punto cuatro de los encuestados responden afirmativamente y consideran que puede llevarse adelante con pocos recursos, pero en muchos casos se observa la necesidad de capacitación para el uso de la misma. En general, todos tienen conocimiento acerca de los grupos interdisciplinarios de la UNC, que pueden prestar colaboración para conformar espacios virtuales.

En "otra" las respuestas fueron:

Para otras actividades que no se desarrollen en aulas virtuales, necesitamos herramientas especificas.

Desconozco.

Falta mejorar la red interna y externa para garantizar un buen funcionamiento

\begin{tabular}{|l|c|}
\hline Respuestas & Resultados \\
\hline Si & 4 \\
\hline No & 1 \\
\hline Otra & 6 \\
\hline
\end{tabular}

Tabla 5. Número que considera se dispone de tecnologia para generar una CVA

\section{Disponibilidad de tencnología}

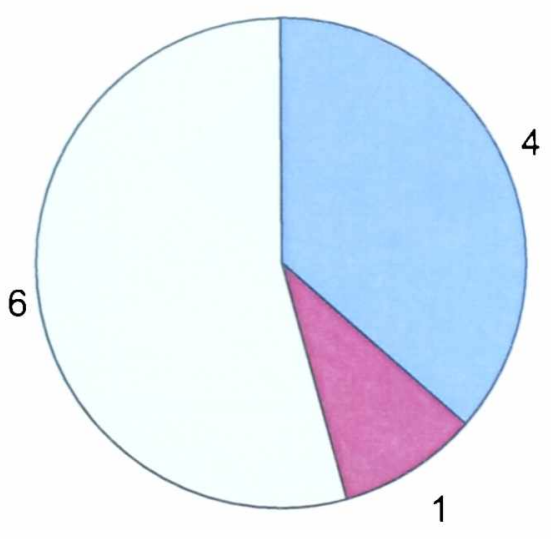

Figura 7. Gráfico que ilustra los resultados de la Tabla 5

\section{Pregunta 6:}

¿Tiene alguna sugerencia para conformar la CVA? 
De los consultados 5 aportan sugerencias, las cuales son pertinentes y significativas. Por ejemplo: generar una base de datos de posibles interesados, presentar los programas en marcha, disponer de un instructivo de acceso a la CVA, fijar metas y evaluar resultados periódicamente, flexibilizar los horarios para la capacitación. contemplar formación académica en temas de actualidad.

\begin{tabular}{|l|c|}
\hline Respuestas & Resultados \\
\hline No & 6 \\
\hline Una & 1 \\
\hline Varias & 4 \\
\hline
\end{tabular}

Tabla 6. Número de sugerencias aportadas para generar una CVA

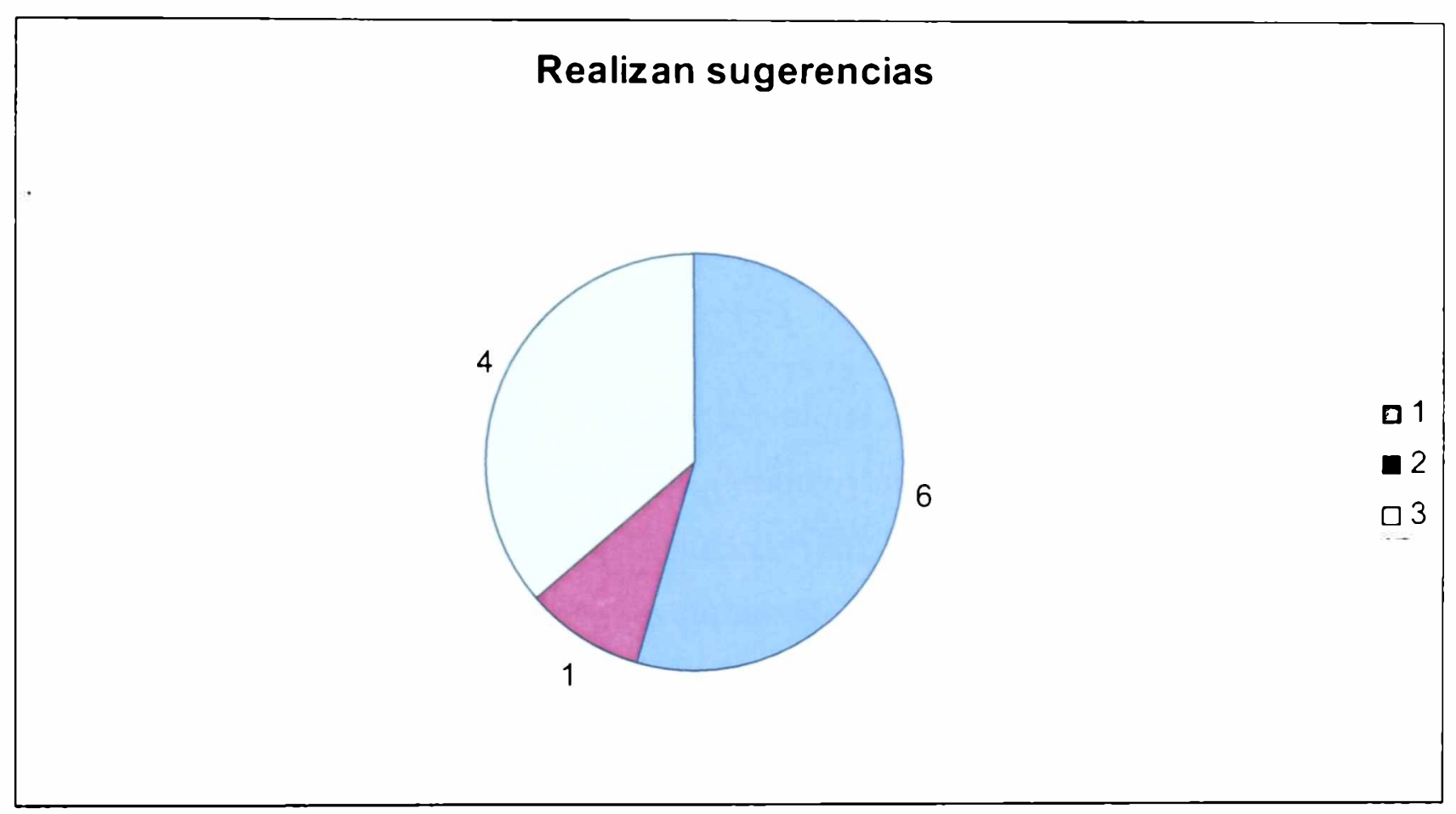

Figura 8. Gráfico que ilustra los resultados de la Tabla 6

\subsubsection{Conclusión}

Dentro del grupo consultado, están los que no tienen en claro el concepto de comunidad virtual de aprendizaje, y por lo tanto las ventajas de disponer de ese espacio. No obstante, todos muestran interés por participar y colaborar en la 
generación de una CVA, y realizan sugerencias en cuanto a la organización y regulación de la misma.

El número de personas consultadas es pequeño dado que se trata de involucrar a los posibles gestores de la CVA (responsables de la organización y administración), quienes son los encargados de generar la difusión y la inclusión de nuevos participantes y grupos de trabajo.

\subsection{Vinculación y comunicación entre miembros}

Evaluada la motivación y el interés para trabajar en una CVA, se continúa en esta sección con un análisis de la experiencia adquirida en comunicación y vinculación. Esto sirve como base para propiciar la participación y el aprendizaje dentro de la comunidad propuesta.

En ese sentido, la vinculación entre los miembros enriquece a la comunidad con sus aportes y la posibilidad de contar con diferentes invitados expertos. Por otra parte, para generar sentido de pertenencia se pueden mantener relaciones personalizadas, y reconocimiento a las personas que participan contribuyendo en la realización de tareas.

\subsubsection{Descripción}

La Facultad de Ciencias Exactas, Fisicas y Naturales de la UNC, dispone de un entorno virtual de enseñanza y aprendizaje (Moodle) que se ha utilizado en el marco de capacitación vinculada al Reactor Nuclear RA 0, y un grupo Google para investigación. Se considera aqui esa experiencia para los puntos referidos a las comunicaciones y vinculaciones. Se toman como experiencias previas, trabajos en foros, wiki, chat. Con ese punto de partida se podrá proyectar la propuesta en un sentido amplio y abarcativo de otros aspectos como desarrollos tecnológicos, proyectos conjuntos, y lo que signifique intercambio de experiencias y conocimientos en un ambiente de trabajo colaborativo y cooperativo, con grupos que se desempeñen en actividades afines dentro de la temática propuesta. La experiencia adquirida es válida en cuanto a la estructura organizativa, forma de trabajo y fundamentalmente para considerar potenciales colaboradores para la conformación y mantenimiento de la CVA en temas Nucleares. En la siguiente subsección se resume parte de la experiencia en este sentido, para tomarla como base de la propuesta de CVA. 


\subsubsection{Nuestra experiencia}

Se toma como experiencia el grupo de trabajo generado en Google (Cedsan_ar), para un proyecto de investigación en marcha denominado "Investigación de los Parámetros Físicos del Reactor Nuclear RA-O necesario para el desarrollo de un Simulador". Desde alli se trabaja con los miembros del proyecto intercambiando datos, volcando resultados, elaborando informes sobre las mediciones realizadas, y fundamentalmente trabajando a través de espacios de comunicación.

Uno de esos espacios es el denominado "Debates", que se indica en la figura siguiente con una flecha, donde aportan sus conocimientos y experiencias para avanzar en el proyecto. Al grupo lo integran profesionales de las Facultades de Ciencias Exactas, Fisicas y Naturales; Matemática, Astronomia y Fisica de la UNC; Comisión Nacional de Actividades Espaciales y Comisión Nacional de Energia Atómica. Los archivos que se colocan en la página del grupo son los que se van confeccionando con la participación de cada uno en su área de conocimiento. Se realizan operaciones periódicas con el Reactor Nuclear RA-0 para obtener datos, los cuales quedan a disposición del grupo en ese espacio para que cada uno los procese, y elabore los informes correspondientes. Hasta el momento la participación se realiza con muy buenos resultados desde el punto de vista académico, dado que se logra obtener aprobación por parte de las entidades acreditadoras (Secretaria de Ciencia y Tecnología de la UNC), y presentación en reuniones cientificas. Desde el punto de vista comunicativo, la realización de informes, el intercambio de documentación, consultas, aportes se realiza desde el grupo en Google. La etapa siguiente propuesta en este grupo es desarrollar un simulador de un Reactor Nuclear para lo cual está previsto continuar con la misma modalidad de trabajo. 


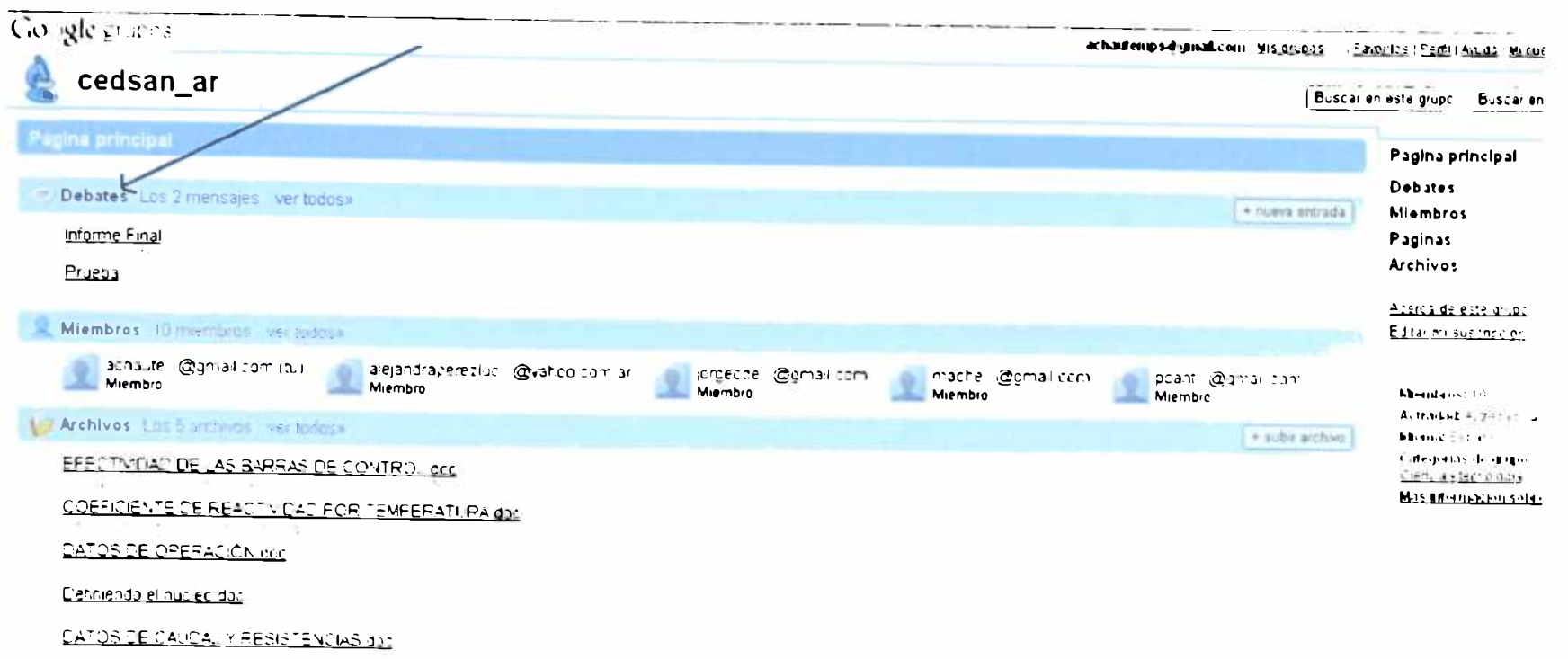

Figura 9. Presentación del grupo Cedsan_ar en Google

Contar con la CVA permitirá integrar estas herramientas con el fin de lograr un único espacio de encuentro, donde se aborde el trabajo colaborativo, que soporte no sólo la capacitación, sino también lo que se viene realizando con los grupos de Google. Es de notar, que existe al momento una dispersión de los grupos intervinientes, trabajando en diferentes espacios virtuales (Moodle para capacitación, Google Groups para compartir experiencias y realizar trabajo colaborativo).

La propuesta va a permitir entonces, disponer de un espacio compartido para los trabajos de investigación o desarrollo, donde se requiere un movimiento fluido de información, intercambio de documentos y disponibilidad de material en un espacio compartido, donde puedan acceder los interesados.

En los párrafos que siguen se da cuenta de lo realizado en capacitación sobre el EVEA Moodle, para luego poder determinar las necesidades para la CVA que se propone.

En lo referido a capacitación la primera experiencia de trabajo fue con el curso "Metodología y Aplicación de Radionucleidos" en el marco de un proyecto conjunto de capacitación entre la UNC (Universidad Nacional de Córdoba) y la CNEA (Comisión Nacional de Energía Atómica). Alli se realizaron los primeros usos de herramientas no convencionales usando Moodle, y algunos de los recursos disponibles como mensajeria y foros. La finalidad de esa iniciativa fue y es mejorar la calidad de las actividades educativas de carácter presencial mediante la incorporación de apoyo a distancia, donde los alumnos puedan interaccionar con los coordinadores y con sus pares. A partir de alli y en los siguientes cursos se fue ampliando el uso de los 
recursos. En una primera instancia, los foros se utilizaron sólo entre los alumnos para trabajar sobre una actividad propuesta, pero paulatinamente se fueron incorporando los tutores o docentes para realizar aportes, sugerencias o generar un debate con los participantes. Finalmente, se trabajó sobre el armado de las conclusiones que se pusieron a disposición de todos, en espacios destinados dentro de la plataforma. La mensajeria se utilizó para comunicaciones informales, anuncios y consultas técnicas sobre uso de los recursos.

Al finalizar los cursos se entregaron encuestas a los participantes a fin de evaluar los logros alcanzados, el cumplimiento de objetivos, la dificultad en el manejo del EVEA. De las preguntas formuladas, dos están relacionadas con las comunicaciones, las cuales se presentan a continuación para mostrar el impacto alcanzado y tomarlo como experiencia para el desarrollo de la CVA.

La encuesta completa se encuentra en el Anexo B.

Preguntas:

1. Respecto a los foros, ¿cuáles son las mayores utilidades que reconoce en este Curso? Puede elegir más de una opción o sugerir una nueva en el casillero en blanco.

- Como espacio de comunicación formal e informal.

- Como espacio para plantear y resolver dudas y consultas.

- Como una instancia para la construcción conjunta de conocimientos.

- Como una instancia para conocer al resto de los participantes del curso.

- Otro

2. ¿Cómo ha sido la comunicación mantenida con los tutores a lo largo del curso? Puede elegir más de una opción o sugerir una nueva en el casillero en blanco.

- Pertinente/Adecuada (de retroalimentación permanente y personalizada)

- Pertinente/Adecuada (respondiendo a las distintas consultas de manera general o conjunta)

- Insuficiente/Inadecuada (no respondió a mis inquietudes personales)

- Insuficiente/lnadecuada (no se comunicaba con la periodicidad necesaria)

- Otro 
Análisis de las respuestas:

\section{Pregunta 1:}

Queda de manifiesto en esta pregunta los múltiples usos de los espacios de comunicación, en este caso asincrónica, a través de los foros.

\begin{tabular}{|l|c|}
\hline Respuestas & Resultados \\
\hline $\begin{array}{l}\text { Como espacio de comunicación formal e } \\
\text { informal }\end{array}$ & 5 \\
\hline $\begin{array}{l}\text { Como espacio para plantear y resolver } \\
\text { dudas y consultas }\end{array}$ & 2 \\
\hline $\begin{array}{l}\text { Como una instancia para la construcción } \\
\text { conjunta de conocimientos }\end{array}$ & 5 \\
\hline $\begin{array}{l}\text { Como una instancia para conocer al resto } \\
\text { de los participantes del curso }\end{array}$ & 1 \\
\hline Otro & 0 \\
\hline
\end{tabular}

Tabla 7. Resultados indicativos de los posibles usos de foros

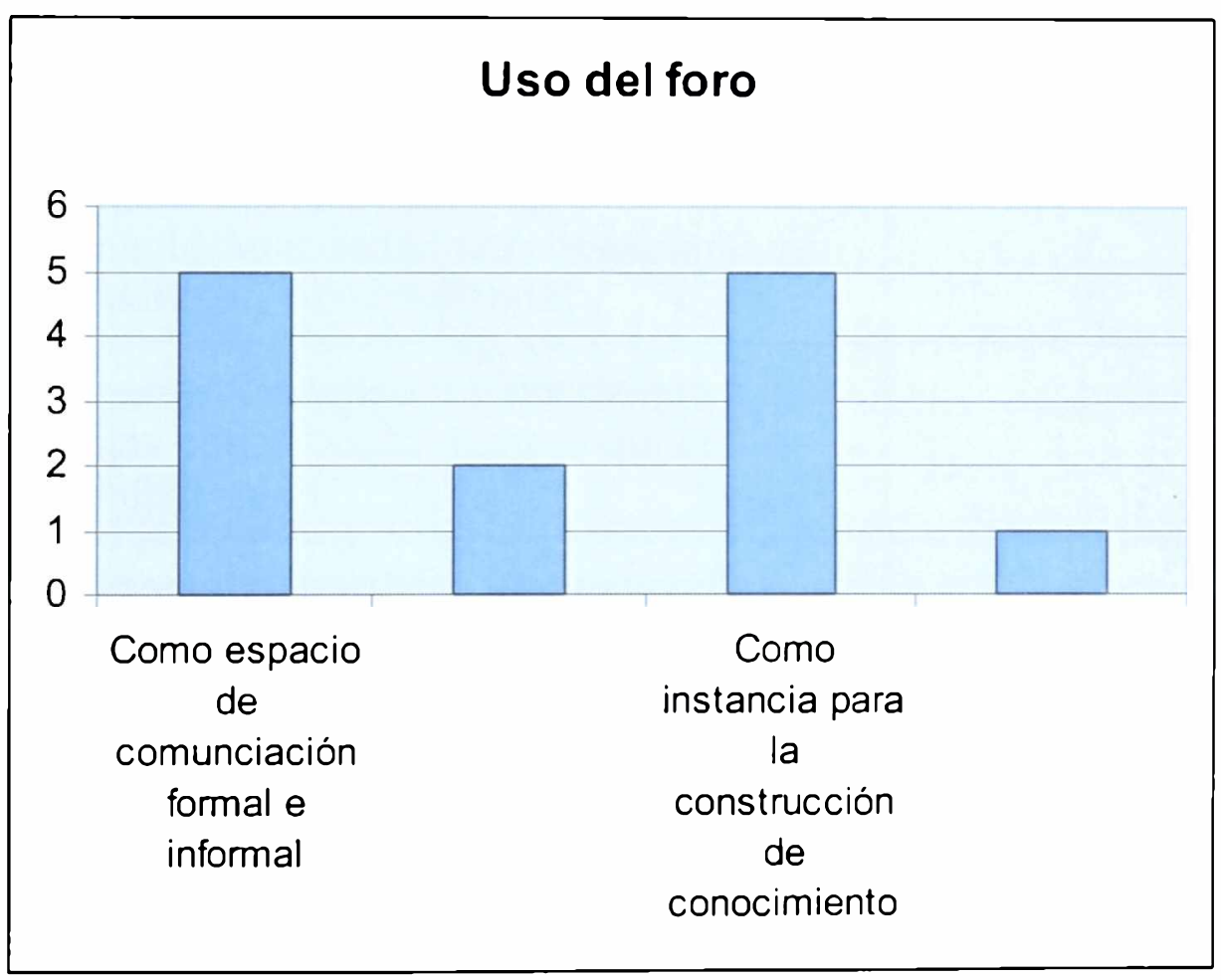

Figura 10. Gráfico que ilustra los resultados de Tabla 7

En nuestra experiencia, los usos de este espacio de comunicación guardan especial relación con las consignas de trabajo. Por ejemplo, si la consigna busca generar 
trabajo colaborativo, los alumnos abordarán el uso de este espacio para comunicaciones referidas a lograr el objetivo común, negociando y acordando sobre diferentes aspectos. En otras oportunidades se puede utilizar para realizar consultas entre todos los participantes sobre un tema especifico, o sobre el manejo de alguna herramienta de ia plataforma, y se genera una situación de ayuda mutua, y asistencia del moderador.

\section{Pregunta 2:}

En relación a la comunicación con los tutores la encuesta refleja que hay comunicación, aunque se debe trabajar en lograr mayores aportes al aprendizaje.

En este sentido, en el marco teórico se expresan las diferencias en cuanto a roles en un entorno virtual de enseñanza y aprendizaje con respecto a una CVA (Capitulo 2.2). En general, en la CVA la responsabilidad es compartida con participación abierta sin esquemas jerárquicos ni verticales. Ahora bien, cabe aclarar que en los cursos que se están analizando, algunos enfocan una participación más abierta, en tanto otros, como el que figura en esta encuesta, se centran en la figura de los tutores que organizan, hacen seguimiento, motivan, estimulan a la reflexión; de alli que los participantes esperen esa retroalimentación personalizada.

\begin{tabular}{|l|c|}
\hline Respuestas & Resultados \\
\hline $\begin{array}{l}\text { Pertinente/Adecuada (de retroalimentación } \\
\text { permanente y personalizada) }\end{array}$ & 7 \\
\hline $\begin{array}{l}\text { Pertinente/Adecuada (respondiendo a las } \\
\text { distintas consultas de manera general o } \\
\text { conjunta) }\end{array}$ & 5 \\
\hline $\begin{array}{l}\text { Insuficiente/Inadecuada (no respondió a } \\
\text { mis inquietudes personales) }\end{array}$ & 0 \\
\hline $\begin{array}{l}\text { Insuficiente/Inadecuada (no se comunicaba } \\
\text { con la periodicidad necesaria) }\end{array}$ & 1 \\
\hline Otra & 0 \\
\hline
\end{tabular}

Tabla 8. Resultados de las comunicaciones con los tutores 


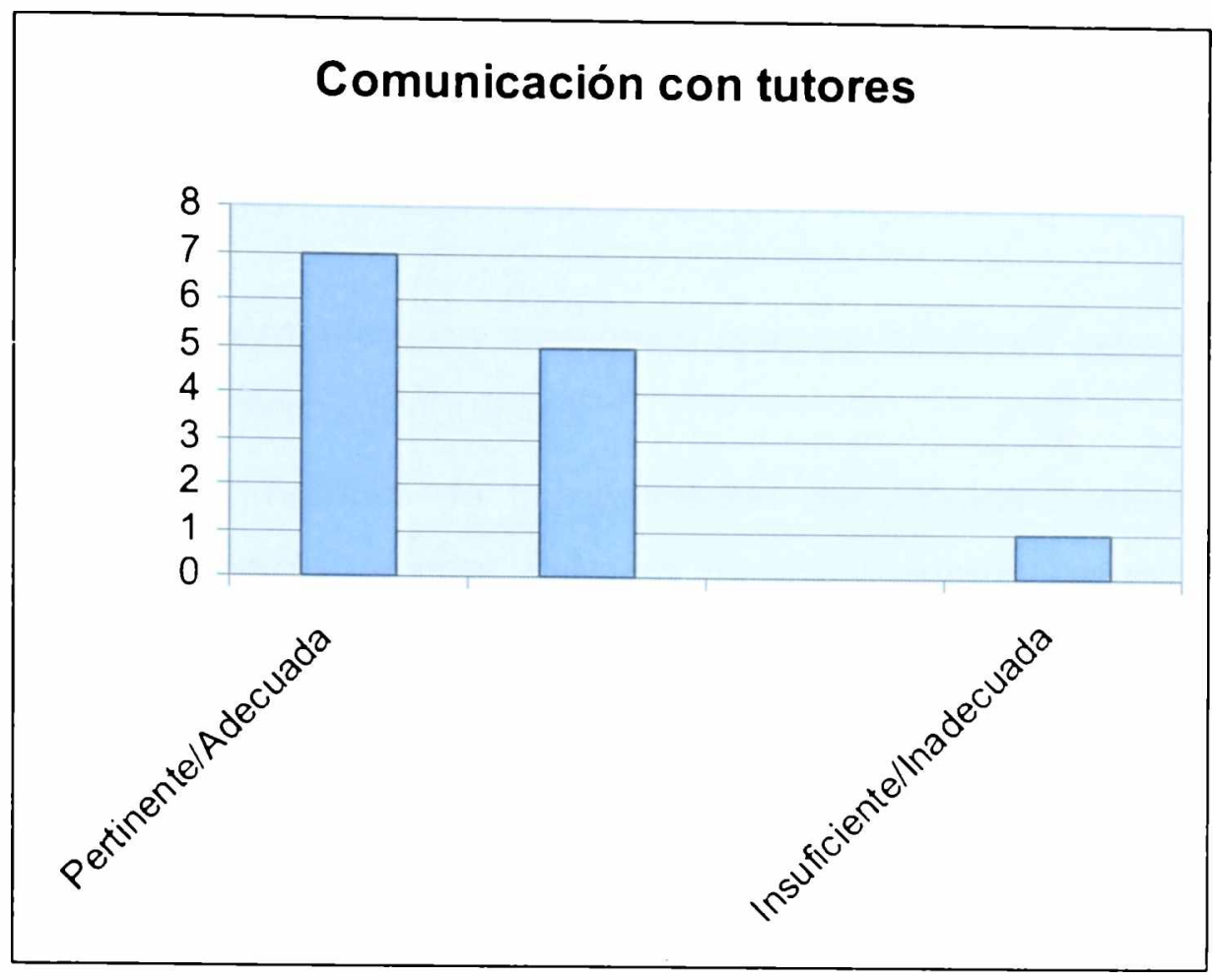

Figura 11. Gráfico que ilustra los resultados de la Tabla 8

En conclusión, la mayoria de los grupos que participan en las capacitaciones reflejan la conveniencia de disponer de espacios de comunicación formal e informal como instancia para la construcción conjunta del conocimiento. Estos espacios pueden darse a través de herramientas como los foros. Además, a fin de fortalecer los vínculos se pueden incorporar reuniones periódicas, por ejemplo a través de videoconferencias, donde los participantes expresen su opinión sobre los avances y proyecciones a futuro. Se detecta asi la necesidad de fortalecer los vinculos utilizando herramientas sincrónicas que flexibilicen aún más la comunicación. Se considera que es necesario contar con actividades que propicien la vinculación de los miembros. Las herramientas de comunicación en sí mismas no sostendrán la vinculación necesaria en una CVA; son las propuestas que nos llevan a usarlas las que la sostienen. Asimismo, el contar con herramientas tecnológicas adecuadas y fáciles de usar, puede potenciar la comunicación y acompañar los procesos de vinculación.

\subsubsection{Propuesta para generar la vinculación y comunicación entre los miembros de la CVA.}

A raiz de las experiencias anteriores y el marco teórico se realiza a continuación una propuesta para generar la vinculación y comunicación entre los miembros de la CVA. Por un lado, se establecen algunos de los requerimientos desde el punto de vista 
tecnológico, y por otra parte, se ejemplifican las decisiones en cuanto a procesos a llevar a cabo, que permitan estimular la vinculación y comunicación.

Las herramientas que se buscará tener disponibles para este espacio son:

- Chat: recurso de comunicación sincrónica que se habilitará para poder efectuar consultas o debatir temas propuestos.

- Mensajería interna: recurso de comunicación asincrónica destinado a formular preguntas, por ejemplo, acerca del uso de los recursos tecnológicos, aportar sugerencias o recomendaciones. También desde alli se solicitará acceso a la base de datos de posible interesados para conformar grupos de trabajo.

- Foro: para realizar comunicaciones asincrónicas con la finalidad de desarrollar debates sobre temas especifico, donde cada miembro aporte sus conocimientos o puntos de vista.

A fin de generar comunicación entre los miembros de la CVA, se buscará que los trabajos de investigación que se desarrollen en la comunidad tengan informes que se pongan a disposición de la comunidad, como se especifica en 4.7. Además se abrirá un foro de debate referido a los informes con acceso a todos los integrantes de los proyectos de investigación. Desde alli podrán hacer aportes o sugerencias tendientes a ampliar las lineas de investigación o mejorar las existentes.

Periódicamente, e informados a través del calendario, se dará a conocer una noticia referida a los temas de interés de la CVA y un listado de expertos a los que se podrá consultar via mensajería. Concluido el tiempo asignado, se publicará un documento con las conclusiones. Estos son algunos ejemplos de actividades que permitirán fomentar la comunicación y vinculación entre los miembros y que tendrán su soporte a partir de las herramientas disponibles en la CVA.

\subsection{Liderazgo y coordinación}

Como se menciona en el marco teórico, el éxito de una CVA está asociado a la coordinación general por parte de los facilitadores, coordinadores o líderes temáticos que promueven la participación, comunicación, realización de actividades, cumplimiento de objetivos, seguimiento de cronogramas de trabajo, motivación de los miembros, intercambio de experiencias y conocimiento, y reflexiones sobre los temas de interés. A su vez, es importante que estén identificadas las personas que asumen esos roles para que la interacción sea fluida. 
Los lideres temáticos se destacan por sus conocimientos especializados, que sirven de apoyo a los facilitadores.

Ahora bien, deben estar claras las formas de participación y los roles pues contribuyen al funcionamiento exitoso de la CVA.

Otro de los roles que se puede incluir dentro de la CVA es el de soporte a las aplicaciones tecnológicas que sustentan los procesos de aprendizaje. El encargado (o encargados) de este aspecto pueden sostener el sitio Web e informar a la comunidad sobre cambios realizados, como asi también capacitarlos en el uso de nuevas tecnologias.

\subsubsection{Experiencia adquirida a través del dictado de cursos con modalidad semipresencial.}

Los entornos virtuales de enseñanza y aprendizaje se han constituido en mediadores de procesos de aprendizaje en las más diversas disciplinas. Fundamentalmente estos EVEA sostiene los roles de docentes y alumnos. En nuestra experiencia, se ha dispuesto para los docentes un espacio para publicar documentos, novedades, administrar foros de consulta, y establecer comunicaciones a través del correo electrónico/mensajeria. Por su parte, los alumnos pueden acceder al material de estudio, enviar trabajos, hacer ejercicios y consultas.

En el primer curso realizado en nuestra universidad que se dictó totalmente a distancia, se modificaron algunos roles. A los de docentes y alumnos se les sumó el rol de administrador del EVEA que tiene a su cargo tareas de gestión tales como coordinar los grupos, presentar la agenda y solucionar inconvenientes relacionados con el uso del entorno.

Este rol facilita en gran medida la tarea del docente, quien se dedica entonces a la planificación de la capacitación, presentar propuestas de trabajo, corrección de tareas y actividades, y motivar la participación.

Finalmente, cuando se capacitó a docentes a través de formadores del PROED (Proyecto de Educación a Distancia de la Universidad Nacional de Córdoba), se logró conformar un grupo donde los roles se ampliaron a docentes, alumnos, coordinador académico, administrador del EVEA, asesor pedagógico y diseñador gráfico. Previo al comienzo del curso, se realizaron reuniones de trabajo donde se acordó:

- Usos del EVEA, la modalidad del dictado de cursos, material a utilizar. 
- Preparación de documentos: cada docente debía elaborar un material especifico usando software de presentación, material de lectura y la actividad correspondiente que en algunos casos fueron cuestionarios, en otros auto evaluaciones, actividades planificadas para abordar en wikis, foros, encuestas, etc. En todos los casos se contó con el asesoramiento pedagógico y la elaboración del diseño gráfico correspondiente.

- Asignación de roles con consignas claras y precisas: en este sentido se incorporó la figura de coordinador académico que tuvo la misión de lograr que se cumplan los objetivos propuestos, facilitar la participación de alumnos y docentes, evitar la deserción por falta de conocimientos en el manejo de la tecnologia, buscar alternativas de trabajo para quienes tuviesen inconvenientes con Internet, promover el cumplimiento de las tareas asignadas, conformar los grupos de trabajo, aportar material complementario de estudio. También incluir actividades de trabajo colaborativo y cooperativo de aprendizaje e integrar la experiencia y conocimiento de los participantes para fortalecer lazos de comunicación.

Como resultado se pudo observar una mayor autonomia de trabajo respecto a las experiencias anteriores, suficiente grado de sociabilización y coparticipación en los procesos de aprendizaje, donde los alumnos se mostraron motivados a presentar sus experiencias y prácticas de laboratorio.

De esa manera el coordinador académico, cumplió un rol de tutor pedagógico, social, administrativo y técnico, en cuanto estas categorias se relacionaron con la construcción, seguimiento y sostén de la comunidad de aprendizaje (Salomón, 2000).

\subsubsection{Asignación de roles para la CVA propuesta}

En base a la experiencia adquirida en el dictado de cursos y proyectos de investigación descriptos, se realiza en esta subsección una propuesta para la CVA que se está diseñando.

En primer lugar, existirá un coordinador general, este rol se puede ampliar a una comisión coordinadora a medida que crezca el número de participantes de la comunidad.

También se considera necesario contar con un administrador técnico de la CVA que pueda dar soporte a las dificultades relacionadas con el uso de los recursos 
tecnológicos y su mantenimiento. Este administrador puede ampliarse luego a un comité o grupo de soporte, pero esto dependerá del crecimiento de la CVA.

Se cree fundamental además disponer del rol de coordinador para cada uno de los pilares que se involucrarán en esta CVA: investigación, capacitación y desarrollos. Estos pilares surgen a partir las necesidades analizadas con el grupo gestor, y de la experiencia de trabajo previa de los destinatarios de la CVA.

Los roles asignados podrán cumplir las siguientes funciones (Brenson Lazan, 2005):

- Moderador: a partir de reconocer la necesidad de satisfacer los procesos de aprendizaje, su rol es guiar y dirigir las comunicaciones hacia los objetivos propuestos, facilitar la participación de todos los miembros, equilibrar la interactividad de la comunidad y motivar la interacción.

- Coordinador: estimular la participación en función del cumplimiento de las tareas acordadas, desarrollar estrategias para facilitar el intercambio de información, asignar actividades como elaboración de conclusiones o documentos.

- Tutor: monitorear y retroalimentar los procesos interpersonales para lograr un trabajo en equipo. Motivar el compartir información y experiencias personales necesarias para afrontar la tarea. Realizar actividades de sintesis que faciliten el intercambio de conocimientos. Lograr la construcción coparticipativa de nuevos conocimientos y realidades. Hacer un seguimiento personal y grupal a través de sugerencias que contribuyan a mejorar los procesos, o buscar asesores externos para afrontar las dificultades que se presenten en el desarrollo de los proyectos.

Estas funciones pueden variar dependiendo de la actividad que se esté desarrollando y del grupo de participantes. En todos los casos, el coordinador tiene la función de consolidar la CVA facilitando y promoviendo la interactividad, la vinculación afectiva y el tiempo de interacción.

Para alcanzar los objetivos, se cuenta con distintos espacios para propiciar los distintos tipos de comunicación (formal o informal), y tareas a desarrollar (dictado de cursos, proyectos tecnológicos, investigación, etc.).

Por otra parte, se va a asegurar la capacitación de los participantes en el uso de las tecnologias de la información y la comunicación, para que adquieran habilidades que les permitan desempeñarse en las distintas actividades. 
Es por ello que su participación se considera fundamental en el desarrollo de la CVA para alcanzar objetivos de aprendizaje, con el aporte individual y colectivo de los participantes.

En resumen, se contará con un coordinador general, un coordinador del área de investigación, otro del área de capacitación y uno para el área de desarrollos. Al mismo tiempo se dispondrá de un administrador técnico. El resto del grupo gestor de la CVA participará en la definición concreta de las reglamentaciones y lineamientos para su funcionamiento.

\subsection{Estimulación de procesos de aprendizaje}

En la CVA propuesta, la estimulación de los procesos de aprendizaje es uno de los principales objetivos, de alli la necesidad de organizar a los participantes en base a los proyectos de trabajo, y de los intereses personales y de la comunidad. Por un lado, los coordinadores y sus posibles colaboradores generarán una metodologia especifica para la estimulación del aprendizaje en cada uno de los aspectos involucrados (investigación, capacitación y desarrollo).

Por otra parte se dispondrá de espacios y roles que faciliten los siguientes puntos:

- Intercambio y discusión de ideas a través de herramientas de comunicación sincrónica y asincrónica. Desde alli se pueden expresar los puntos de vista, experiencias, conocimientos sobre los conceptos o actividades sobre las que se trabaje, y negociar una significación común.

- Intercambio de documentos por medio de espacios de almacenamiento que están disponibles en un EVEA integrado a la CVA, para los cursos, o en grupos de trabajo para las otras actividades. En todos los casos se pueden subir y descargar archivos, material bibliográfico y multimedia.

- Colaboración entre los participantes para la elaboración de informes, documentos, discusión de temas. Para ello las herramientas disponibles en la CVA permitirán que todo el material esté disponible para los integrantes de la comunidad y que se puedan presentar en distintos formatos, además de permitir la edición conjunta de los documentos

- Distribución de las tareas en base a intereses particulares o generales, pero fundamentalmente teniendo en cuenta las necesidades del proyecto y las habilidades para sustentarlo por parte de los participantes. 
- Seguimiento de los avances y logro de objetivos, participación de los interesados, metas a cumplir, cronograma de actividades. La finalidad es tomar medidas que aseguren el éxito en las tareas, lo cual estimulará a seguir trabajando dentro de la CVA.

- Confección de informes periódicos donde se expresen las reflexiones que se dieron en las distintas actividades o grupos de trabajo identificando a los autores, para ir consolidando el aprendizaje y estimular la incorporación de nuevos miembros.

A partir de la estimulación de los procesos de enseñanza y aprendizaje realizados desde la plataforma educativa (que tomamos como punto referencial) se produce el efecto red, como menciona Zangara (2008), "que significa que cuanta más gente se ve involucrada, más valor adquiere el fenómeno y más gente se interesa por participar. De alli que el principal fenómeno de crecimiento de la Web provenga de la participación de usuarios en la generación de contenidos (textuales o multimedia) y en la comunidad que se crea alrededor de ellos".

En ese sentido se utiliza toda esa experiencia para establecer los mecanismos de estimulación del aprendizaje dentro de la CVA. Primeramente en los aspectos de comunicación, por lo que se proponen las herramientas mencionadas. Seguidamente a través de una observación continua de la participación de los miembros y del planteo de estrategias de estimulación para su participación.

Resulta fundamental en este sentido, que exista una planificación previa de los coordinadores de cada pilar de la CVA, de manera tal que defina las estrategias necesarias de motivación para el aprendizaje acorde a los objetivos planteados.

\subsection{Incentivo a la cultura de participación}

Asi llegamos a la etapa de incentivo de la participación necesaria para conformar una CVA, con un espacio en la web donde puedan desarrollarse las actividades, desde donde interaccione la comunidad entre si y con el exterior. Un lugar con identidad propia y características necesarias para alcanzar los objetivos generales y particulares.

La CVA será entonces un canal para propiciar la colaboración, la voluntad de compartir, el flujo de información.

En ese sentido la comunidad propuesta estará dispuesta dentro de un contexto propio, con un nombre que la identifique y haga referencia a la temática de la misma. 
En ese espacio los miembros podrán expresar sus opiniones y experiencias en un marco de integración, para lo cual el coordinador buscará mecanismos que estimulen a quienes no estén participando.

Las decisiones se tomarán entre todos en la medida de las posibilidades, dependiendo de la tarea en la que se esté trabajando, propiciando climas de confianza y transparencia como base de una buena convivencia dentro de la comunidad.

Dado que las comunicaciones tendrán un papel fundamental, se consideran varias herramientas teniendo en cuenta las posibilidades de acceso a cada una de ellas por parte de los participantes, o la destreza en el uso de unas y otras.

Para que la participación sea fluida, y como parte de nuestra experiencia, se dispondrá de un espacio destinado a la capacitación en el uso del sitio web de la comunidad y de cada una de sus herramientas.

\subsubsection{Nuestra experiencia}

Teniendo en cuenta las dificultades que se pueden presentar en el uso de las tecnologias y cómo se puede promover la cultura de la participación evitando ese tipo de dificultades, se presenta a continuación una pregunta que se formuló como parte de la encuesta referenciada anteriormente. El total es de 13 encuestados y los resultados son los siguientes (La encuesta completa en Anexo B):

\section{Pregunta:}

¿Le resultó fácil navegar a través del aula virtual?

Si

No

En caso de haber seleccionado "No" en el apartado anterior ¿podría identificar alguno de los problemas de navegación con los que se ha encontrado? Puede elegir más de una opción o sugerir una nueva en el casillero en blanco.

- Inconvenientes con su usuario y contraseña.

- Interfaz de navegación confusa.

- Problemas de conectividad o disponibilidad técnica de la plataforma.

- Inconvenientes en la configuración de su navegador/explorador de Internet.

- Problemas para acceder a archivos/recursos publicados en el curso.

- Problemas con el soporte técnico 
- Otro

\section{Respuesta:}

Las respuestas reflejan una amplia mayoría a la que le resultó fácil navegar en el aula virtual, y eso se debe a que previo al curso se les facilitó un material educativo digital con la explicación sobre el funcionamiento del EVEA, y el uso de los recursos educativos.

Los que encontraron dificultades son de a conexión a Internet o algunos problemas técnicos, los cuales se fueron solucionando paulatinamente.

\begin{tabular}{|l|c|}
\hline Respuestas & Resultados \\
\hline Si & 12 \\
\hline No & 1 \\
\hline
\end{tabular}

Tabla 9. Resultados sobre la facilidad de manejo del aula virtual

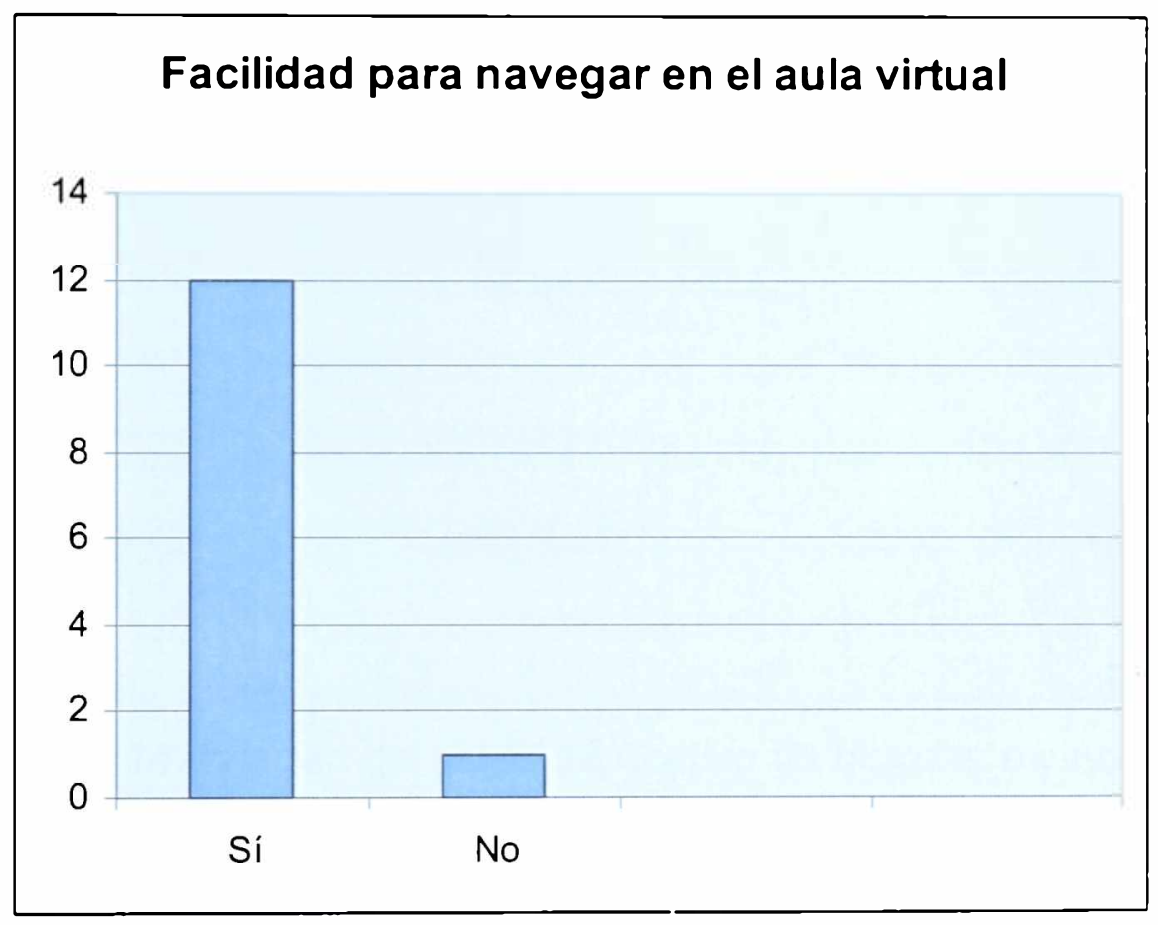

Figura 12. Gráfico que refleja los resultados de Tabla 9

Esta pregunta refleja entonces la importancia de capacitar previamente a los integrantes de la CVA en el uso de las diferentes tecnologías.

A continuación se presentan algunos ejemplos empleados para explicar el uso de la plataforma Moodle: 
- Video explicativo disponible dentro de la plataforma, donde describe el funcionamiento de cada uno de los recursos mostrando cómo realizar cada acción. En la Fig. 14 se observa el cursor en amarillo.

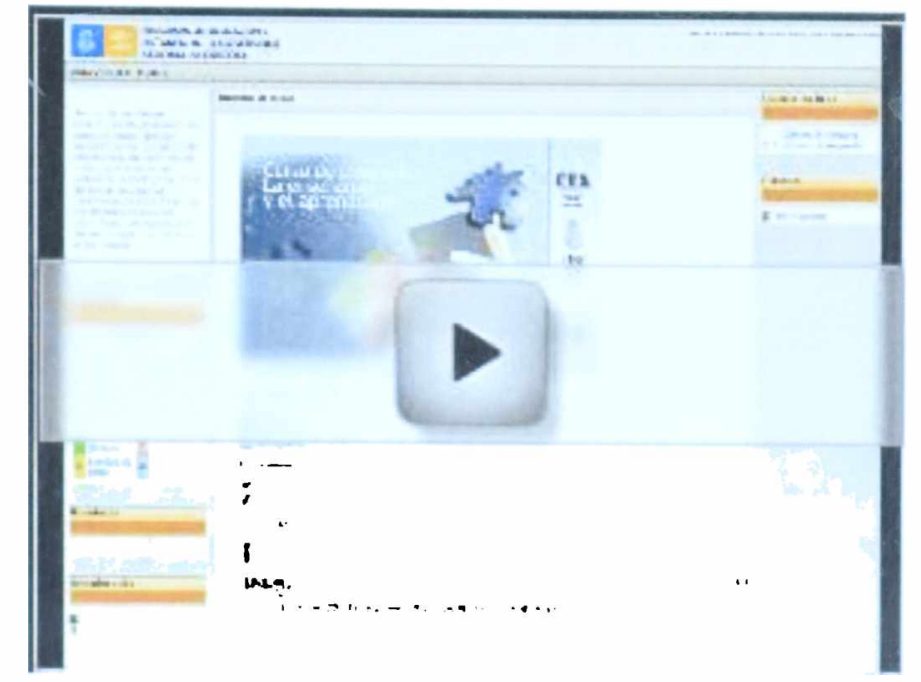

Figura 13. Imagen del video explicativo de Moodle: presentación

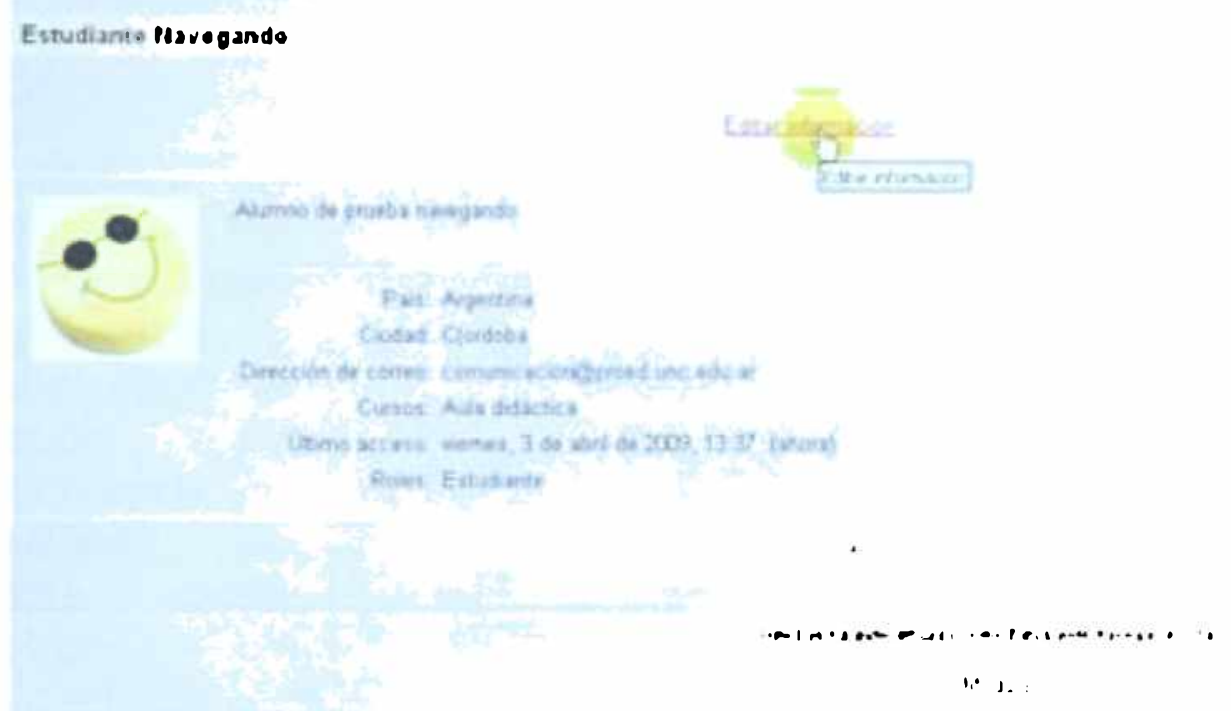

Figura 14. Imagen del video explicativo de Moodle: avances

- Uso de capturas de pantallas indicando la secuencia de pasos a seguir desde la inscripción al sitio hasta la utilización de todas sus herramientas. En cada una hay una flecha que señala qué acción realizar. 


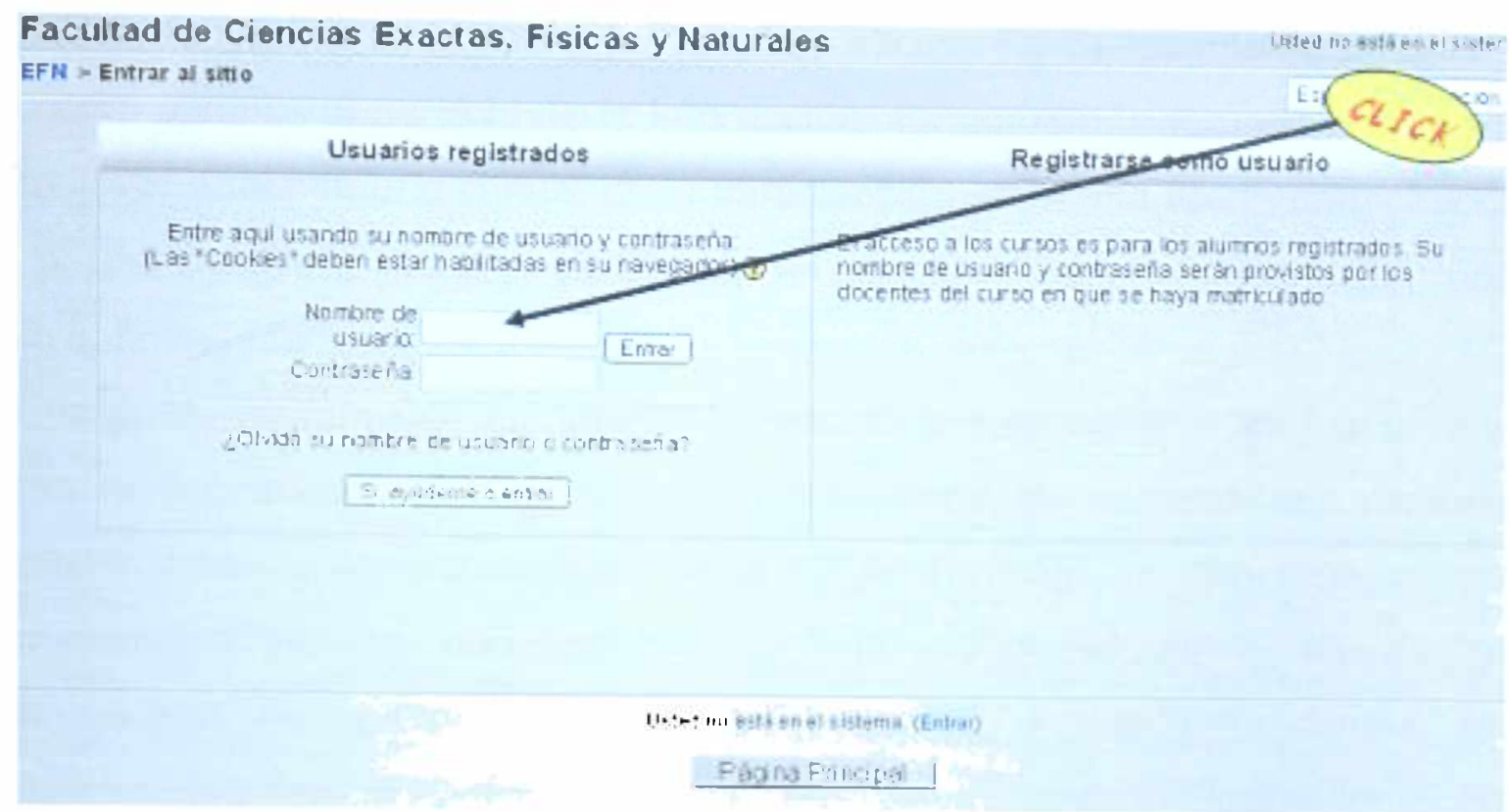

Figura 15. Imagen del Power Point explicativo de Moodle

- Manual para aprendices conteniendo una descripción detallada de todo el funcionamiento, en este caso de Moodle. Este recurso es más completo que los anteriores pues está dirigido a docentes que necesitan aprovechar al máximo las ventajas de la plataforma educativa.

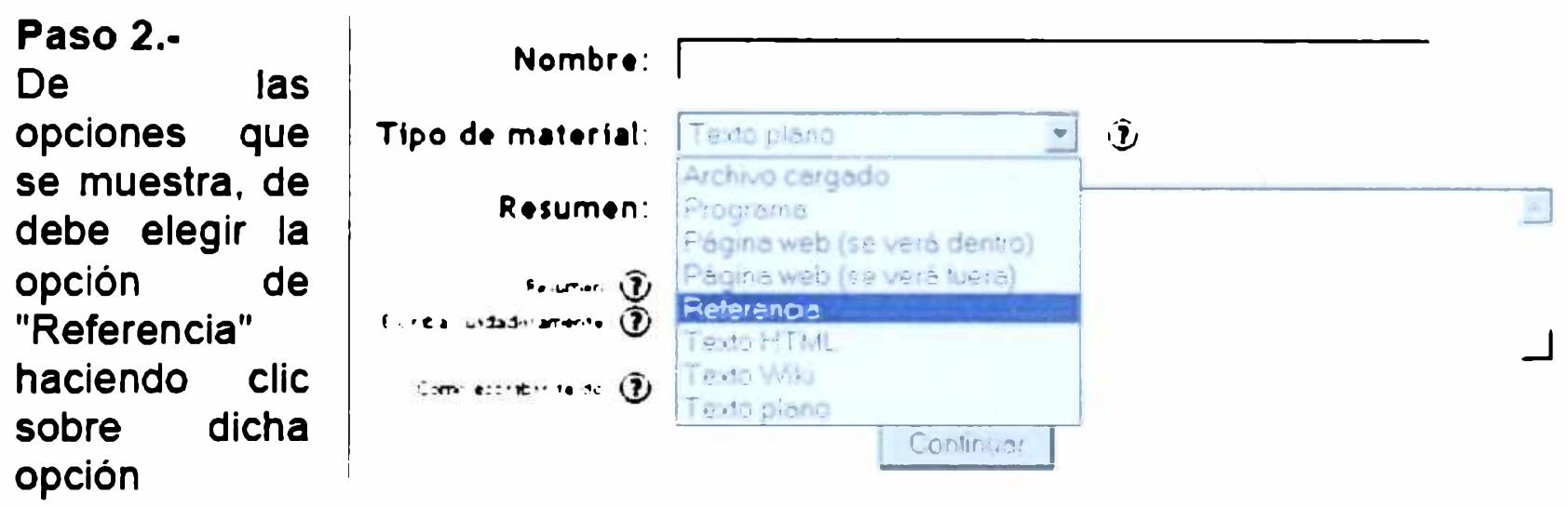

Figura 16. Imagen del manual explicativo de Moodle

Estas tres situaciones descriptas se complementaron con consultas por teléfono, mail y chat.

Finalmente, resultó de gran utilidad dedicar un tiempo previo al inicio de la actividad para hacer reuniones informativas en los laboratorios del centro de cómputo. Alli cada uno de los interesados pudo realizar prácticas previas guiado por docentes.

Como resultado de este análisis, se cree que será de importancia generar material adecuado para la formación de los miembros de la comunidad en el uso de las herramientas tecnológicas involucradas en el espacio virtual de trabajo. Se espera que 
estas no funcionen como barreras para la participación de los miembros de la CVA, si no como canales al servicio de la interacción. Es por ello, que una de las estrategias para llevar adelante una cultura de la participación, será una fuerte capacitación inicial en el uso del CVA, y sus posibilidades en cuanto a metodologia de funcionamiento para la comunidad.

Se propone inicialmente un tutorial indicando la secuencia a seguir para navegar sobre la comunidad, y principalmente para utilizar los recursos alli disponibles. El mismo estará dentro del espacio de la CVA. También se ofrecerán instancias de entrenamiento a los coordinadores $y$ sus colaboradores a fin de gestionar metodologias de uso adecuado de dicho espacio y sus herramientas. Al mismo tiempo, todas las actividades que se programen tendrán como fin incentivar la participación de los miembros de la comunidad de una u otra manera.

\subsection{Resumen}

Promover el aprendizaje desde una comunidad virtual demanda condiciones minimas tales como planificación, consideración de aspectos vinculados a las comunicaciones, coordinación, estimulación de los procesos de aprendizaje e incentivo de la participación. No obstante, con una planificación flexible se pueden ir modificando los temas y las modalidades de intercambio de conocimiento, de acuerdo a las inquietudes de la comunidad.

Alcanzar esos objetivos de aprendizaje depende del sentido de pertenencia que tengan sus miembros respecto a la comunidad, como a sus metas y contenidos. Siempre el desafio está en fomentar la participación activa de los integrantes.

El rol del coordinador es estratégico en cuanto a la responsabilidad de lograr esa participación activa como asi también los objetivos propuestos. De alli la importancia de contar con expertos que ayuden sobre temas especificos y de tipo tecnológicos.

Trabajar en el monitoreo y evaluación de la CVA permitirá probar la efectividad del aprendizaje, participación, y de ser necesario cambiar las estrategias de trabajo a fin de incentivar la generación de nuevos proyectos y la incorporación de miembros.

Para generar la CVA referida a temas nucleares, se parte de la experiencia adquirida en el dictado de cursos utilizando un EVEA, de los recursos humanos que trabajan en ellos y de los grupos que vienen trabajando en forma virtual en algunos proyectos de investigación referidos a la temática. 
Una de las caracteristicas de la CVA propuesta tiene en consideración lo que apunta Suárez (2003), y es hacer invisible la tecnologia para dar protagonismo a los procesos de interacción social.

En base al análisis del marco teórico, de las CVA existentes y de los resultados del cuestionario, la CVA propuesta, tendrá las siguientes caracteristicas:

- Diseño que permita la participación abierta en las distintas propuestas de trabajo.

- Coordinación general de la CVA, y en particular para cada uno de los proyectos, líderes temáticos y apoyo tecnológico.

- Espacios de comunicación y participación formal e informal.

- Repositorio de información académica, recursos tecnológicos, servicios educativos, publicaciones.

- Sitio especifico para la capacitación y entrenamiento en diferentes temas.

En este capitulo se presentó una propuesta de diseño utilizado para generar la CVA teniendo en cuenta las etapas mencionadas en el punto 2.5 como base metodológica, y fundamentando el análisis de cada una de ellas a partir de la experiencia adquirida en entomos virtuales de enseñanza y aprendizaje. Como parte de esas actividades se realizaron encuestas para evaluar distintos aspectos del desempeño en el uso de los recursos tecnológicos, del logro de objetivos propuestos, y a partir de los resultados se plantearon cambios y mejoras. El análisis de esas encuestas se volcó en los diferentes puntos de este capitulo, dado que representan la opinión de quienes participan en este proceso de gestar la CVA, y aporta material de utilidad en su diseño. 


\section{Capítulo 4}

Diseño y desarrollo de una comunidad virtual de aprendizaje referida a temas nucleares 
A partir de la propuesta de diseño presentada en el capitulo 3, se detalla a continuación cómo se ha desarrollado un primer prototipo de la comunidad virtual de aprendizaje referida a temas nucleares en el marco de un proyecto de trabajo en espacios virtuales, coordinado por el grupo del Reactor Nuclear RA-0.

El diseño de la CVA se ha realizado en función de los recursos disponibles, atendiendo a los objetivos de este tipo de comunidad, entre los que se mencionan la posibilidad de comunicación, intercambio de información y participación cooperativa y colaborativa entre los participantes.

En todas las fases del diseño y desarrollo que se presentará se toman en consideración de manera articulada los aspectos tecnológicos y pedagógicos que propicien el aprendizaje.

En el punto referido al diseño de la CVA, que completa el análisis que se viene realizando desde el capitulo anterior, primeramente se hace una presentación general de la comunidad en cuanto a la organización, estructura y servicios disponibles. Esto se ilustra a través de un diagrama que presenta las secciones principales.

Finalmente, se presenta un primer prototipo de la CVA que está en funcionamiento, el cual se encuentra en una fase preliminar y sobre el que se continúa trabajando. El mismo está disponible en wuw.raO.efn.uncor.edu perteneciente al Reactor Nuclear RA-0. Este sitio ha sido desarrollado con el software Joomla $1.5^{3}$. El servidor está ubicado en las instalaciones del Reactor Nuclear RA-0.

\subsection{El contexto de trabajo}

Retomando lo desarrollado en el capitulo 3.1 sobre el grupo de trabajo del Reactor Nuclear RA-0, se observó la necesidad de contar con una CVA que involucre los distintos sectores sobre los que se viene participando desde hace varios años. Esos sectores son básicamente cuatro:

- Capacitación

- Desarrollo tecnológicos

- Investigación

- Entrenamiento

\footnotetext{
3 Joomla es un sistema de administración de contenidos web, de código abierto. Es un software libre, que no paga licenciamiento y se basa en herramientas que no generan costos de licencias. Desde alli se puede diseñar y organizar el sitio, publicar contenidos, implementar nuevas funcionalidades (galerias de imágenes, foros), administrar usuarios jerárquicamente, levantar estadistica de visitas, encuestas, etc. En definitiva permite colocar herramientas para trabajo cooperativo y colaborativo planteadas en la tesis,
} 
La CVA nace con la idea de realizar trabajos de tipo cooperativos y colaborativos entre instalaciones nucleares, centros educativos (como los institutos de la Comisión Nacional de Energia Atómica), universidades nacionales y extranjeras (fundamentalmente de América Latina), servicios de medicina nuclear nacional y regional y otras reparticiones nacionales e intemacionales (Organismo Internacional de Energia Atómica, Ministerio de Educación). Por otra parte está en marcha la "Propuesta de Alfabetización Cientifica y Tecnológica" entre la Facultad de Ciencias Exactas, Fisicas y Naturales de la Universidad Nacional de Córdoba y el Ministerio de Ciencia y Tecnología de la Provincia, desde donde se trabaja con establecimientos educativos que promueven los usos de TICs como potenciadores de los procesos de aprendizaje. En este sentido, contar con este espacio permitiria establecer vínculos de trabajo, comunicación y acercamiento a lugares distantes.

Una de las lineas estratégicas del desarrollo de la CVA es la experiencia adquirida en el diseño y desarrollo de cursos a distancia utilizando EVEAs, y en trabajos de investigación desde grupos conformados en Internet. Como consecuencia de esas actividades se logró cierta capacitación en el uso de recursos tecnológicos, la incorporación de un lenguaje común entre los participantes, un discurso unificado en cuanto a los aspectos pedagógicos caracteristicos de la formación virtual, y un espacio de interacción para aportar conocimientos y experiencia.

También surgió la inquietud de mejorar la forma de trabajo potenciando los recursos humanos y tecnológicos disponibles, teniendo la oportunidad de converger en un sitio con identidad propia, con material educativo innovador, y con espacios que promuevan las comunicaciones y vinculaciones necesarias para el debate $y$ el fortalecimiento de los lazos existentes, aunando los diferentes sectores y herramientas disponibles hasta el momento.

\subsection{Descripción de la CVA propuesta}

La CVA propuesta es una comunidad centrada en temas nucleares, que se desarrolla en un entomo virtual dentro de un espacio propio del grupo de trabajo Reactor Nuclear RA-0. De acuerdo a las normas de funcionamiento se debe solicitar autorización para suscribirse en los cursos o proyectos; y existe un control sobre las intervenciones, y

tendientes a mejorar las interacciones y favorecer el proceso compartido y conjunto del aprendizaje. unw.joomla.org.ar 
formas de participación de algunos sectores de la CVA, por ejemplo, en la parte de capacitación o trabajos de investigación.

La asignación de los miembros es voluntaria y su función es la de distribuir y compartir experiencias, conocimientos, material de estudio, documentos. Hay diferentes roles entre los participantes según se menciona en el punto 3.3.2 en función de la actividad que se esté desarrollando.

Un coordinador general del espacio virtual es encargado de organizar la CVA, pautar el cronograma de actividades, asignar roles y mantener reuniones periódicas para evaluar el funcionamiento y logro de los objetivos generales. Existe también un coordinador para cada uno de los pilares de la CVA: capacitación, investigación y desarrollo. Cada uno de ellos puede a su vez proponer a sus colaboradores y generar metodologias para llevar adelante los objetivos propuestos. Se dispone de un encargado de analizar y organizar los materiales y enlaces que se publican libremente dentro de la CVA, de manera tal de garantizar cierta calidad en este sentido.

Finalmente, se cuenta (inicialmente) con un administrador técnico encargado del manejo del software, de incluir nuevos recursos tecnológicos en base a la demanda, y realizar actualizaciones, modificaciones y asistir técnicamente a los miembros.

\subsection{Objetivo de la CVA}

La CVA está centrada en el aprendizaje de temas sobre reactores nucleares y manejo de radioisótopos, ya sea a través del dictado de cursos y participación en foros de debate, como asi también en la realización de actividades de investigación y desarrollo, desde subgrupos que se conforman dentro de la CVA. Esos subgrupos pueden estar orientados a las actividades que se vienen desarrollando hasta el momento (independientemente de la CVA), como investigación, aplicaciones tecnológicas, entrenamiento en reactores; o surgir de otras propuestas a partir de necesidades o inquietudes del momento.

Como se menciona en el punto 3.1, la CVA permite la participación desde puntos remotos, lo que facilita la incorporación de profesionales de nivel académico, sin necesidad de trasladarse.

El contar con la CVA brinda un respaldo intelectual al cual acudir a la hora de consultar sobre temas de interés, pedir opinión o sugerencias para afrontar determinadas actividades, y fundamentalmente, para realizar transferencia de experiencias con personas que están trabajando en proyectos afines. 
Como se menciona en los capitulos anteriores, ese espacio comunitario permite poner a disposición, material de estudio tales como objetos de aprendizaje, videos explicativos, autoevaluaciones, simuladores y cualquier otro recurso que surja a partir de los grupos de trabajo que faciliten los procesos de aprendizaje de los miembros.

\subsection{Los integrantes de la CVA}

Entre los integrantes de la CVA se encuentran aquellos grupos con los que se viene trabajando desde hace varios años, tal como se indica en capitulos precedentes, que están conformados por docentes e investigadores de varias universidades del pais; profesionales de la salud que utilizan radioisótopos o radiaciones, persona de otras instituciones que desarrollan actividades referidas a tecnologia y aplicaciones nucleares. Esas personas fueron en su momento invitadas a participar en proyectos afines. A partir de la CVA pueden trabajar desde un espacio virtual especifico, y la admisión dependerá del tipo de actividad. Asi por ejemplo, si una persona va a trabajar en un proyecto de investigación, ingresa al grupo correspondiente y pide ser admitido. El coordinador acepta esa admisión, y a partir de alli obtiene una clave de acceso al subsitio correspondiente a proyectos. A su vez, cada grupo de trabajo dispone de un coordinador encargado de mantener activa la participación y publicar los resultados finales.

En caso de alumnos que deseen tomar un curso, desde la CVA pueden optar por las propuestas en marcha y solicitar la inscripción al mismo. En esa situación, es el responsable del curso el encargado de admitirlo en base a la reglamentación para esa instancia especifica de capacitación. Algunos serán cursos dirigidos a profesionales que necesitan la licencia para el manejo de radioisótopos, donde el cupo es limitado y tienen prioridad quienes estén trabajando bajo la dirección de un supervisor.

En los espacios abiertos a toda la comunidad, como sala de chat no es necesario solicitar admisión, simplemente pueden expresar su opinión o realizar consultas y el resto de la comunidad responder o aportar conocimientos.

Si un extemo está interesado en pertenecer a la CVA puede registrarse a través de un formulario disponible, y a partir de alli el coordinador le indica los pasos a seguir. Este punto se describe en 4.6.1.

La asignación de roles la hace el coordinador general de la CVA asesorado por profesionales del grupo del Reactor Nuclear RA-0, desde donde funciona la comunidad. 


\subsection{Diseño general de la CVA}

En esta sección se presenta el diseño macro del espacio virtual para la CVA, en base a un diagrama general que ilustra las secciones disponibles, y una descripción de cada una de ellas.

La CVA está conformada por un espacio de información general y cuatro secciones principales integradas todas en un mismo entorno, que se detallan en el siguiente gráfico:

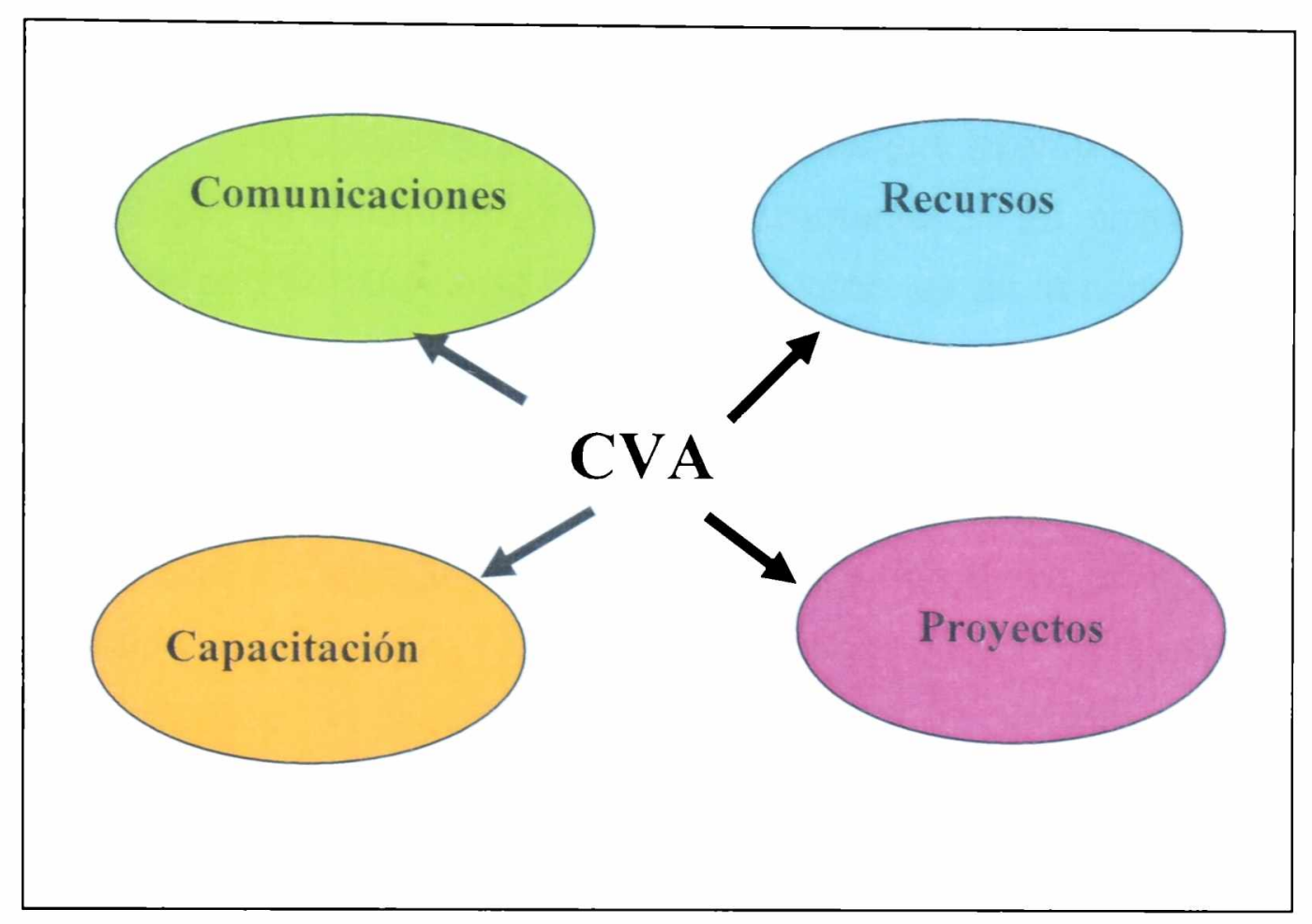

Figura 17. Gráfico general de la CVA

La parte central de la CVA contiene información general de la comunidad tales como: "Nuestra CVA", "Objetivos", "Integrantes", "Coordinadores", "Noticias", "Instituciones", "Registro", "Calendario" y "Servicios".

La sección "Comunicaciones" contiene un espacio destinado establecer vínculos entre los miembros de la comunidad: chat, mensajería interna y foro.

Para disponer de material de estudio y acceder a la base de datos de recursos, está la sección "Recursos" que contiene los siguientes segmentos: "Educativos", "Publicaciones" y "Enlaces".

Para las actividades de enseñanza y aprendizaje que se desarrollan, está disponible el espacio "Capacitación" que se vincula al EVEA Moodle, dentro de la cual se configuran sitios de comunicación para llevar a cabo las actividades de aprendizaje basadas en la interacción (wikis, foros, espacios de trabajo) y otra de comunicación 
social, para intercambiar mensajes entre los participantes (chat); y uno con información general (calendario, participantes). Esos son los recursos mínimos con los que cuenta el EVEA para garantizar la cooperación y colaboración en el aprendizaje, sin embargo, cada curso puede incorporar otros según las necesidades o la diagramación de los contenidos.

Finalmente, en la sección "Proyectos" se presentan vinculaciones a grupos Google para "Investigación", "Desarrollos Tecnológicos" y "Discusión”. Este último como herramienta de comunicación para tratar temas en particular dentro de grupos privados que no forman parte de los antes mencionados.

Es decir, la CVA tiene espacios públicos para todos sus miembros y otros privados para los subgrupos que trabajan más especificamente en un proyecto o actividad particular. Luego podrán publicarse resultados o informes en la sección de recursos, para que queden disponibles para todos los miembros. El coordinador podrá asistir a los miembros en la forma y organización de las publicaciones.

A continuación se muestra un diagrama del sitio que la alberga con cada uno de los espacios mencionados, y seguidamente se presenta una breve justificación de cada una de las cuatro secciones, en base a lo expresado a lo largo de la tesis. Lo referido a "Información General" se describe en el punto 4.6.1.: 


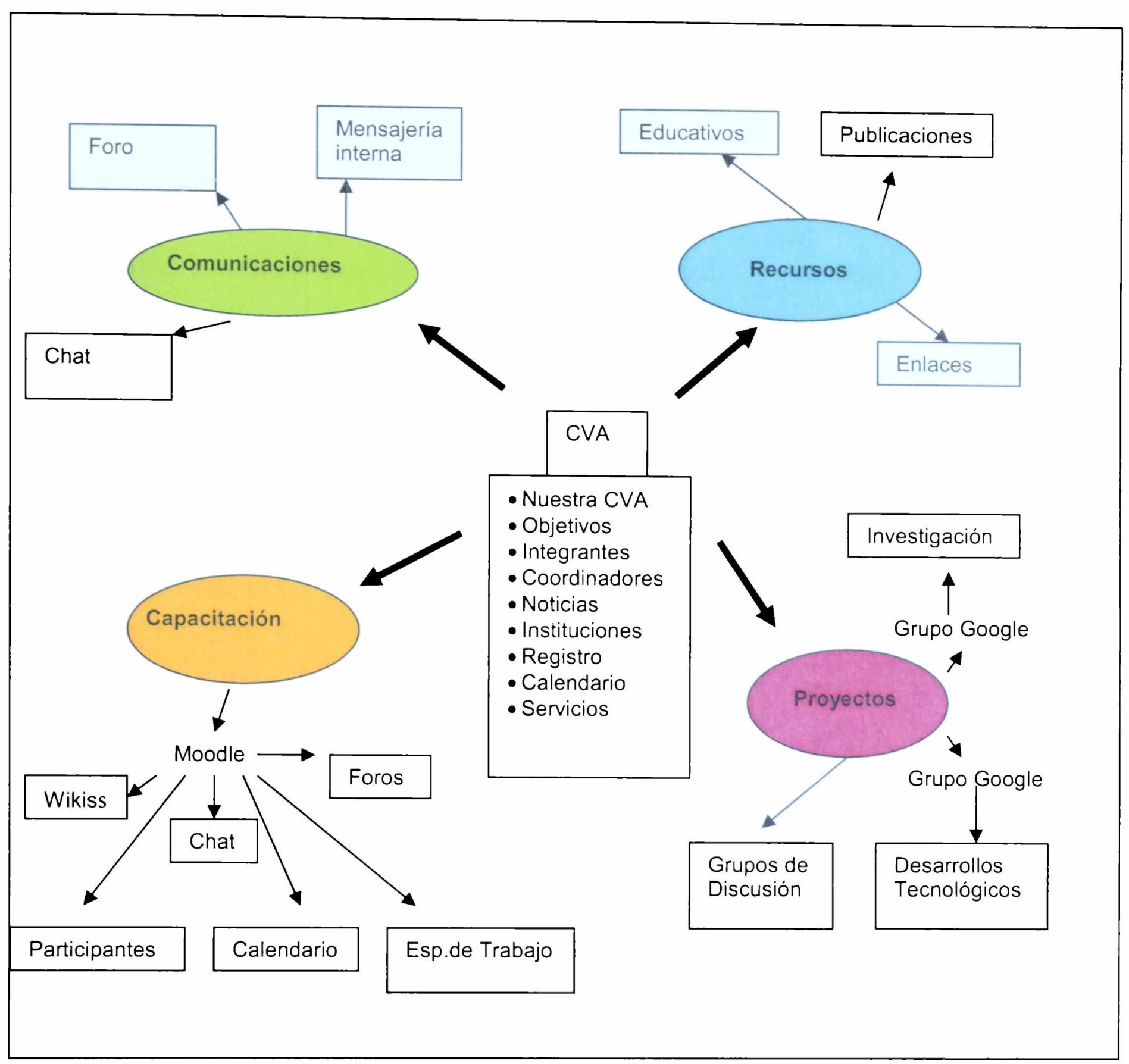

Figura 18. Diagrama detallado de la CVA

\subsubsection{Comunicaciones}

Como se menciona en el marco teórico, Capítulo 2.5 en las CVA se trabaja a partir de vínculos preestablecidos, donde es importante generar sentido de pertenencia personalizando las relaciones.

Una comunidad se define en términos de comunicación, donde se comparte e intercambia información. Como ya hemos aclarado, comunicación viene del latín comunis (común) o de comunicarse (establecer una comunidad), y al hacerlo mediante redes telemáticas se está hablando de comunidades virtuales (Salinas, 2003). 
Como señala Chemy (1999), el sentimiento de comunidad es esencial en la vida de las comunidades virtuales, ya que éstas requieren algo más que el mero acto de conexión; la clave está en la interacción humana a través de computadoras.

\subsubsection{Recursos}

La sección recursos se refiere a aquellos de tipo educativo y tecnológico, donde se encuentran diferentes opciones de material para promover el aprendizaje, tales como objetos de aprendizaje, videos, simulaciones, laboratorios, como asi también un listado de programas para elaborarlos.

En una comunidad virtual de aprendizaje, la participación e intercambio de información dependen, entre otras cosas, del contenido relevante disponible entre los miembros (Pazos, Pérez Garcias y Salinas, 2001).

Ese material educativo sirve para potenciar el conocimiento, utilizando recursos multimedia que faciliten la comprensión. Estos recursos estarán a disposición de todos los interesados. Estos pueden ser el resultado de trabajos dentro de la comunidad como los que se pueden dar en investigación, desarrollo y capacitación.

\subsubsection{Proyectos}

Según lo desarrollado en el Capitulo 1.3, aprender colaborativamente potencia el aprendizaje al intercambiar conocimientos entre pares. Para ello, es importante conformar grupos de trabajo heterogéneos.

La finalidad entonces de esta sección, es crear un espacio donde colectivos con el mismo perfil científico o académico, de diferentes organizaciones, puedan llevar a cabo trabajos en común. Promover y facilitar la colaboración en proyectos conjuntos de investigación, producción, desarrollo tecnológico e innovación, relacionados a temas nucleares. Esto potencia además, parte del trabajo que ya se venía realizando en espacios virtuales.

\subsubsection{Capacitación}

La capacitación es uno de los ejes fundamentales de la Comunidad Virtual de Aprendizaje y se implementa a partir de tres ejes: 
- Institucional: tiene en cuenta la organización dentro de las instituciones (facultad, universidad), administración, planificación de acuerdo a las políticas del ministerio de educación y cumplimiento de normas y reglamentos.

- Educativo: provee las bases teóricas y metodológicas necesarias para la capacitación, como teorias de aprendizaje, modelos de enseñanza y aprendizaje, enfoques sobre el aprendizaje (Capitulo 1.3).

- Tecnológico: referido a las herramientas con las cuales se median esos procesos educativos.

Dado que la CVA que se propone está dentro de un ámbito educativo, es necesario contar con un espacio flexible en cuanto a horarios, con contenidos actualizados, proyección nacional e intemacional, aprovechando los avances en tecnologia educativa, y siendo soporte de los procesos de construcción del conocimiento y trabajo colaborativo.

Las propuestas de capacitación y actualización dentro de una CVA permiten descubrir nuevos entornos de trabajo y enriquecimiento personal y profesional.

La experiencia con la que se cuenta hasta el momento, que sirve de base para fundamentar la capacidad de organizar y desarrollar esta sección, son los cursos, seminarios, talleres de reentrenamiento, y demás actividades que se desarrollan desde el Reactor Nuclear RA-0 de las cuales se mencionan algunas:

\section{1) Capacitaciones de Posgrado}

- Fisica Nuclear y Protección Radiológica Para Instalaciones Radiactivas

- Capacitación y Entrenamiento para Ingresantes a la Centrales Nucleares

- Metodología y Aplicación de Radionucleidos

- Actualización Profesional en Protección Radiológica

- Seminario Operativo en Emergencias Radiológicas

- Ingeniería de Reactores Nucleares de Investigación

- Radiofármacos en Diagnóstico, Terapia e Investigación

- Fundamentos y Aplicación de los Radionucleidos

- Curso de Formación Complementaria para Personal de Ciclotrones 


\section{2) Capacitaciones de grado y de divulgación}

- Energia y Medio Ambiente, La Alternativa Nuclear

- Usos Pacificos de la Energía Nuclear

- Ciclo de Conferencias sobre Radioisótopos y Radiaciones

A su vez se realiza transferencia de conocimientos en cuanto a organización y dictado de cursos a otras instituciones, como Reactor Nuclear RA-4 de Rosario, Universidad Tecnológica Nacional de San Rafael Mendoza, y carrera de Producción de Bioimágenes de la UNC. Contar con un espacio virtual de gestión del conocimiento facilita el aprendizaje colaborativo y cooperativo en las actividades descriptas.

\subsection{Descripción de las vinculaciones ubicadas dentro de cada sección principal de la CVA}

A continuación se detallan los principales espacios de cada una de las secciones descriptas. De esta manera queda conformado un modelo de CVA con los recursos tecnológicos disponibles hasta el momento.

La selección de esos espacios se basa en la capacidad para amplificar las posibilidades de seguimiento por parte de los participantes, de los procesos interactivos que se desarrollan en el contexto de la CVA (Onrubia, Cooll, Engel, Mauri y Rochera, 2004), el intercambio y la comunicación entre sus miembros, y la necesidad de lograr objetivos de aprendizaje propios de este tipo de comunidad.

\subsubsection{Información General}

Al margen de las cuatro secciones descriptas y que se completan con los respectivos recursos en el punto siguiente, se encuentra un espacio de información general, conteniendo:

- Nuestra CVA: aqui hay una breve explicación sobre la historia de la comunidad, cómo surge la idea, necesidades y expectativas.

- Objetivos: se especifican los objetivos de la CVA.

- Integrantes: se muestra la información de la base de datos de todos los integrantes de la comunidad, visitantes y colaboradores, con una foto, un breve curriculum y datos personales para poder establecer comunicación (teléfono, mail, 
etc.). Asi se puede contar con ellos de manera rápida y eficaz a la vez que acceder a sus páginas personales.

- Coordinadores: se indica nombre, profesión y actividad de los coordinadores divididos por áreas. Alli se dispone de un foro donde pueden interactuar los coordinadores entre si, tal como se detalla en 4.7

- Noticias: se dispone de un notiweb que es un boletín de información que recoge diariamente las noticias más relevantes sobre ciencia e investigación vinculadas a la temática principal de la CVA.

- Instituciones participantes: se detallan las instituciones que auspician y colaboran en la comunidad.

- Registro: aquí se encuentra disponible un formulario para los usuarios, donde se especifica el nombre, e-mail, profesión, etc. Luego de completado se envia por mail una llave de acceso, si correspondiera, para el ingreso a los espacios privados de la comunidad, dependiendo si se va a participar en un curso o en un proyecto en particular.

- Calendario: este es un espacio con información sobre fechas de eventos, actividades, cursos, reuniones y encuentros. En base al calendario, los posibles interesados se registran para comenzar a participar.

- Servicios: incluye un listado de los servicios que se prestan en las instalaciones nucleares, como irradiación, mediciones, calibraciones. y datos sobre cada uno de los lugares para poder contactarlos.

\subsubsection{Comunicaciones}

Los espacios aqui disponibles son de uso general, dado que cada grupo de trabajo cuenta con un sector particular para la comunicación. Por ejemplo, los participantes de un curso se comunican a través de los espacios asignados en Moodle; los del grupo de investigación por el canal abierto en Google (Cedsan_ar).

Las herramientas de uso general para todos los miembros de la CVA (descriptas en 3.2.3) son:

- Chat: la finalidad es contar con un espacio para realizar reuniones virtuales en tiempo real. La hora y día de reunión se anuncia en el calendario que se encuentra en Información General. 
- Mensajeria interna: desde alli se envia un mensaje que será respondido por el coordinador.

- Foro: para realizar comunicaciones asincrónicas. Hay un foro dentro del espacio "La Comunidad" que está planificado para la evaluación de la CVA, entre otras cosas, según se detalla en el capitulo 5.4.

\subsubsection{Recursos}

Esta sección está dividida por tipo de contenido en:

- Recursos Educativos: se clasifican por temas; por ejemplo Fisica Nuclear que sirve de base para todos los otros abordados en esta CVA, referida a temas nucleares. Para ese tema se dispone de recursos educativos para facilitar el aprendizaje a través de estimulaciones multisensoriales. Estos pueden ser Applets educativos seleccionados en Internet o de desarrollo propio. A modo de ejemplo puede consultarse la página correspondiente a Física III http://www.efn.unc.edu.ar/secretarias/extension/PagWebF3/ donde se estuvo ensayando el uso de los mismos; o los que a continuación se muestran, que fueron elaborados con Exelearning, y se utilizan en el dictado de cursos a distancia.

El primero refiere a conocimientos generales en temas nucleares, cuenta con una parte teórica y un video explicativo; el segundo es un simulador de una central nuclear. Estos recursos de aprendizaje contienen varias páginas cada uno pero aqui solo se muestran dos de ellas:

\section{Primer ejemplo}

Se presentan dos páginas a continuación en las figuras, la de presentación y la que contiene un video. 


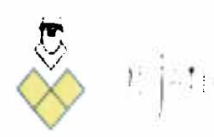

Figura 19. Imagen del material de aprendizaje diseñado para conceptos generales de Fisica Nuclear

\section{Fisión del Uranio 235}

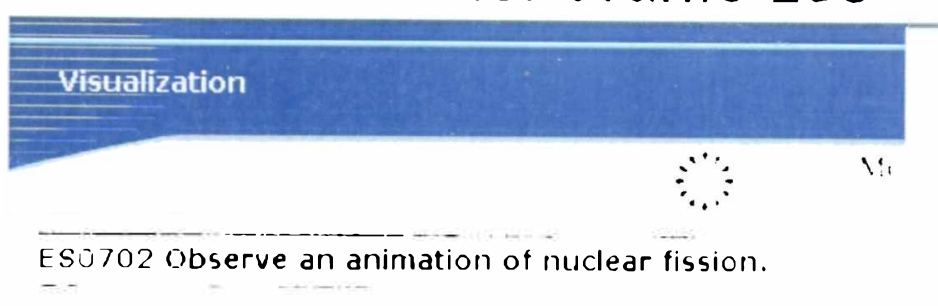

[]

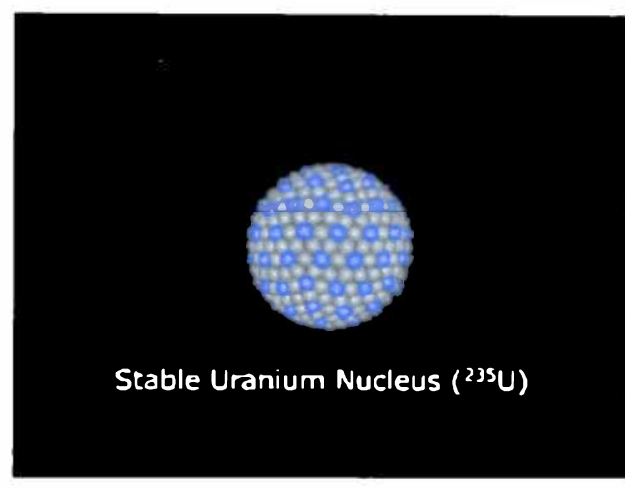

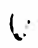

A stoble arom at

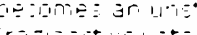

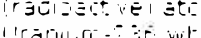

nesto, The nL.

ur: $=-3$ and $11-25$

ar

- 1 g-

at 5 .w. loghtom ale

促

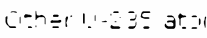

the rieuraristh

in the reartior t

un:ave aton:

muncers of urist.

exper ence fisilg

ary i=Ltrarsar resutribla a $t_{1}$

¿อnกife, L.ounu: TEF.

Figura 20. Imagen de material de aprendizaje que presenta un video explicativo

\section{Segundo Ejemplo}

Presentación de un simulador de funcionamiento de una planta nuclear, donde se pueden tomar acciones sobre lo que se está ejecutando a fin de observar los fenómenos producidos como consecuencia de ello. Se muestran dos páginas, la de presentación y la que contiene el simulador. 


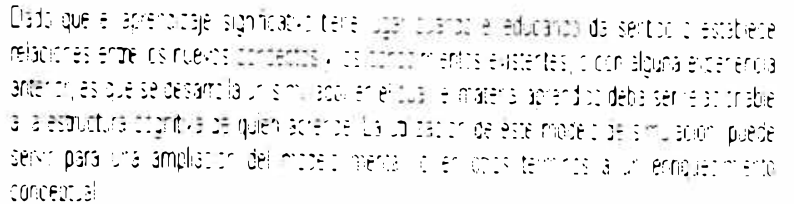
carcerta:

Figura 21. Imagen de un material de aprendizaje que presenta un proyecto de simulación

\section{El Simulador}

b

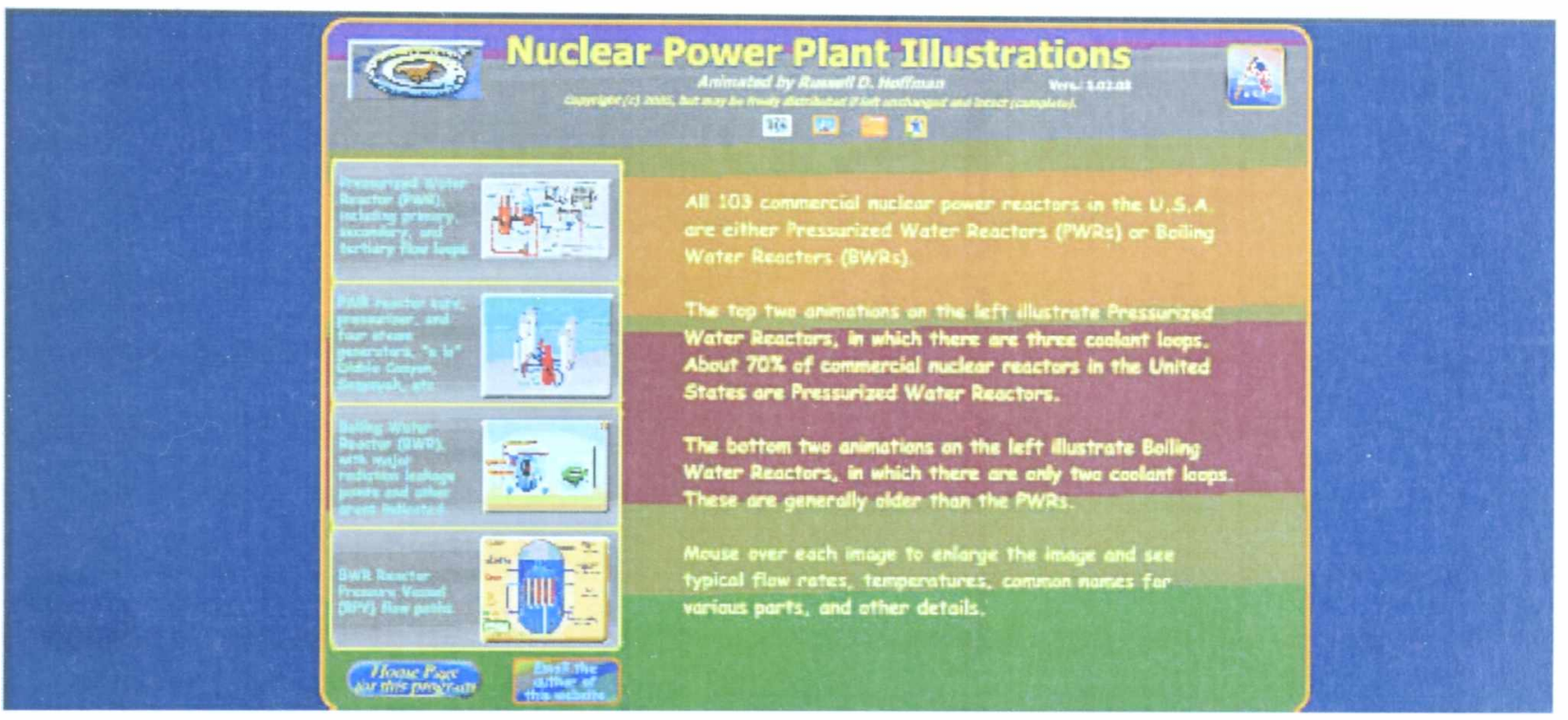

Figura 22. Imagen de un material de aprendizaje que muestra la simulación de una planta nuclear

En esta sección también se encuentra un listado de sitios para descargar software para la elaboración de material educativo: mapas conceptuales, objetos de aprendizaje, tutoriales.

- Publicaciones: la finalidad de esta sección es colocar a disposición de los interesados, las publicaciones referidas a los temas de interés, y ofrecer un espacio para escribir y publicar entre varios autores. En nuestra experiencia encontramos la necesidad de difundir los proyectos de investigación o desarrollo tecnológico que se realizan con otros sectores o instituciones, para lo cual es de 
gran utilidad contar con un sitio que contenga la documentación necesaria, y donde se puedan colocar los informes, manuales, documentación técnica, como asi también los trabajos realizados como parte de los cursos.

- Enlaces: sitio que se construye con el aporte de los miembros de la CVA, en base a los intereses comunes. Como punto de partida, se anexa un listado de portales referidos a temas nucleares centrados en los usos pacificos de la energía nuclear, y a los cuales se pueden agregar otros.

Los miembros de la comunidad que participan en proyectos, pueden subir enlaces y materiales; el resto puede enviar propuestas a los coordinadores. El administrador técnico se encarga de mantener actualizados estos enlaces, y los coordinadores que la información sea pertinente.

\subsubsection{Capacitación}

Esta sección está vinculada a una instalación de Moodle ya disponible. Una vez alli, se puede observar el listado de cursos desde donde se selecciona el que se esté por dictar. Para ello, previamente solicitan la inscripción a través de "Información General", "Registro". En caso que ya esté registrada la persona, sólo debe inscribirse al curso correspondiente. Dependiendo del tipo de curso, son los recursos que se utilicen; que es común a todos, es la metodología vinculada al trabajo colaborativo y cooperativo, y las comunicaciones fluidas entre los participantes y los coordinadores o tutores. Para ello se dispone de herramientas para la gestión del conocimiento. A continuación se presenta un listado de los principales recursos disponibles en todos los cursos:

- Participantes: este es uno de los tópicos fundamentales para trabajar en grupo pues alli figura la lista de tutores y alumnos con información personal.

- Calendario: lugar donde figuran los eventos propios del curso, plazo de entrega de trabajos, exámenes.

- Espacio de trabajo: se vuelcan las consignas, objetivos, modalidad y el vínculo para subir los trabajos realizados. Desde alli se hacen las devoluciones con comentarios y calificaciones.

- Foros: como herramienta que permite la comunicación, cooperación, coordinación de miembros del grupo o la solución de problemas entre personas que trabajan en un objetivo común. Se basa en la comunicación a través de aplicaciones asincrónicas y en la posibilidad de compartir archivos en varios formatos. 
- Wikis: son recursos especificos para el trabajo colaborativo. Funcionan como editores multiusuarios.

- Chat: Moodle permite habilitar sala de chat para una comunicación sincrónica entre los participantes. Es una herramienta que se aprovecha de diferentes maneras dependiendo de la modalidad del curso.

\subsubsection{Proyectos}

Los proyectos de investigación y desarrollo tecnológico forman parte de las actividades del Reactor Nuclear RA-0, y por ello, surge la necesidad de contar con un espacio que propicie el trabajo en equipo, facilite la sinergia entre sectores económicos y cientificos, públicos y privados, y ofrezca tecnologia innovadora a las empresas que deseen incorporarlas en sus productos o procesos.

Ahora bien, para llegar a resultados concretos en los plazos establecidos son importantes las delimitaciones y distribuciones de funciones y actividades (Castillo, 2000), como asignar responsabilidades de dirección, coordinación, ejecución de tareas. Un espacio destinado a esa organización facilita los procesos de trabajo, teniendo en cuenta lo expresado por Lucero (2003): "Cada miembro del grupo debe asumir integramente su tarea y además, tener los espacios para compartirla con el grupo y recibir sus contribuciones".

Dentro de la sección "Proyectos" se incluyen los siguientes espacios:

- Investigación: ya hay un prototipo en funcionamiento para un proyecto de investigación, contando con recursos disponibles en Internet como es la sección "Grupos" dentro de Google. Partiendo de la página del Reactor $\rightarrow$ CVA $\rightarrow$ "Proyectos", se establece un enlace a la página de Google, se coloca usuario y contraseña. Una vez que se ha ingresado, se selecciona el grupo de trabajo que en este caso es Cedsan_ar. La idea es que los proyectos similares se trabajen desde un mismo grupo. Se ampliará esta sección de Investigación a medida que surjan otros nuevos.

- Desarrollo Tecnológico: la finalidad es lograr un lugar donde converjan y desde donde trabajen los grupos interesados en desarrollos tecnológicos, ya sea realizando propuestas, consultas, como solicitando colaboración o asesoramiento. Se utiliza el mismo recurso que en investigación, es decir grupos conformados en Google, dado que es lo que se venia utilizando (resulta entonces un buen punto de 
partida) y dispone de recursos para la comunicación como es el caso del denominado "Debates", crear y editar "Páginas", cargar "Archivos". El grupo que alli funciona se denomina Tecnodes.

- Grupos de Discusión: es un sitio disponible para debatir temas de actualidad, entre los integrantes de la comunidad. Un ejemplo de utilización del espacio es convocar a especialistas de diferentes profesiones para abordar la problemática de la "Mineria a cielo abierto". Luego se elabora un informe para su difusión en distintos medios, y en el sector de recursos de la CVA. . En un futuro se realizará por videoconferencia.

\subsection{Interacción en la CVA}

La interacción y participación entre los miembros de la CVA puede ser sincrónica o asincrónica. A fin de fomentar el debate, la discusión entre los miembros, el intercambio científico y tecnológico. Para ello se cuenta con una sala de chat dentro del sector "Comunicación", o foros ubicados dentro de espacios de "Capacitación" para tratar temas referidos a un determinado curso. La mensajería disponible en "Comunicaciones" dentro de la CVA puede facilitar la comunicación interpersonal afianzando los vínculos. Este sistema de comunicación permite el intercambio de contenidos o la realización de consultas personalizadas.

Por otra parte, los coordinadores y administrador técnico, como parte del grupo gestor de la CVA, cuentan con un espacio propio para generar una dinámica de interacción entre ellos volcando sugerencias, comentarios y analizando el funcionamiento y fortalecimiento de la comunidad. Ese espacio es un foro dentro de "Coordinadores" en el sector general "CVA", destinado sólo a evaluar los avances o retrocesos en los objetivos propuestos. De esta manera, se pretende garantizar el aprendizaje dentro de la comunidad a partir de análisis periódicos por parte de quienes están próximos a medir los logros alcanzados como asi también verificar el cumplimiento por parte de los coordinadores, de publicar las noticias, agregar archivos, documentos, manuales o todo aquello que se genere en los grupos de trabajo.

Con la finalidad de asegurar procesos de aprendizaje, al concluir los cursos los responsables pueden poner a disposición de la comunidad, los documentos o trabajos generados, dentro de "Publicaciones" en el sector "Recursos". De esa manera, se ampliará la participación a toda la comunidad. También alli, estará la memoria colectiva de los grupos de trabajo, tanto en investigación como desarrollo tecnológico, 
y otros que surjan eventualmente. Estos últimos serán vertidos por el coordinador de cada grupo de trabajo.

De esta manera, el conocimiento que se genera a través de las distintas formas de trabajo y de los grupos involucrados, estará disponible a toda la comunidad en los sitios descriptos. No obstante, para garantizar la llegada a todos sus miembros, se confecciona una memoria anual con una descripción de cada uno de los principales documentos y la respectiva vía de acceso (link), donde se puede ingresar para ampliar la información. La misma tiene un espacio previsto en la sección "Publicaciones".

\subsection{Implementación de un primer prototipo de CVA}

Tal como se menciona al inicio del capitulo, el prototipo se está implementando en base al diseño propuesto, dentro de www.ra0.efn.uncor.edui perteneciente al Reactor Nuclear RA-0.

Como se observa en la siguiente imagen en la presentación general del sitio se encuentra un link a la CVA.

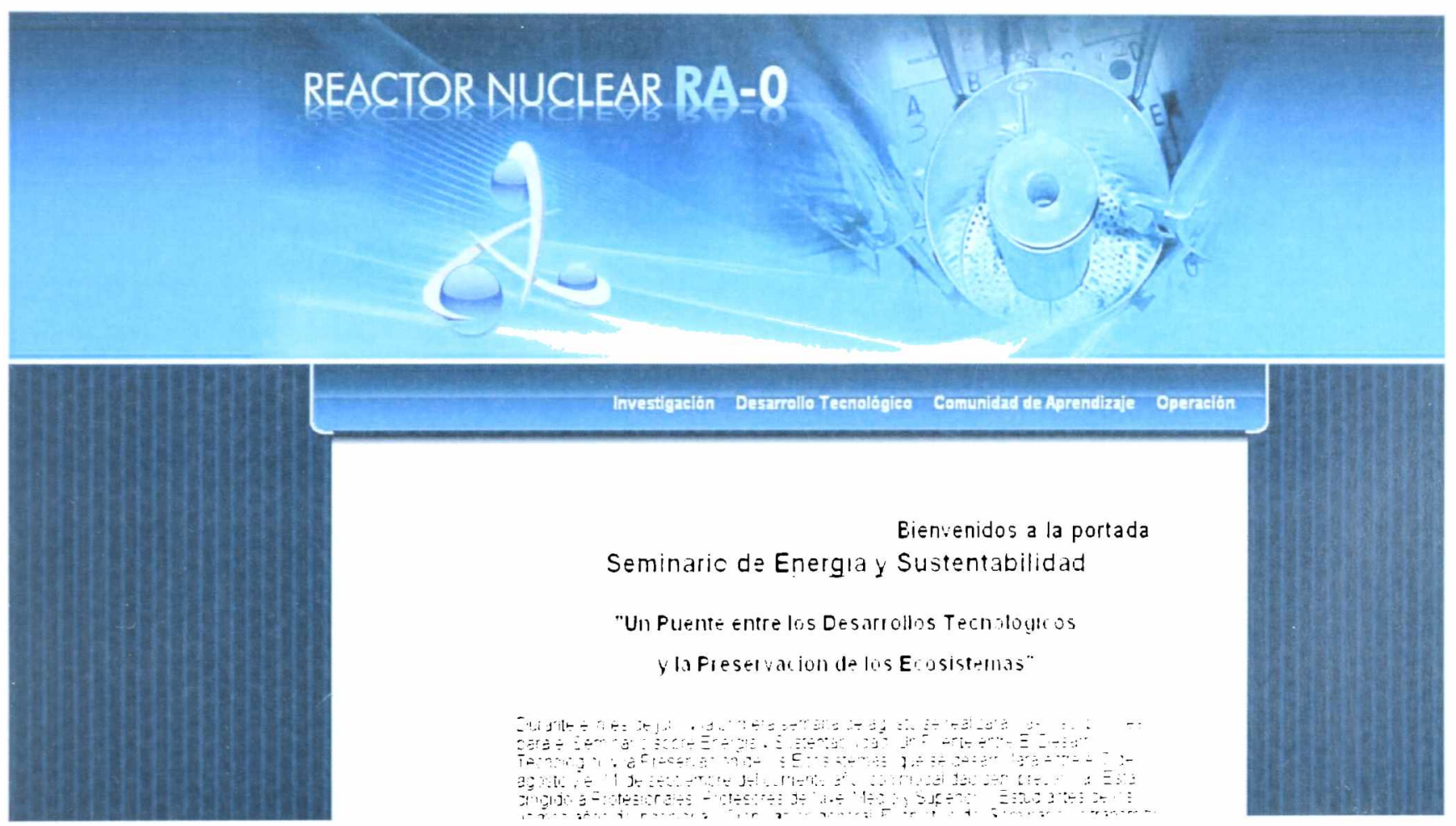

Figura 23. Imagen de la página del Reactor Nuclear donde se encuentra la CVA

Dentro de la CVA los espacios propios son los que corresponde a la parte superior, que contiene los cuatro sectores principales, y la inferior con información general de la comunidad. 


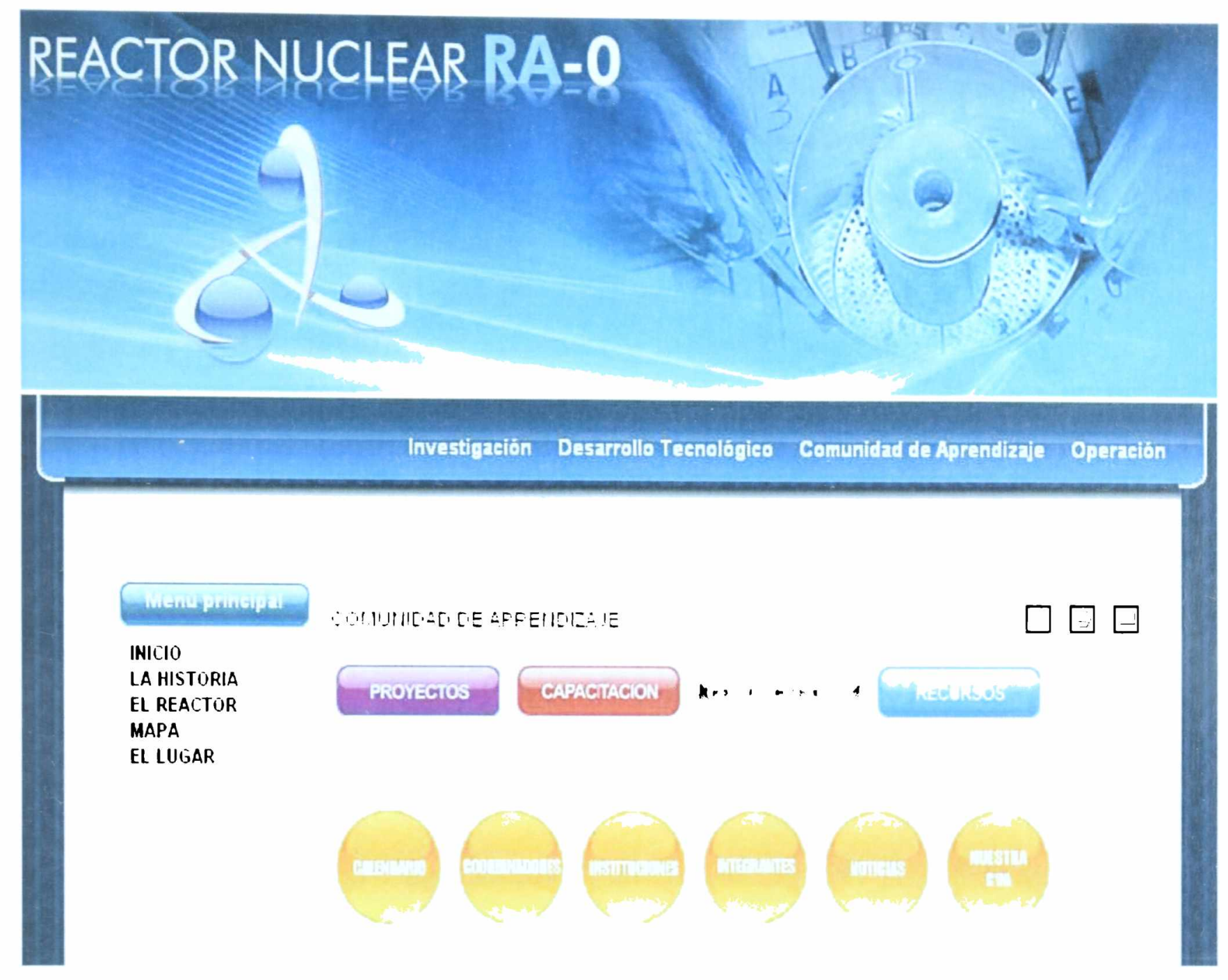

Figura 24. Imagen de la CVA

A continuación se hace una descripción de cada uno de ellos, los cuales siguen el diseño propuesto.

\subsubsection{Espacio de información general}

Esta sección cuenta con todos los recursos descriptos en el diseño: "Nuestra CVA", "Objetivos", "Integrantes", "Coordinadores", "Noticias", "Instituciones", "Registro", "Calendario" y "Servicios".

Toda la información contenida en esta parte central, está disponible para cualquier persona que ingrese a visitar la página del Reactor Nuclear. No hay privacidad en ninguno de los puntos pues la finalidad es despertar interés en los visitantes sobre las actividades que se desarrollan en la CVA.

El calendario anuncia los próximos eventos en los que se espera participación de la comunidad y del público en general.

En instituciones se encuentran los vínculos con páginas de los principales organismos nacionales e internacionales vinculados con la temática. 
Estos espacios son flexibles pues se pueden modificar en función de las condiciones nuevas que se presenten. Por ejemplo, al comienzo de un año pueden cambiar los coordinadores, el calendario, o incluso se pueden incorporar nuevos servicios a las instalaciones nucleares, los que deben reflejarse erı la sección "Servicios", para información de posibles participantes o interesados.

Esa es una ventaja para afrontar cambios que pudieran surgir en la dinámica, objetivos y roles de la CVA.

\subsubsection{Espacio principal}

Bajo esta denominación se engloban las cuatro secciones generales que se mencionan en 4.5. Cada una de ellas persigue objetivos diferentes, pero todas contienen herramientas que facilitan el intercambio de información y la colaboración entre los miembros de la comunidad. Aqui se combinan espacios privados para los miembros de la CVA (capacitación, proyectos) y otros abiertos (recursos, comunicaciones).

La primera sección es "Capacitación" que se vincula con el EVEA Moodle, desde donde se accede a diferentes cursos. Para ingresar a cada uno de ellos debe solicitarse la inscripción al mismo. Cada propuesta de capacitación, dentro del EVEA, está estructurada con herramientas que pueden favorecer el trabajo colaborativo como foros, posibilidad de compartir archivos, wikis, chats. En cada una hay un tutor que autoriza las inscripciones, y junto con el profesor designado para cada curso, diagrama el aula virtual y usa en base a su propuesta los recursos disponibles en el entorno tecnológico. También se encarga de hacer el seguimiento de los alumnos y estimular la participación. Tanto docentes como estudiantes tienen distintos roles dentro del EVEA, y la asignación la hace el tutor dependiendo del curso.

La segunda es la sección correspondiente a "Proyectos" donde se encuentran los link a "Investigación", "Desarrollo" y "Grupos de discusión" tal como se explica en el diseño de la CVA. Para ingresar los integrantes tienen una clave de acceso. Una vez alli, se dispone de herramientas de comunicación sincrónica y asincrónica para trabajar en el marco de cada proyecto. Cada uno de esos espacios tiene un coordinador encargado de distribuir el material, incentivar la participación, asignar tareas, solicitar información, verificar el cumplimiento del cronograma de trabajo y la publicación de los resultados. El tercer punto corresponde a "Recursos", destinado a colocar objetos de aprendizaje, juegos educativos, laboratorios virtuales, software educativo, simuladores, documentos, material de estudio, direcciones de interés, videos explicativos e 
información que surja de los trabajos realizados dentro de la CVA. Es un espacio libre, sin restricciones y de fácil acceso para los usuarios. Los enlaces dispuestos alli son de tipo general; algunos refieren a temas nucleares, otros ambientales, de investigación, energía, usos pacificos de la energia nuclear, comunidades nacionales e internacionales. Como ya se mencionó anteriormente, el administrador técnico se encarga de actualizar los enlaces. También tiene la responsabilidad de deshabilitar alguno que se considere inapropiado por parte de los coordinadores de la CVA, de manera tal de que exista un cierto control de calidad de los materiales publicados.

Finalmente la sección "Comunicaciones" posibilita contactarse con el coordinador de la CVA, enviar mensajes solicitando información o admisión a alguno de los sitios. La finalidad es contar con un espacio donde interesados externos puedan presentarse a partir de sus experiencias formativas y profesionales para integrar grupos o realizar cursos.

Este primer prototipo de CVA buscará contar con un diseño tecnológico flexible que apoye las siguientes acciones:

- Conformación de grupos de trabajo en base a las necesidades o propuestas que surjan.

- Interacción y comunicación entre usuarios como forma de aportar visión y experiencia.

- Contribución desde los diferentes campos del conocimiento a la resolución de dificultades que puedan surgir.

- Análisis de las líneas de actuación de proyectos de manera colaborativa para perfilar y mejorar las futuras lineas de trabajo.

- Fomento de la elaboración de protocolos de actuación y proyectos que surjan, a fin de producir nuevos conocimientos.

Esta sección incorpora un link a foros, con la finalidad de evaluar diferentes aspectos de la CVA en una etapa posterior. 


\subsection{Resumen}

A lo largo de este capitulo se tomaron decisiones acerca del diseño y su implementación en un primer prototipo de la CVA referida a temas nucleares. En la conformación se tuvieron en cuenta las consideraciones tecnológicas y requerimientos presentados en el marco teórico de la tesis.

Se combinaron herramientas disponibles en la Facultad de Ciencias Exactas, Fisicas y Naturales, como es el EVEA Moodle donde tiene asignado un espacio el Reactor Nuclear RA-0, para las propuestas de capacitación.

Se utilizó Joomla para el diseño del sitio correspondiente al Reactor en www.ra0.efn.uncor.edu

La CVA sigue procesos de reconstrucción y evolución en función de los objetivos que se presenten año a año.

Lo que se pretende lograr son acuerdos para promover la investigación, desarrollos y capacitación de una manera diferente, propiciando la vinculación con otros sectores, abriendo el debate sobre temas de actualidad. Como refieren autores tales como Lave y Wenger (1991), "El ser humano desarrolla su propia identidad mediante los vínculos que le unen a la comunidad y enriquece sus habilidades de conocimiento en el ejercicio del mismo proceso".

En las comunidades virtuales de aprendizaje encontramos una manera de comunicarnos y de interactuar con los otros, a partir de las nuevas tecnologias como puertas de acceso a la cultura y educación.

Se cree que este primer prototipo será el disparador para ir evolucionando en una comunidad dinámica y activa que cumpla con los objetivos propuestos. 


\section{Capítulo 5}

Evaluación de la comunidad virtual de aprendizaje 
En esta sección se considerará la etapa de evaluación del prototipo desarrollado. La evaluación se concibe como un instrumento de diagnóstico, aprendizaje y comprensión orientada a la mejora (Santos Guerra, 1996).

En el proceso de análisis se recogerán evidencias a partir de encuestas o de la observación de indicadores de lo que sucede en el entorno.

La CVA será monitoreada constantemente según una planificación establecida, de acuerdo a los objetivos y metas propuestas. En ese sentido, la coordinación estará atenta al desarrollo de la comunidad para proponer e implementar los ajustes necesarios.

\subsection{Objetivo}

La finalidad de realizar una evaluación de la CVA es ofrecer una oportunidad a los usuarios para que puedan determinar aspectos de interés y mejora, a la vez que permita reorientar los procesos de funcionamiento tendientes a garantizar los objetivos planteados.

Se pueden realizar ajustes en función de las propuestas que surjan, incluir nuevas herramientas, mejorar el funcionamiento de otras, invitar expertos que aporten soluciones a problemas tecnológicos, cientificos o de aprendizaje.

La evaluación permite comparar los logros alcanzados en los planes de trabajo, verificar el cumplimiento de plazos establecidos y los cronogramas de realización, y fundamentalmente asegurar un aprendizaje significativo.

Primeramente, se plantea una evaluación sobre el diseño de la CVA, que permita validar algunos aspectos del mismo y reformular la implementación del prototipo.

En una etapa posterior, cuando esté superada la de diseño e implementación definitiva del prototipo, se prevé hacer un seguimiento, evaluación y análisis de impacto de la CVA siguiendo los lineamientos indicados en el capitulo 2.6 cuyas categorias e indicadores se resumen en el siguiente cuadro: 


\begin{tabular}{|c|c|}
\hline CATEGORIA & INDICADORES \\
\hline $\begin{array}{l}\text { Esfuerzo e } \\
\text { implementación de } \\
\text { actividades }\end{array}$ & $\begin{array}{l}\text { "No de participantes } \\
\text { "Variación de niveles de participación } \\
\text { "Flujo de intercambio de información entre participantes } \\
\text { "Número de documentos generados con nuevos conocimientos } \\
\text { "Nivel de cumplimiento de las responsabilidades asumidas }\end{array}$ \\
\hline $\begin{array}{l}\text { Cumplimiento de } \\
\text { objetivos de la } \\
\text { comunidad }\end{array}$ & $\begin{array}{l}\text { *Satisfacción y apropiación de los integrantes de la comunidad } \\
\text { „Desarrollo de capacidades y mejora en la práctica } \\
\text { *Generación de conocimientos que se ha dado }\end{array}$ \\
\hline $\begin{array}{l}\text { Medición del } \\
\text { impacto }\end{array}$ & $\begin{array}{l}\text { *Cumplimiento de los objetivos institucionales } \\
\text { *Institucionalización de mejores prácticas } \\
\text { ”Fortalecimiento institucional } \\
\text { ^Profesionalización de los recursos humanos }\end{array}$ \\
\hline
\end{tabular}

Figura 25. Categorias e indicadores para evaluar el impacto de la CVA

A continuación entonces, se plantea la metodología, destinatarios e instrumentos de evaluación para esta primera etapa enfocada en el diseño de la CVA.

\subsection{Metodología}

La metodología de evaluación sobre el diseño consiste en fijar los indicadores, teniendo en cuenta para su selección la especificidad y la universalidad de los mismos, la posibilidad de medirlos en el tiempo y su adaptación al entorno cambiante (Kozma y Wagner, 2005).

Para eso, se seleccionan categorias de evaluación y sobre ellas se especifican los posibles indicadores. Luego se establecen los destinatarios de la evaluación, y finalmente se describen los instrumentos de evaluación que se aplicarán a esos destinatarios en base a los indicadores seleccionados. 
Esas categorias son:

- Organización de la información disponible

- Navegación

- Estética

En cada una de esas categorias se tienen en cuenta indicadores sobre los cuales se realiza la evaluación, con diferentes destinatarios e instrumentos de evaluación.

En la siguiente tabla se presentan esos indicadores:

\begin{tabular}{|c|c|}
\hline CATEGORIA & INDICADORES \\
\hline $\begin{array}{l}\text { Organización } \\
\text { de la } \\
\text { información }\end{array}$ & 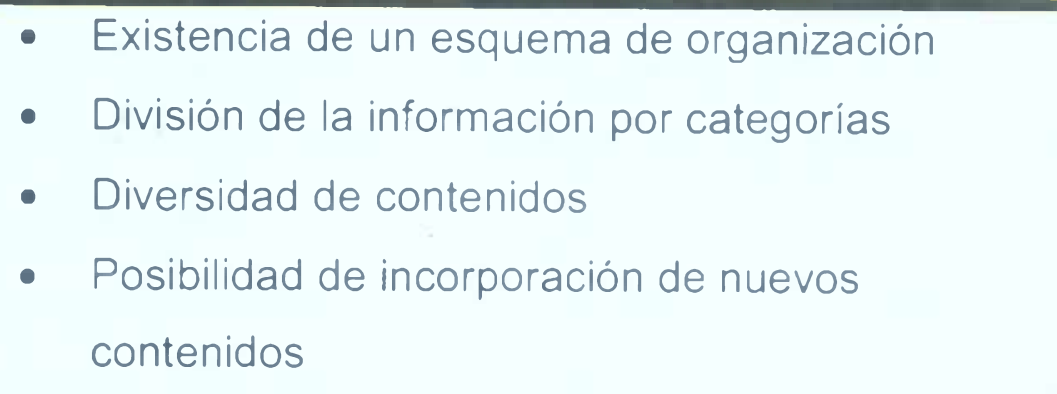 \\
\hline Navegación & $\begin{array}{l}\text { - Existencia de un sistema de navegación global } \\
\text { - Empleo de rutas de navegación } \\
\text { - Existencia de enlaces que faciliten la navegación } \\
\text { - Accesibilidad a los contenidos } \\
\text { - Etiquetado de contenidos }\end{array}$ \\
\hline Estética & $\begin{array}{l}\text { - Representación gráfica (tipografia, color) } \\
\text { - Representación de los elementos de navegación } \\
\text { - Homogeneidad de estilos } \\
\text { - Existencia de iconografía pertinente } \\
\text { - Recursos audiovisuales disponibles } \\
\text { - Elementos multimedia: calidad y cantidad } \\
\text { - Fondo de pantalla y fuente (tipo, color, tamaño) } \\
\text { - Formato en general }\end{array}$ \\
\hline
\end{tabular}

Figura 26. Categorias e indicadores para evaluar el diseño de la CVA 
A continuación se presenta una descripción de cada uno de ellos:

a) Organización de la información: se refiere a los contenidos y su influencia de acuerdo al agrupamiento en la CVA. Los contenidos se agrupan en clases en función de sus propiedades y caracteristicas comunes. En algunos casos, dependiendo del tipo de información (noticias, servicios), y en otros, de los usuarios a los que está dirigido (capacitación, proyectos). La organización de la información se evalúa en base a la funcionalidad. Los indicadores que se valoran para este criterio son:

- Existencia de un esquema de organización: se pretende evaluar la facilidad que ofrece la CVA para que el usuario localice la información acorde al esquema de organización y estructuración que ofrece. Claridad en los contenidos de cada sección. Existencia de jerarquias.

- División por categorias: busca determinar si el contenido es el que se espera.

- Diversidad: intenta analizar el material que está disponible en la CVA, si es suficiente para las necesidades de los miembros y usuarios.

- Posibilidad de incorporación de nuevos contenidos: se evalúa la factibilidad de colocar información para uso de la comunidad en algún sitio dentro de la organización de contenidos.

b) Navegación: la navegación aporta sentido de contexto y comodidad. Se evalúa de acuerdo a la facilidad con que el usuario pueda desplazarse por todos los espacios planificados de la CVA, localizando la información y orientándose en la búsqueda. En este aspecto se considera la navegación dentro del espacio de la CVA, y la que se realiza hacia el exterior a través de enlaces, analizando la necesidad de contar con una ayuda de navegación o mapa del sitio.

Los indicadores seleccionados son los siguientes:

- Existencia de un sistema de navegación global: se pretende analizar si está ubicado siempre en el mismo lugar y en cada página, para que se tenga en todo momento presente la estructura general de la CVA. Se evalúa la existencia de enlaces y que la información esté organizada y sea fácil de acceder a ella.

- Empleo de rutas de navegación: esto permite evaluar la posibilidad de ubicación del usuario en el sitio en que se encuentra, y retornar a cualquier punto de interés con facilidad. 
- Existencia de enlaces que faciliten la navegación: analizar si existe la posibilidad de regresar a la página anterior o a la página principal, por ejemplo.

- Accesibilidad a los contenidos: permite observar la facilidad para transitar las páginas antes de acceder al material que se busca.

- Etiquetado de contenidos: se evalúa el cumplimiento de su función, es decir, la de comunicar a través de un mensaje claro y directo para facilitar la búsqueda sin necesidad de navegar por todas las páginas. Se analiza el icono que representa el contenido, o la claridad en el mensaje de la etiqueta.

c) Estética: en esta categoria se valoran cuestiones relacionadas con el aspecto físico y visual de la CVA, que contribuye a hacer del recurso digital un espacio agradable a la vista y fácil de interactuar por el usuario. De ello puede depender la permanencia en el sitio por un tiempo prolongado, y la curiosidad por avanzar en la navegación. Se evalúa que el usuario se sienta cómodo, a gusto y con entusiasmo por volver, o invitar a otras personas a ingresar al sitio. Otro aspecto fundamental es que la estética colabore en la identidad de la CVA (estilos consistentes, imágenes pertinentes)

Se tienen en cuenta los siguientes indicadores:

- Representación gráfica: analizar el tamaño de letra, color, legibilidad, que garanticen su correcta visualización. También es importante considerar el contraste entre el texto y el fondo.

- Representación de los elementos de navegación: evaluar la claridad de estilos empleados y su ubicación en la página. Si las acciones son sencillas, el usuario tendrá una experiencia positiva y volverá a visitar el sitio (Royo, 2004).

- Homogeneidad de estilos: se enfoca en los gráficos, textos, imágenes, para observar si guardan relación visual coherente en las diferentes zonas, pues ayuda al usuario en el proceso de navegación y afianza el discurso de identidad inherente a cada contenido. Mantener una coordinación gráfica del sistema de interfaz de usuario, le hará sentir que se mueve en un espacio organizado (Royo, 2004).

- Existencia de iconografia: referida a dibujos, fotos o imágenes que reemplacen o complementen el texto para evitar la monotonia visual. El icono es univoco, es decir no lleva a confusiones por el parecido con la representación de otro objeto o acción (Royo, 2004). 
- Recursos audiovisuales: contempla la existencia de videos u otros objetos de aprendizaje audiovisuales como complementos para ofrecer altemativas a los usuarios.

Al analizar cada uno de los indicadores se pueden identificar las potencialidades de la CVA, como asi también las dificultades presentadas a fin de remediarlas.

Lo que se pretende es cubrir aspectos relacionados con la organización del espacio virtual, los recursos que están disponibles en cuanto a si son suficientes, si el sitio es de fácil navegación y atractivo. La organización de la comunidad puede facilitar las interacciones entre los participantes, y por lo tanto, el cumplimiento de objetivos propuestos, de alli la importancia de conocer cómo se sienten los miembros dentro de la CVA, si tienen sentido de pertenencia y si está disponible todo el material que necesitan.

En cuanto a la tecnologia (desde el punto de vista de la navegabilidad y estética) de la CVA, propiciará la comunicación, el acceso a la información de manera amigable y eficiente. La idea es a través de la evaluación, encontrar la tecnologia que se ajuste a las necesidades de la comunidad, manteniendo la innovación que es lo que puede producir verdaderos impactos. Se pretende que, en un entomo abierto de aprendizaje, los usuarios construyan su propio conocimiento, mediante la indagación, la resolución de problemas, los razonamientos hipotético-deductivo e inductivo (Pontes, 2005), aprovechando los recursos disponibles.

A continuación se fijan los destinatarios de la evaluación en base a los aspectos considerados importantes a evaluar, y la participación de esos destinatarios dentro de la CVA. Seguidamente, se analizan los instrumentos de evaluación, esto es encuestas, trabajo en foro, mesas redondas, entrevistas telefónicas, u otros dependiendo del presupuesto disponible, los objetivos buscados y los recursos humanos con que se cuenta (James y Miller, 2005). Esos instrumentos son trabajados con los destinatarios.

En una etapa posterior a la presentada en la tesis, con los resultados obtenidos se prevé realizar mejoras a la CVA en base a los cambios sugeridos, reorganizar los contenidos o lo que fuere necesario en pos de lograr un funcionamiento activo y participativo y mejorar esta primera versión del prototipo. Finalmente, como se indica al comienzo del capitulo, evaluar el impacto y éxito alcanzado con el manejo de la CVA, planteando nuevos indicadores y criterios de evaluación que contemplen la cultura de la participación y colaboración, claridad en las directrices que rigen a la 
comunidad, evaluación y presentación de resultados, objetivos y metas (Cabero, 2006).

\subsection{Destinatarios}

Los destinatarios de la evaluación son los visitantes y los miembros de la CVA.

Como visitantes se consideran aquellas personas que eventualmente navegan por el sitio pero no están registrados como miembros, y no participan como alumnos de un curso, o en los trabajos que se desarrollan desde la CVA. No obstante es importante su opinión como potenciales integrantes de algunos de los grupos de trabajo, dado que el sitio de la CVA puede ser el primer contacto que tenga un visitante con las actividades que en ella se desarrollan.

Por miembros, se entiende a todos los integrantes de la CVA que forman parte de los proyectos de investigación, capacitación o desarrollos tecnológicos. Entre ellos se encuentra el coordinador, encargado de organizar la CVA, y los coordinadores responsables de los distintos espacios.

Los tres aspectos a evaluar, organización de la información, navegación y estética, se aplican a todos los destinatarios mencionados utilizando diferentes instrumentos de evaluación.

\subsection{Instrumentos de Evaluación}

Los instrumentos de evaluación que se implementan para cada uno de los destinatarios mencionados se detallan a continuación.

- Visitantes: para los visitantes que ingresan eventualmente a la CVA, que tienen importancia como potenciales usuarios o miembros activos, se prepara una encuesta con una serie de preguntas cerradas y abiertas. Las mismas están disponibles en un archivo, dentro del "Foro" ubicado en el sector "Comunicaciones", con una dirección de correo electrónico para su reenvio. Las preguntas formuladas se encuentran en el Anexo C.

- Miembros: a los miembros de la CVA se les envia un cuestionario por mail. En el mismo se debe indicar la participación como miembro, coordinador o tutor. Este grupo puede dar información sobre su experiencia de trabajo desde la CVA, lo que aporta datos relevantes para reorganizar o mejorar los contenidos o el diseño propuesto. El cuestionario está disponibles en el Anexo D. 
Posteriormente se procesan los datos obtenidos teniendo en consideración las opiniones vertidas por cada uno. Si bien las preguntas pueden ser similares, los visitantes, reflejan la primera impresión sobre el diseño y funcionamiento de la CVA; en tanto las respuestas de los miembros están relacionadas con los contenidos y la comodidad que encuentran para trabajar alli.

Luego de aplicar estos instrumentos, y en base a un primer análisis, se realizarán mesas redondas de debate con el grupo gestor de la CVA para continuar con la evaluación y realizar un informe de mejoras.

\subsection{Resumen}

En el presente capitulo se presentó la metodologia de evaluación planificada para la CVA; una primera etapa, dirigida a la organización de la información disponible, navegación y estética. Para cada una de esas categorias se fijaron indicadores que luego se utilizaron para elaborar los instrumentos de evaluación. Esos instrumentos se aplicarán a diferentes destinatarios, para esta etapa los visitantes y miembros de la CVA. Cada uno de ellos, hará aportes desde diferentes lugares, los primeros desde un primer impacto visual, y los segundos a partir de su experiencia de trabajo en el sitio. Esta planificación aún no ha arribado a su etapa de implementación definitiva. 
Capítulo 6

Conclusiones 
A lo largo de la tesis se ha trabajado en el tema comunidades virtuales, en particular, las orientadas al aprendizaje. Se ha presentado una metodologia de diseño y se ha puesto en marcha a fin de crear una CVA considerando criterios tecnológicos y de comunicación que promuevan el aprendizaje. El proceso de diseño no se da por concluido; es necesario seguir construyendo el entorno virtual de acuerdo a la evolución de la comunidad, los resultados de sucesivas evaluaciones y los requerimientos que surjan para alcanzar los objetivos propuestos.

\subsection{Conclusiones generales}

La conformación de un espacio denominado CVA implicó como punto de partida profundizar aspectos teóricos referidos al significado, similitudes y diferencias con otros espacios virtuales, comparación entre aquellas que están funcionando como referencia para el diseño de la misma. Se fue introduciendo el concepto de aprendizaje a partir de una revisión sobre las ideas presentadas por diferentes autores, y la influencia de la CVA en la construcción del conocimiento. Se analizó la diferencia entre aprendizaje cooperativo y colaborativo como parte de los procesos que tienen lugar. Este análisis teórico permitió contextualizar los temas referidos a CVA, que fueron necesarios para realizar una propuesta que permitiera poner en marcha un prototipo, objetivo de esta tesis.

A continuación se realizaron diferenciaciones entre expresiones que pueden parecer similares como es el caso de un entorno virtual de enseñanza y aprendizaje respecto a una comunidad virtual de aprendizaje. Para ello, se analizaron los roles, orientación de cada una, esquemas jerárquicos. Aclarados esos conceptos se hizo una clasificación de comunidades que sirvió como ejemplo y aportó conocimiento sobre las que están funcionando. También se analizaron requerimientos teóricos, tecnológicos y arquitectónicos, necesarios para asegurar el éxito de la misma en cuanto a estimulación del aprendizaje y su continuidad en el tiempo. Para monitorear los logros se presentaron indicadores a utilizar en las evaluaciones planificadas. Es decir, en esta sección de la tesis se obtuvieron herramientas de diseño y configuración.

Seguidamente, fue necesario proponer un marco metodológico para el desarrollo articulando aspectos tecnológicos y comunicacionales, con la experiencia adquirida en las actividades desarrolladas conjuntamente con el grupo que la integra. Se tuvo en cuenta una planificación flexible que permitiera modificar los temas o la forma de intercambiar conocimientos, en base a las inquietudes de la propia comunidad. Se enfatizó el rol del coordinador, tanto para lograr la participación activa de los 
integrantes, como para alcanzar los objetivos propuestos a partir de un monitoreo y evaluación. Como parte de ese marco metodológico, se analizaron las experiencias adquiridas por el grupo encargado de gestar la CVA en el dictado de cursos utilizando entornos virtuales de enseñanza y aprendizaje. El resultado de ese análisis dio origen a las características fundamentales en cuanto a diseño, coordinación, comunicación, recursos tecnológicos, que se plasmaron en una propuesta concreta.

Como resultado de ellos se desarrolló un primer prototipo que se incorporó dentro del sitio del Reactor Nuclear RA-0. Esta etapa implicó el manejo de la herramienta seleccionada, Joomla, la cual se utilizó por primera vez para diseñar simultáneamente el espacio del Reactor Nuclear y la CVA. Esto dificultó algunas tareas y presentó obstáculos, los cuales se prevé solucionar en sucesivas etapas. Para el diseño e implementación del prototipo se combinaron herramientas disponibles en la Facultad de Ciencias Exactas, Fisicas y Naturales, como es el EVEA Moodle. Eso facilitó el uso de recursos alli disponibles para el dictado de cursos. Con la conformación del prototipo comienza una nueva etapa que es incentivar la participación, aprovechando la CVA y la posibilidad que esta ofrece de interactuar con otras personas, brindando herramientas y recursos para lograrlo; fortaleciendo los procesos de aprendizaje.

Una vez que se logre obtener un prototipo más evolucionado, se evaluará la CVA en diferentes etapas, en función de la evolución de la misma y de los diferentes aspectos que se necesite analizar, a fin de reformular el diseño, mejorar el funcionamiento o implementar cambios tendientes a alcanzar los objetivos acordados. Para ello se fijaron indicadores que fueron utilizados para elaborar los instrumentos de evaluación. La implementación de la evaluación forma parte de los trabajos a futuro.

\subsection{Trabajo a futuro}

Se prevé integrar un grupo de trabajo para continuar con el desarrollo técnico.

Luego se continuará con la profundización en mejoras sobre las interacciones dentro de la CVA, tanto en calidad como en cantidad de las comunicaciones, ampliando los canales y promoviendo los procesos de intercambio de conocimiento y experiencia. Para ello se establecerán reuniones periódicas entre coordinadores a fin de analizar la evolución, los resultados de las encuestas y hacer un seguimiento sobre la dinámica de la comunidad en base a la propuesta de evaluación planificada.

El trabajo a futuro se resume en los siguientes apartados: 
- Conformar un grupo de soporte tecnológico para la CVA. Esto permitirá introducir mejoras tales como unificar las credenciales de acceso para las diferentes secciones privadas de la CVA.

- Realizar el proceso de evaluación inicial de la CVA e implementar mejoras en función de los criterios: organización de la información, navegación y estética.

- Evaluar el funcionamiento de la CVA respecto de objetivos. Implementar mejoras.

- Monitorear el progreso de la CVA en los niveles relacionados con el esfuerzo e implementación de las actividades, con los resultados obtenidos a partir de las actividades realizadas, y finalmente con el impacto alcanzado en los miembros desde su participación en la CVA.

- Establecer reuniones periódicas entre coordinadores a fin de evaluar los resultados obtenidos en la utilización de la CVA.

- Incentivar la participación de los miembros tendiente a lograr que se incorpore nuevo material bibliográfico, recursos educativos, y nuevos proyectos a partir de la CVA.

- Articular talleres sobre aprendizaje e incorporación de las tecnologias en los procesos de aprendizaje.

- Difundir información sobre la CVA en ámbitos nacionales e internacionales con la finalidad de convocar a nuevos participantes.

Estos puntos forman parte de las metas propiamente dicha, que garanticen el éxito y que se cumplan los objetivos propuestos. Sin embargo, el trabajo se verá completado al abrir lineas de investigación sobre el impacto alcanzado en el aprendizaje, el logro de objetivos personales y grupales, y la forma de incentivar el trabajo colaborativo, cooperativo e intercambio de conocimiento, propio de la CVA.

Esta investigación aplicada abrirá puertas para quienes estén vinculados a los temas de comunidades virtuales de aprendizaje, brindando la posibilidad de mejorar metodologías de diseño y estableciendo nuevos aspectos a considerar para lograr el éxito de una CVA.

\subsection{Palabras finales}

Se habla hoy en dia de espacios de conocimiento colaborativo en comunidades virtuales donde se conforma la socialización de los individuos. En ellas se constituye una cultura digital para aprender, enseñar, interactuar en desarrollos tecnológicos, investigación, prestación de servicios, donde pueden participar personas de diferentes 
espacios sociales, geografias, costumbres y forma de trabajo. Todos esos aspectos enriquecen el conocimiento, contribuyen al desarrollo de un espiritu crítico, amplian los criterios para aceptar las diferencias, fomentan lazos profesionales y de camaraderia, en busca de un desarrollo tecnológico y de investigación aplicada al crecimiento e innovación.

En ese sentido, la propuesta de una comunidad virtual constituye un aporte, a los fines de lograr una interacción social para gestar conocimiento, en vinculación con las temáticas subyacentes a dicha comunidad.

Aunque puede haber responsables o coordinadores de las CVA, la participación activa depende de los integrantes que determinan el éxito o fracaso en su evolución.

Por lo expuesto, el grupo de trabajo que la conforma tendrá el desafío de mantenerla viva, activa, promoviendo la socialización necesaria para alcanzar un aprendizaje a través de la cooperación y colaboración de sus integrantes. 


\section{Bibliografía}


- Brenson Lazan, G. (2005). Más allá de los equipos: La comunidad de aprendizaje $y$ autodesarrollo integral. En http://amauta-international.com/B|BVIRT/ Consultada en octubre de 2009.

- Brown, J., Collins, A. y Duguid, P. (1989) Situated Cognition and the Culture of Learning. (artículo entregado en la maestria)

- Brown, A.L. y Palincsar, A.S. (1989). Guided, cooperative learning and individual knowledge adquisition, en Resnick, L.B., Knowing, Leaming an instruction. Hillsdale: Lawrence Erlbaum Associates.

- Bruner, J. (1990). Actos de Significado. Más allá de la Revolución Cognitiva. Madrid: Alianza.

- Bucheli, B. y Romo, G. (2005). Comunidades de Aprendizaje: Lecciones aprendidas en América Latina. Praxis Note 16. INTRAC. http://wnw.intrac.org/docs.php/2089/PraxisNote\%2016\%20Spanish.pdf Consultado en Octubre 2008

- Cabero A., J. (2006). Comunidades virtuales para el aprendizaje. Su utilización en la enseñanza. Edutec. Revista Electrónica de Tecnologia Educativa 20 (1): sp.

- Castillo, J. (2000). El aprendizaje cooperativo en la enseñanza de matemática. En http://uww.monografias.com/trabajos4/aprend mat/aprend mat.shtml Consultado en Junio 2009.

- Coll, C. (2001). Las comunidades de aprendizaje y el futuro de la educación: el punto de vista del forum universal de las culturas. Simposio Internacional sobre comunidades de aprendizaje. Barcelona. Revista Electrónica Teoria de la Educación, vol. 8, No3. http://uww.usal.es/teroriaeducacion Consultado en Diciembre 2009

- Coll, C., Sánchez, A. y Rocamora, A. (2007). Configuración y evolución de la comunidad virtual MIPE/DIPE: retos y dificultades. Salamanca. Revista Electrónica Teoria de la Educación, vol.8, №3. 
http://campus.usal.es/ -teoriaeducacion/rev numero $0803 / \mathrm{n} 8 \quad 03$ coll bustos en gel.pdf

Consultado en Octubre 2010

- Cherny, L. (1999). Conversation and Community. Chat in a Virtual World. Standford, Californa: CSLI Publications.

- Dewey, J. (1929). La Escuela y la Sociedad. Madrid: Francisco Beltrán.

- Diaz Barriga, F. y Hernández, G. (1998). Estrategias docentes para un aprendizaje significativo. Una interpretación constructivista. México: McGraw Hill.

- Dillenbourg, P. (1999) Collaborative learning: Cognitive and computacional approaches. Amsterdam: Elsevier Science.

- Driscoll, M.P. y Vergara, A. (1997). Nuevas tecnologias y su impacto en la educación del futuro. En Pensamiento Educativo. Santiago de Chile: Pontificia Universidad Católica.

- Duffy, T. y Cunningham, D. (1996). Constructivismo: implications for the design and delivery of instruction. En D. Jonassen (Eds.). Handbook of Research for Educational Communications and Technology (pp.171). New York: Macmillan Library Reference.

- Figallo, C. (1998). Hosting Web Communities. New York: John Wiley \& Sons. Estados Unidos.

- Garcia Fernández; N. (2002): http://mww.um.es/ead/red/6/comunidades.pdf Consultado en Diciembre 2007

- Garrison, D.R., Anderson, T. y Archer, W. (2000). Critical inquiry in text-based environment: Computer conferencing in higher education. The Internet an Higher Education. Volume 2, Issues 2-3, Spring 1999, Pages 87-105. Canada: University of Alberta. 
- Garrison, D.R., Anderson, T. y Archer, W. (2001). Critical thinking, cognitive presence, and computer conferencing in distance education. The American Journal of Distance Education. 25 (1), 7-23.

- Hagel, J. y Armstrong, A. (1997). Expanding markets through virtual communities. Boston: Harvard Bussines School Press.

- James, T. y Miller, J. (2005). "Developing a Monitoring and Evaluation Plan for ICT in Education". En Wagner et al (2005), "Monitoring and Evaluation of ICT in Education Projects. A Handbook for Developing Countries". Washington, USA

- Johnson, D.W. Johnson, R.T., y Holubec, E.J. (1999). El aprendizaje cooperativo en el aula. Barcelona: Paidos.

- Jonassen, D., Pech, K. y Wilson, B. (1998). Learning with technology. A constructivist Perspective. Prentice may Upper Saddle River (NJ).

- Kozma, R. y Wagner, D. (2005). "Core Indicators for Monitoring and Evaluation Studies for ICT in Education". En Wagner et al (2005), "Monitoring and Evaluation of ICT in Education Projects. A Handbook for Developing Countries". Washington, USA

- Kreimer, P. (2009). El científico también es un ser humano. La ciencia bajo la lupa. Argentina: Siglo XXI Editores.

- Lage, F. y Cataldi, Z. (2000). El modelo 4C para capacitación de recursos humanos cooperativo-colaborativo. Informe interno, LIE: laboratorio de informática educativa. Facultad de Ingenieria. Universidad de Buenos Aires.

- Lave, J. y Wenger, E. (1991). Situated learning: legitimate peripeherical participation. Cambridge: Cambridge University Press.

- Loughlin, C.E. y Suina, J.H. (1995). El ambiente de aprendizaje. Morata: Madrid 
- Lucero, M. M. (2003). Entre el trabajo colaborativo y el aprendizaje colaborativo. Revista Iberoamericana de Educación (ISSN: 1681-5653). http://mww.rieoei.org/deloslectores/528Lucero.PDF consultado en Julio 2009

- Merton, R. (1964). Teoria y estructura social. México. Fondo de Cultura Económica.

- Montero, M. (1998). La comunidad como objetivo y sujeto de acción social, en A. Martin González Psicologia Comunitaria. Fundamentos y Aplicaciones. Madrid: Sintesis.

- Morueta, R.T., Carreño, A.B., Guzmán Franco, M.D. (2008). Efectos de las interacciones en la creación de comunidades virtuales de prácticas. http://redalyc.uaemex.mx/redalyc/html/547/54702101/54702101.html consultado en Septiembre 2009

- Mugridge, I. y Kaufman, D. (1986). Distance education in Canada. London: Croom Helm.

- Onrubia, J.; Coll, C.; Engel, A.; Mauri, T.; Rochera, M.J. (2004). Ayudas no presenciales para la enseñanza presencial: algunos ejemplos de uso de una plataforma virtual de enseñanza y aprendizaje como apoyo a la docencia presencial en el ámbito de la psicología de la educación. Comunicación presentada en el III Congreso Internacional de Docencia Universitaria e Innovación. Girona. En http://uww.psyed.edu.es/prodGrintie/conf/AB COLOQUIO INV UNAM 06.pdf Consultada en Junio 2009

- Palloff, R. y Pratt, K. (1999). Building learning communities in cyberspace. San Francisco. CA: Jossey-Bass.

- Panitz, Ted (1998). A Definition of Collaborative vs. Cooperative Learning. En: http://mww.londonmet.ac.uk/deliberations/collaborative-learning/panitz-paper.cfm Consultado en Julio 2009 
- Pazos, M.;Perez Garcias,A. y Salinas, J. (2001): Comunidades virtuales: de las listas de discusión a las comunidades de aprendizaje. Comunicación. Edutec'01. V Congreso Internacional de Tecnología, Educación y Desarrollo sostenible. 17-19 de septiembre, Murcia. En http://tecnologiaedu.us.es/bibliovir/pdf/gte46.pdf Consultado en Julio 2009

- Pontes, A. (2005). Aplicaciones de las tecnologias de la información y de la comunicación en la educación cientifica. Segunda parte: Aspectos metodológicos. Revista Eureka sobre Enseñanza y Divulgación de las Ciencias, vol. 2, n 3, 330343.

- Quaas, C. (2000). Nuevos enfoques en la evaluación de los aprendizajes. (En línea), Revista enfoques educacionales Vol.2 №2. Universidad de Chile, en http://rehue.csociales.uchile.cl/publicaciones/enfoques/04/docs/enfoques 041999 $\underline{\mathrm{pdf}}$

Consultado octubre 2009

- Rheingold, H. (1996). La Comunidad Virtual: Una sociedad sin fronteras. Barcelona: Gedisa.

- Royo, J. (2004). Diseño Digital. Barcelona: Ediciones Paidós Ibérica. España.

- Salinas, J. (2003) Comunidades virtuales y aprendizaje digital. Ponencia presentada en Edutec 03 Universidad Central de Venezuela. http://gte.uib.es/publicacions/comunica/edutec03/salinas cv.pdf Consultado en Enero 2008

- Sánchez, V. y Saorin, T. (2001). Las comunidades virtuales y los portales como escenarios de gestión documental y difusión de información. España: Universidad de Murcia.

- Salomón, G. (1993). Cogniciones distribuidas. Argentina: Amorrortu.

- Salmon, G. (2000). E-Moderating: The Key to Teaching and Learning Online. London: Kogan Page. England. 
- Santamaria, C. (1995). Introducción al razonamiento humano. Madrid: Alianza Editorial.

- Santos Gerra, M. (1996). Evaluación Educativa. Buenos Aires: Editorial Magisterio del Rio de la Plata.

- Sarramona, J. (2000). Teoria de la Educación. España: Ariel

- Suárez, C. (2003). Del aprendizaje en red a una red de aprendizaje. En http://tecnologiaedu.us.es/bibliovir/pdf/archivoPDF3.pdf Consultado en Febrero 2009

- Stufflebeam, D. y Shinkfield, A. (1987). Evaluación sistemática. Guia teórica y práctica. Barcelona: Paidós

- Tyler, R. (1973). Principios básicos del curriculum. Buenos Aires. Troquel

- Vygotsky, L.S. (1978). La mente en la sociedad: el desarrollo de las funciones psicológicas superiores. Cambridge: Harvard Universitiye Press.

- Vygotsky, L.S. (1979). El desarrollo de los procesos psicológicos superiores Barcelona: Grijalbo.

- Zangara, Alejandra (2008). Las posibilidades de interacción y de construcción compartida del conocimiento en la web 2.0. La importancia de generar y sostener comunidades virtuales genuinas en el intercambio de conocimientos $y$ experiencias. Universidad del Salvador - II Jornadas de Educación a Distancia. Desafios de la capacitación 2.0: ¿Paradigma del futuro?

En http://mww.salvador.edu.ar/vrid/publicaciones/jornadavirtual.htm Consultado en Julio 2009

- Zañartu Correa, Luz María (2003). Aprendizaje colaborativo: una nueva forma de diálogo interpersonal y en red. En http://contexto-educativo.com.ar/2003/4/nota02.htm Consultado en noviembre 2009. 
- Zeller, R.A. y Carmines, E. (1980). Measurement in the Social Sciences: The link between theory and data. Cambridge: Cambridge University.

\section{Otras fuentes documentales:}

- Rico Sánchez, Isabel y Fontecha Martinez, Carmen. Instituto Nacional de Educación Física. Universidad Politécnica de Madrid

- Sánchez Angeles y Paniagua Elvira, Aprendizaje autónomo y autorregulado. XXII Curso Iberoamericano de Educación a Distancia. Hyperlink http://univirtual.utp.edu.co/conıunidad/file.php/1/documentos/CVA.pdf Consultado en Diciembre de 2007.

- Sánchez Angeles, Paniagua hyperlink: http://univirtual.utp.edu.co/comunidad/file.php/1/documentos/CVA.pdf consultado en Enero 2008

- Salomón, G., Perkins, D. y Globerson, T. Coparticipando en el conocimiento: la ampliación de la inteligencia humana con las tecnologias inteligentes. (artículo entregado en la maestria)

- Campus Virtual, Universidad Nacional de San Luis. http://campus.unsl.edu.ar/frecuentes.htm

- Conformación de una Comunidad Virtual de Aprendizaje a partir de un proceso de formación de maestros universitario. http://www.um.es/ead/red/18/prado.pdf

- Corbella, Marta y Dominguez Figaredo, Daniel.-Editorial Ariel(http://www.horizonteweb.com/biblio/aretio2.htm). Consultado en Enero 2008.

- Investigación en Educación a Distancia. Un acercamiento sistémico. http://uww.matedu.cicata.ipn.mx/Publicaciones/(Farfan-Montiel2002)-ALME15-.pdf Consultado en Diciembre 2007 
- Karash R. "Groupware and Organizational Learning". 1995. Hiperlink: http://world.std.com/ rkarash/GW-OL/ Consultada en Enero 2008

- Lage, J. y Cataldi, Z. Modelo Cooperativo-Colaborativo para capacitación de recursos humanos a través de Intranet/Extranet.

http://unw.uib.es/depart/gte/edutec/edutec01/edutec/comunic/EXP09.html

Consultado en Enero 2008

- www.joomla.org.ar Definición de Joomla

- www.efn.uncor.edu

- $\quad$ http://moodle-efn.unc.edu.ar/

- $\quad$ http://moodle-efn.unc.edu.ar/course/category.php?id=9

- www.efn.uncor.edu/investigacion/reactor

- uww.educ.ar

- $\quad$ www.portaleducativo.edu.ve

- $\quad$ www.perueduca.edu.pe

- mww.eun.org

- muw.webct.com

- muw.webtrain.com

- www.atutor.ca

- unw.moodle.com

- mww.e-ducativa.com

- http://uww.uned.es/catedraunesco-ead/abajo7.htm|\#2

- http://webunlp.unlp.edu.ar

- http://fedvirtual2.fed.uh.cu

- http://unw.unifesp.br

- $\quad$ www.mentor.mecd.es

- $\quad$ www.psyed.edu.es

- http://campusmoodle.proed.unc.edu.ar

- http://redproductores.perueduca.edu.pe

- www.civila.com

- uww.bibliotecasvirtuales.com

- unw.aprender.or 
Anexos 


\section{Anexo A: Cuestionario para los gestores de la CVA \\ Cuestionario para indagar al grupo de trabajo que conformará la CVA}

Solicitamos que responda a cada una de las siguientes preguntas las cuales se utilizarán como referencia para conformar una comunidad virtual de aprendizaje. Gracias por su colaboración.

1. ¿Qué es una Comunidad Virtual de Aprendizaje?

2. A partir del concepto de CVA que encuentra al hacer clic AQUI, ¿Considera necesario disponer de una CVA en temas Nucleares? ¿Por qué? (A los fines de esta tesis el concepto de CVA se encuentra a continuación del cuestionario).

3. ¿Piensa que podrá mejorar su irabajo disponiendo de esa CVA?

4. ¿Con quién le gustaria interactuar a través de la CVA?

5. ¿Disponemos de la tecnologia necesaria para conformar la CVA?

6. ¿Tiene alguna sugerencia para conformar la CVA?

Concepto de Comunidad Virtual de Aprendizaje

Por comunidad virtual de aprendizaje se entiende al grupo de participantes activos dentro de un contexto social, que asumen la responsabilidad de su propio aprendizaje en un entomo virtual.

A través de las comunidades de aprendizaje se busca establecer procesos de aprendizaje a largo plazo que apuntan a la innovación, el desarrollo de capacidades, el mejoramiento de la práctica y el fortalecimiento de los vinculos entre miembros.

Lo que se pretende es satisfacer necesidades de aprendizaje entre diferentes generaciones, entre pares, a través de un esfuerzo conjunto y aprovechando las potencialidades de la comunidad, el material disponible, los proyectos regionales y la sinergia de esfuerzos compartidos- 


\section{Anexo B: Encuesta del curso "Energía y Medio Ambiente" \\ Cuestionario para los alumnos del curso}

Su opinión nos permitirá identificar los aspectos positivos y aquellos que necesitan mejorar. Le pedimos un especial esfuerzo por completar las preguntas abiertas. Desde ya muchas gracias por su colaboración.

\section{COLOQUE UNA X AL LADO DE LA RESPUESTA SELECCIONADA}

1) ¿Le resultó fácil navegar a través del Aula virtual?
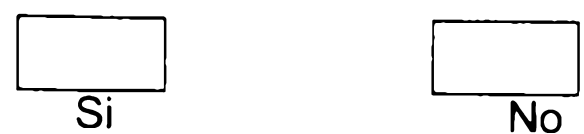

1.1) En caso de haber seleccionado "No" en el apartado anterior ¿podria identificar alguno de los problemas de navegación con los que se ha encontrado? Puede elegir más de una opción o sugerir una nueva en el casillero en blanco.

Inconvenientes con su usuario y contraseña.

Interfaz de navegación confusa.

Problemas de conectividad o disponibilidad técnica de la plataforma.

Inconvenientes en la configuración de su navegador/explorador de Internet.

Problemas para acceder a archivos/recursos publicados en el curso.

Problemas con el soporte técnico

Otro:

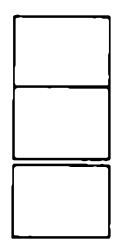

2) Considera que el desarrollo de los contenidos contribuye a alcanzar los objetivos del Curso:

No contribuyen

De manera escasa

Contribuyen en parte

$\mathrm{Si}$, muy pertinentemente

3) Considera que la extensión de los materiales de estudio fue:

Adecuada

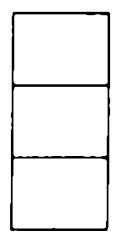

Excesiva

Escasa

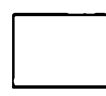

4) La cantidad de actividades que debió completar para aprobar el curso le parecieron:

Escasas..

Excesiva

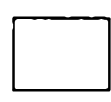

Adecuadas. 
5) El tipo de consignas que se le solicitaron como actividades de aprendizaje, le parecieron:

Muy adecuadas

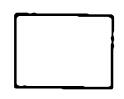

Adecuadas....

Poco adecuadas

Nada adecuadas

6) En una escala del 1 al 10, la organización general del curso le pareció:

Muy Mala

Muy Buena

7) Respecto a los foros, ¿cuáles son las mayores utilidades que reconoce en este Curso? Puede elegir más de una opción o sugerir una nueva en el casillero en blanco.

Como espacio de comunicación formal e informal.

Como espacio para plantear y resolver dudas y consultas.

Como una instancia para la construcción conjunta de conocimientos.

Como una instancia para conocer al resto de los participantes del curso.

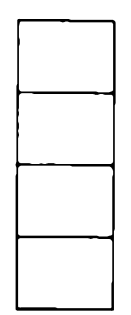

Otro:

8) ¿Qué utilidad les reconoce a las Guias de Estudio o Texto Clase?

Nos introduce en el tema.

Aporta información relevante

Promueve interés por la temática.

Otro:

9) Respecto a la duración del Curso, el tiempo adjudicado le parece:

Muy escaso

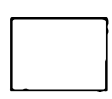

Escaso

Adecuado

Muy Adecuado

9.1) ¿Cuántas semanas cree que seria el tiempo ideal para el desarrollo del curso?

10) ¿Qué opina respecto de la participación del docente en el seguimiento de su proceso de aprendizaje?

11) ¿Cómo ha sido la comunicación mantenida con los tutores a lo largo del curso? Puede elegir más de una opción o sugerir una nueva en el casillero en blanco. 
Pertinente/Adecuada (de retroalimentación permanente y personalizada) Pertinente/Adecuada (respondiendo a las distintas consultas de manera general o conjunta)

Insuficiente/Inadecuada (no respondió a mis inquietudes personales) Insuficiente/Inadecuada (no se comunicaba con la periodicidad necesaria) Otro:

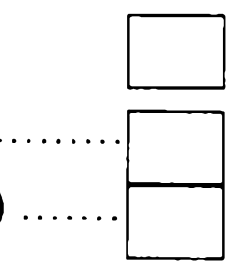

12) ¿Cuáles cree que son los principales aprendizajes que le dejó a usted este curso? Por favor sea lo más especifico posible.

13) ¿Qué tan útiles son para su práctica profesional los aprendizajes alcanzados?

$$
\begin{array}{lllll}
1 & 2 & 3 & 4 & 5
\end{array}
$$

Poco utiles

Muy útiles

14) ¿Cuáles fueron las mayores dificultades con las que tropezó en este curso? Puede elegir más de una opción o sugerir una nueva.

Manejo tecnológico del aula (competencias personales)

Desconocimiento técnico de la herramienta

Dificultad con los contenidos desarrollados en el curso

Dificultad para llevar adelante la metodologia de trabajo en el aula (consignas, tipos de actividades propuestas)

Falta de tiempo para cumplimentar las exigencias del curso

Otro:

15) Otras sugerencias u opiniones en relación al curso (Contenidos, Metodologia, Organización, Diseño, Aula Virtual, Actividad de Tutores, etc.) Exponga aquí cualquier observación que considere pertinente en relación a la temática abordada. 


\section{Anexo C: Encuesta inicial de evaluación de la CVA}

\section{Cuestionario para los visitantes externos}

Su opinión nos permitirá identificar los aspectos positivos y aquellos que se necesitan mejorar. Le pedimos un especial esfuerzo por completar las preguntas abiertas. Desde ya muchas gracias por su colaboración.

1) ¿Cuál es su opinión sobre el diseño de la Comunidad Virtual de Aprendizaje? Marque la opción correspondiente

Amigable
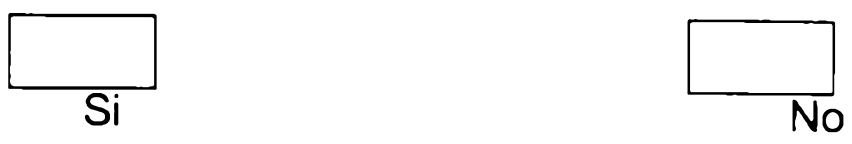

Intuitivo
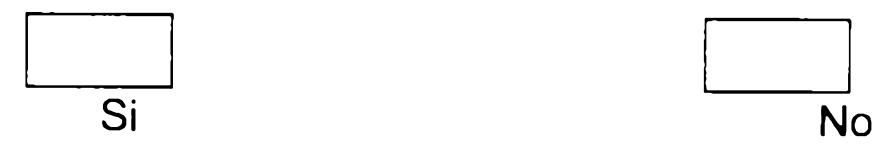

2) Respecto al contenido:

Suficiente

Escaso

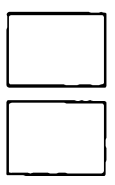

Complete con las sugerencias que crea necesarias:

3) Los recursos disponibles: enlaces a otros sititos, videos, objetos de aprendizaje, cree que constituyen un aporte

$\mathrm{SI}$

NO
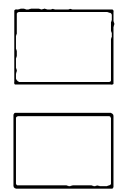

Justifique su opinión:

4) En cuanto a la navegación ¿le resultó fácil?
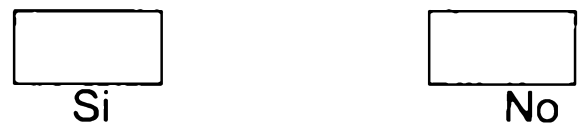

4.1) En caso de haber seleccionado "No" en el apartado anterior ¿podria identificar algunos de los problemas de navegación con los que se ha encontrado? Describalos a continuación

5) Acceso a los contenidos: ¿Cómo le resultó el acceso a los contenidos? Marque con una cruz en los ítems que describan mejor su experiencia Los ubiqué fácilmente. 
El contenido no estaba de acuerdo con la etiqueta o icono

Tuve que navegar por varias páginas para encontrarlo

No encontré lo que buscaba.

Sugerencias.

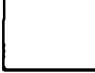

6) Evalúe del 1 al 10 cada uno de los siguientes puntos referidos a la estética del sitio Tipografía: tamaño de letra, color, legibilidad, contraste.

Elementos de navegación: ubicación en las páginas, claridad del icono utilizado.

Estilo: relación visual coherente entre gráficos, textos e imágenes.

Iconografia que reemplaza al texto.

Recursos audiovisuales: música, videos, objetos de aprendizaje.

Comentarios:

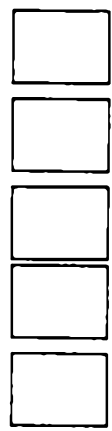




\section{Anexo D: Encuesta de evaluación de la CVA}

\section{Cuestionario para los miembros de la CVA}

El siguiente cuestionario le brinda la oportunidad de plantear aspectos de interés y mejora sobre el funcionamiento y contenidos de la CVA. Le pedimos un especial esfuerzo por completar las preguntas abiertas. Desde ya muchas gracias por su colaboración.

1) ¿Se encuentran disponibles todas las publicaciones que considera imprescindibles?:

$\mathrm{Si} \quad$ No

1.1) Si la respuesta es No, ¿cuáles cree que seria necesario incorporar?

2) Como miembro de la CVA considera que la división por categorias presentada en el sitio de la comunidad es adecuada:

En su totalidad

En parte.

Escasamente

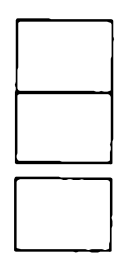

Detalle su opinión al respecto:

3) Referido al material que se encuentra en el sitio de la CVA ¿Cubre sus necesidades?

En su totalidad

En parte

Escasamente

No cubrió mis necesidades

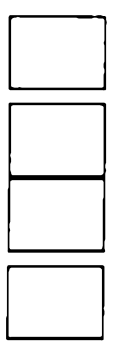

Si no alcanzó para sus proyectos ¿Qué tipo de materiales cree que haria falta incorporar?

4) Respecto a la posibilidad de subir material para uso de la comunidad ¿Le fue factible hacerlo?

$\mathrm{Si}$

Si la respuesta es No, especifique los motivos:

No encontré el lugar apropiado.

No supe hacerlo. 
Explique su experiencia al respecto:

5) En cuanto a la navegación ¿Cómo le resultó el sistema de navegación? Claro.

Poco claro.

Confuso.

6) ¿Pudo volver desde cualquier página a su punto de origen?

$\mathrm{Si}$

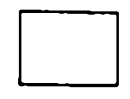

No

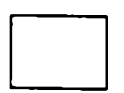

7) ¿Cómo califica los enlaces para realizar la navegación?

Apropiados

No pude retomar la página anterior.

La navegación no me permitió saltear páginas

Tuve que transitar por varias páginas para acceder al contenido

Comentarios:

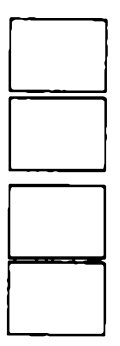

8) Respecto al etiquetado o icono que representa cada contenido

Es claro.

No se entiende.

Comentarios:

9) Evalúe del 1 al 10 cada uno de los siguientes puntos referidos a la estética del sitio

Tipografia: tamaño de letra, color, legibilidad, contraste.

Elementos de navegación: ubicación en las páginas, claridad del icono utilizado.

Estilo: relación visual coherente entre gráficos, textos e imágenes.

Iconografia que reemplaza al texto.

Recursos audiovisuales: música, videos, objetos de aprendizaje.

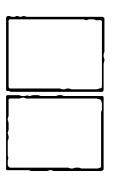

Comentarios:

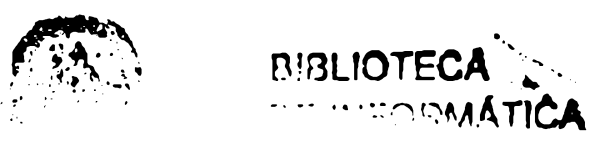

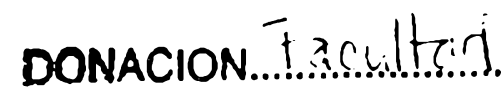

\$...

Fecha. $07-03-2012$

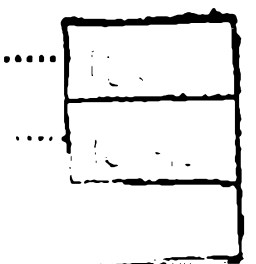

Inv. E........ 